\title{
Reward circuitry dysfunction in psychiatric and neurodevelopmental disorders and genetic syndromes: animal models and clinical findings
}

\author{
Gabriel S Dichter ${ }^{1,2,3,5^{*}}$, Cara A Damiano ${ }^{3}$ and John A Allen ${ }^{4}$
}

\begin{abstract}
This review summarizes evidence of dysregulated reward circuitry function in a range of neurodevelopmental and psychiatric disorders and genetic syndromes. First, the contribution of identifying a core mechanistic process across disparate disorders to disease classification is discussed, followed by a review of the neurobiology of reward circuitry. We next consider preclinical animal models and clinical evidence of reward-pathway dysfunction in a range of disorders, including psychiatric disorders (i.e., substance-use disorders, affective disorders, eating disorders, and obsessive compulsive disorders), neurodevelopmental disorders (i.e., schizophrenia, attention-deficit/hyperactivity disorder, autism spectrum disorders, Tourette's syndrome, conduct disorder/oppositional defiant disorder), and genetic syndromes (i.e., Fragile X syndrome, Prader-Willi syndrome, Williams syndrome, Angelman syndrome, and Rett syndrome). We also provide brief overviews of effective psychopharmacologic agents that have an effect on the dopamine system in these disorders. This review concludes with methodological considerations for future research designed to more clearly probe reward-circuitry dysfunction, with the ultimate goal of improved intervention strategies.
\end{abstract}

Keywords: Reward, Mesolimbic, Dopamine, Nucleus Accumbens, Striatum, Neuroimaging

\section{Review}

\section{Introduction}

Despite the categorical nosology of the Diagnostic and Statistical Manual of Mental Disorders (DSM) [1], different neurodevelopmental and psychiatric disorders share phenotypic features, etiologies, and aberrant neurobiological processes. Indeed, there are multiple examples of distinct disorders that are characterized by common pathophysiological mechanisms. For example, anxiety disorders and mood disorders share hyperactive amygdala responses to negatively valenced stimuli $[2,3]$ and schizophrenia and post-traumatic stress disorder are both characterized by prefrontal dysfunction during tasks that require sustained attention $[4,5]$. Such overlap suggests the utility of examining common patterns of dysregulated brain function and associated phenotypes

\footnotetext{
* Correspondence: dichter@med.unc.edu

'Carolina Institute for Developmental Disabilities, University of North Carolina at Chapel Hill School of Medicine, Chapel Hill, NC, USA

${ }^{2}$ Department of Psychiatry, University of North Carolina at Chapel Hill School of Medicine, Chapel Hill, NC, USA

Full list of author information is available at the end of the article
}

with the ultimate goal of more accurately linking pathophysiological processes to rationally derived and targeted interventions.

The identification of common neurobiological deficits across disparate neurodevelopmental and psychiatric disorders has helped to motivate goal 1.4 of the NIMH Strategic Plan [6], the Research Domain Criteria project (RDoC; http://www.nimh.nih.gov/research-funding/rdoc. shtml), which aims to foster research that uses neuroscience tools to investigate constructs that cut across traditional nosological classification boundaries $[7,8]$. Although optimal methodological approaches to address these questions are still emerging, the ultimate goal of this framework is to refine classification and develop empirically derived approaches to treatment [9-11]. At the heart of this approach is the search for dysfunctional mechanistic processes shared by disorders with seemingly disparate phenotypic profiles, a strategy that represents a particular instantiation of the endophenotypic approach to identifying pathophysiological disease mechanisms [12-14]. 
The functioning of reward-processing systems through development has recently garnered increased research attention in both nonclinical [15,16] and clinical [17-19] contexts, and the functioning of so-called 'positive valence systems' has been proposed as one of the five domains relevant to the NIMH RDoC project [6]. Given the focus of this thematic issue on reward processing in autism specifically, the purpose of this review is to place dysfunctional reward processing in autism within the larger context of emerging evidence that reward-circuitry dysfunction may be present in multiple distinct disorders, and may thus represent a common target for treatments of these disorders.

In this review, we summarize preclinical models and clinical research addressing reward-circuitry dysfunction in a range of neurodevelopmental and psychiatric disorders and genetic syndromes. Specifically, we focus on the functional output of ascending mesolimbic dopamine (DA) projections systems, referred to broadly in this review as 'reward-processing' systems. In its fundamental unit, the mesolimbic DA pathway consists of a population of DAcontaining neurons in the ventral tegmental area (VTA) that project to neurons in the nucleus accumbens (NAc); however, these VTA neurons also extend projections into the amygdala, the bed nucleus of the stria terminalis, the lateral septal area, and the lateral hypothalamus (collectively, these connections comprise the entire mesolimbic DA system). The processes subserved by these systems have been referred to by multiple names in the research literature, including 'motivation' [20], 'goal-directed behaviors' [21], 'incentive salience' [22], and simply 'drive' [23]. Furthermore, it is clear that these DA systems affect not only reward processing, but a number of related functions, including punishment [24], decision-making [25,26], cognition [27], reward prediction [28,29], and reward valuation [30-32].

\section{Organization and criterion for disorders included in this review}

This review is organized as follows. First, we briefly outline the neurobiology of the reward system and discuss potential molecular and cellular mechanisms underlying dysregulated reward-pathway functions. Next, animal models of neurodevelopmental and psychiatric disorders that involve dysregulated reward systems are reviewed, followed by a review of clinical studies of rewardcircuitry function within multiple disorders, with a particular emphasis on functional neuroimaging studies and molecular-imaging studies that address striatal DA transmission. We first present psychiatric disorders (i.e., substance-use disorders, affective disorders, eating disorders, and obsessive-compulsive disorder

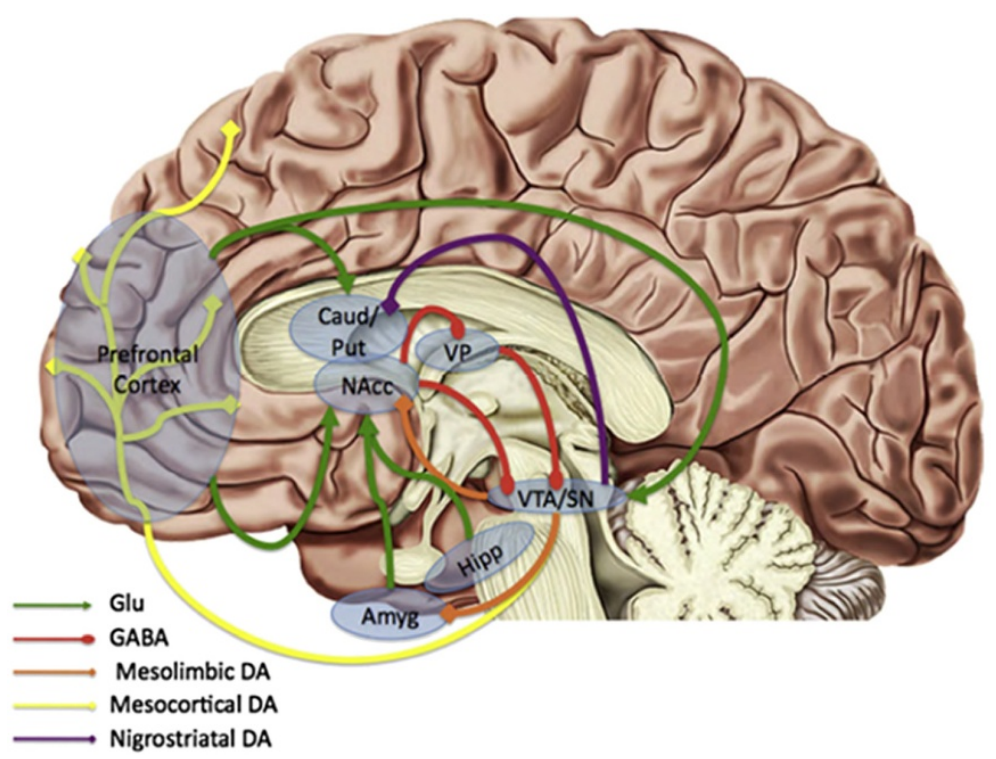

Figure 1 Schematic illustration of the DA pathways and circuitry that regulate dopamine (DA) release in the human brain. The DAcontaining neurons in the ventral tegmental area (VTA)/substantia nigra (SN) project to the nucleus accumbens (mesolimbic pathway; orange), to the cortex (mesocortical pathway; yellow) and caudate putamen (nigrostriatal pathway; purple). DA neuron firing rates are maintained at tonic levels in part due to steady-state inhibitory firing from the ventral pallidum. Excitatory glutamatergic fibers (green) project from the prefrontal cortex, amygdala, and hippocampus, that synapse on striatal targets, including the nucleus accumbens (NAc). The NAc sends GABAergic projections (red) to the ventral pallidum that suppress ventral pallidum inhibition of the VTA, thereby facilitating phasic burst firing of ventral tegmental area DA neurons. Note: Placement of structures is only approximate. Amyg, amygdala; Caud, caudate; DA, dopamine; GABA, GABAergic projections; Glu, glutamatergic projections; Hipp, hippocampus; Put, putamen; VP, ventral pallidum. (Figure and legend adapted with permission from Treadway and Zald [19].) 
$(\mathrm{OCD})$ ), then neurodevelopmental disorders (i.e., schizophrenia, attention deficit/hyperactivity disorder (ADHD), autism spectrum disorders (ASDs), Tourette's syndrome (TS), and conduct disorder/oppositional defiant disorder (CD/ODD)), and finally genetic syndromes (Fragile $\mathrm{X}$ syndrome (FXS), PraderWilli syndrome (PWS), Williams syndrome (WS), Angelman syndrome (AS), and Rett syndrome (RS)). For all disorders, we emphasize how phenotypic expression of disparate symptoms may be interpreted within the context of reward-processing deficits. We also include brief summaries of effective pharmacologic treatments for each disorder affecting DA function. We conclude with suggestions for directions for future research aimed at treatment of reward-system dysfunction. To constrain the scope of this review, we have considered only disorders primarily considered as psychiatric and neurodevelopmental disorders and genetic syndromes. We therefore have not included disorders such as Huntington's disease and Parkinson's disease that are both considered to be neurodegenerative diseases coded as Axis III conditions in the DSM ('general medical conditions') and that are typically listed as an associated feature of an Axis I condition [1].

Although this review focuses primarily on DA transmission in the mesolimbic pathway, multiple other brain neurotransmitter systems are crucially involved in reward processing. For example, pharmacological studies in rodents indicate that distinct serotonin-receptor subtypes expressed both within and outside the mesolimbic system can modulate responses to either natural rewards or drugs of abuse [33]. Whereas norepinephrine has been traditionally associated with stress responses, both DA and norepinephrine are released in an opposing manner in the bed nucleus of the stria terminalis, in response to either aversive or rewarding taste stimuli, indicating interplay in these chemical systems [34]. Endogenous opioids, including endorphins, enkephalins, and dynorphins, can modulate DA transmission in the mesolimbic pathway [35]. Substance-abuse studies have shown that alcohol, which promotes gamma-aminobutyric acid $(\mathrm{GABA})_{\mathrm{A}}$ receptor function, may inhibit GABAergic terminals in the VTA and hence disinhibit these DA neurons, thereby facilitating mesolimbic reward-pathway transmission [36]. Abusive opiates such as heroin function similarly, but in an indirect manner: they inhibit GABAergic interneurons in the VTA, which disinhibits VTA DA neurons and thus enables activation of the reward pathway. These observations highlight the importance of GABA transmission in the VTA for reward processing. Finally, synaptic transmission in the NAc relies on glutamatergic inputs from multiple areas, and glutamate can induce modifications in dendritic morphology, ionotropic glutamate receptors, and the induction of synaptic plasticity in the NAc, implicating glutamatergic transmission in coordinating reward processing $[37,38]$. These examples indicate that processing of rewarding information involves a complex crosstalk between the DA mesolimbic system and other neurotransmitters, and that interdependency probably occurs across multiple systems and circuits. To simplify this considerable complexity, we aim in this review to summarize the importance of animal models and clinical findings in addressing dysfunction in systems mediating reward processing (broadly defined) by focusing on striatal DA responses to rewarding stimuli.

\section{Brain reward circuitry}

Responses to rewards are mediated primarily by the ascending mesolimbic DA system that is highly similar between humans and other animals (Figure 1 shows structures that will be discussed as part of the mesolimbic DA system) [39]. Although the terms 'reinforcement', and 'reward' are often used interchangeably, these terms have discrete behavioral definitions, and describe largely distinct neurobiological processes. Indeed, there are multiple constructs mediated by the mesolimbic system, and at least four such systems have been described in depth in numerous seminal reviews [39-43]: 1) reward motivation, also termed anticipation (typically subsuming what is colloquially described as 'wanting,') refers to processes that facilitate anticipation of reward and approach behaviors towards biologically relevant goals, including reward valuation, willingness to expend effort to obtain rewards, reward prediction, and reward-based decision-making [44]; 2) reward outcome (or the hedonic responses widely referred to as 'liking' or 'pleasure') includes both consummatory behaviors during reward obtainment and the processes associated with regulation of such behaviors [45]; 3) reward learning includes reward processes that shape the experience-dependent learning that guides future behaviors [46]; and 4) reward-related habitual behavior reflects those processes that are initiated based on reward feedback, but that persist even in the absence of such feedback $[47,48]$.

The neurobiological bases of reward-processing behaviors are well understood in animal contexts [41,49-51], and cognitive affective neuroscience techniques have facilitated the investigation of reward circuits in human clinical contexts [52,53]. The mapping of brain-reward regions began with the seminal discovery that animals are willing to work to obtain electrical stimulation to mesolimbic brain regions [54]. Subsequent research showed that activity of DA neurons within mesolimbic pathways that project from the VTA to the NAc serve to reinforce responses to both primary rewards (for example, food) and secondary rewards (for example, money) [55]. Reward information is processed via a limbic cortico-striatal-thalamic circuit that interdigitates 
with the mesolimbic DA pathway [56,57], and the NAc serves as a DA-gated mediator for information passing from the limbic system to the cortex [58]. This tract is composed of projections from A10 cells in the VTA to cells in limbic areas, including the NAc, the amygdala, the olfactory tubercle, and the septum [59]. This tract has been linked to primary rewards, secondary rewards, and emotional processes, and is part of the limbicstriatal-pallidal circuit that is involved in motivated behavior [60].

Primary DA centers in the mammalian brain are located in two mesencephalon structures: the substantia nigra and VTA. These distinct brain nuclei contain DA-synthesizing neurons that project to the NAc (mesolimbic pathway), the cortex (mesocortical pathway), and the caudate putamen (nigrostriatal pathway). The central node within the mesolimbic DA reward system is the NAc within the ventral striatum. The NAc, along with the extended amygdala, mediates reward-based drive and motivation $[61,62]$, and receives afferents from a number of limbic regions, including the medial and orbital frontal cortices, the hippocampus, and the amygdala [62]. Of particular relevance to reward-based processes is the ventromedial shell of the NAc (the core region regulates cognition and motor control) [63], that serves as an interface between limbic and motor circuits, translating emotions into actions [64]. For this reason, as will be reviewed below, most animal models and clinical neuroimaging studies on rewardrelated processes focus on functioning of the NAc, and of related afferent and efferent projection regions within the striatum and frontal lobes.

\section{Mechanisms of neurotransmission in the mesolimbic reward pathway}

The molecular and cellular mechanisms that facilitate neurotransmission in the mesolimbic DA reward pathway involve the cellular elements modulating synaptic DA neurotransmission, including neurotransmitters, transporters, receptors, $\mathrm{G}$ proteins, second-messenger-generating enzymes, ion channels, and immediate early response genes that regulate neuronal functions (Figure 2) [65-67]. Afferents from the VTA of the mesolimbic DA system project outward, and primarily terminate onto the MSNs, which are the principal cell type in the NAc, and produce and secrete GABA, the main inhibitory neurotransmitter used in the CNS. These MSNs are also the main projection or output neurons of the NAc.

Neurotransmission within the mesolimbic pathway begins with an action potential that is generated in VTA neurons, resulting in the presynaptic release of DA. Neurotransmission of the DA signal to MSNs in the NAc is mediated by binding to specific DA receptors. These DA receptors are part of the Gprotein-coupled receptor superfamily, and upon binding DA, activate heterotrimeric G proteins (Golf/Gs or Gi/o) that in turn regulate the activity of effector proteins such as ion channels, or the enzyme adenylyl cyclase that produces the second messenger cAMP [65]. Five distinct DA receptors $\left(D_{1}\right.$ to $\left.D_{5}\right)$ can mediate neurotransmission, and are coupled positively to activation of adenylyl cyclase ( $D_{1}$ and $D_{5}$ receptors) or negatively to inhibition of adenylyl cyclase $\left(D_{2}, D_{3}, D_{4}\right)$. Consequently, MSNs that express $\mathrm{D}_{1}$-like receptors become activated by DA, resulting in an increase in cAMP synthesis, whereas MSNs that express $\mathrm{D}_{2}$-like receptors respond to DA by decreasing cAMP synthesis. cAMP in turn activates protein kinase $\mathrm{A}$, that phosphorylates target proteins resulting in modulation of neuronal activity, gene expression, and target-protein functions. The response to DA in this neuronal pathway is terminated by reuptake of DA into the presynaptic neuron terminals, which is controlled by the DA transporter (DAT). In addition, the enzymes monoamine oxidase (MAO) and catechol-o-methyltransferase (COMT) can regulate DA levels by breaking down DA to the metabolites homovanillic acid or 3-methoxytyramine (3-MT), respectively.

Given its anatomical organization, the NAc is considered a limbic-motor interface [68] translating information about rewards into appropriate behavioral responses to obtain these rewards. The major effect of DA transmission is to modulate the sensitivity of NAc MSNs to other types of input. For example, DA modulates the sensitivity of MSNs to excitatory glutamatergic projections from pre-frontal and limbic regions, and thereby modulates firing activity of NAc neurons $[35,69]$. The result of DA transmission on NAc neuronal firing is largely determined by the types of DA receptors expressed in post-synaptic MSNs. Although the precise causal link between DA release and NAc cell firing is unclear, $D_{1}$ and $D_{2}$ receptors are generally considered to exert opposite effects at the cellular level, with $\mathrm{D}_{1}$-like receptor-expressing cells responding to DA with excitatory increases in firing activity, and $\mathrm{D}_{2}$-like receptor-expressing cells responding with decreased firing activity. However, in the context of DA release in the brain, a cooperative interplay between NAc neurons that encode reward information probably occurs. For example, DA increases spike firing in MSNs, requiring coactivation of both $D_{1}$ and $\mathrm{D}_{2}$ receptors [70]. Furthermore, transmission of DA to the NAc occurs with the same temporal resolution as NAc neuron-patterned cell firing, and this DA release and firing are coincident during goal-directed actions in rodents [71]. In addition, the frequency of firing activity of VTA neurons may be a key component in modulating the mesolimbic reward pathway and encoding reward information. Studies using channel rhodopsin to precisely control VTA neuron firing 


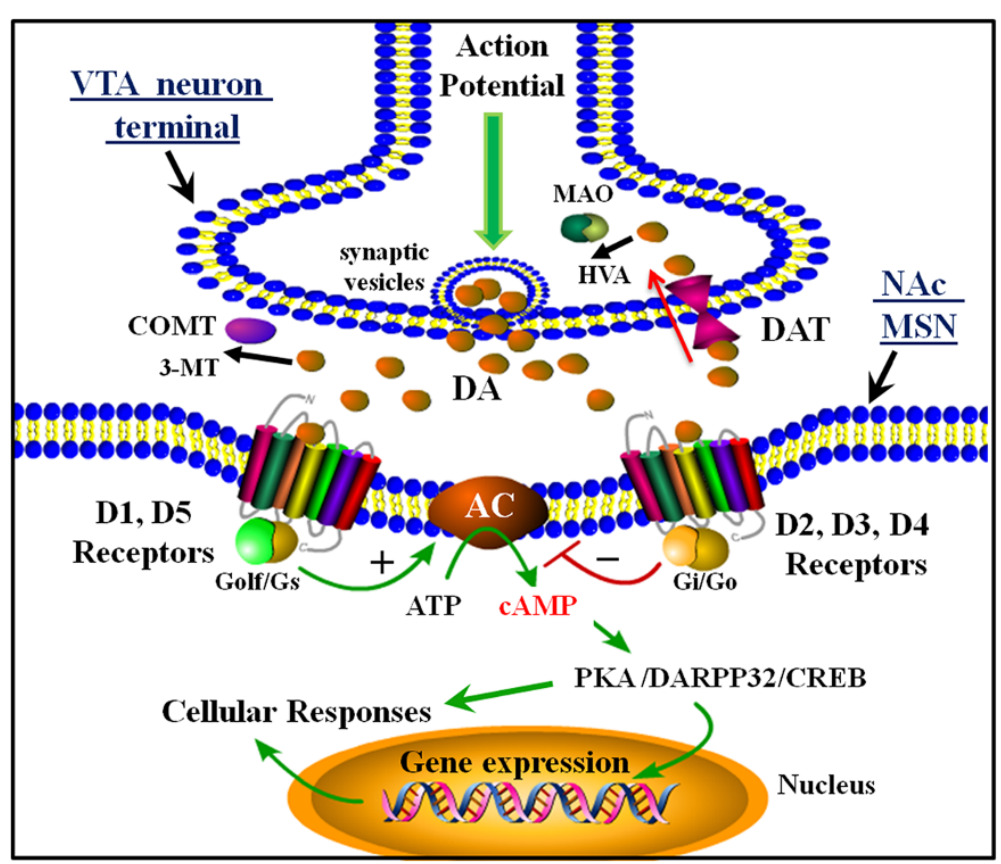

Figure 2 Schematic illustration of cellular mechanisms of neurotransmission in the mesolimbic dopamine (DA) reward pathway. Shown is a synapse between a ventral tegmental area DA neuron axon terminal and a medium spiny neuron (MSN) in the nucleus accumbens (NAc) in the ventral striatum. Transmission begins with an action potential that arrives to the terminal, inducing synaptic vesicle fusion and release of DA. The release of DA into the NAC stimulates various populations of MSNs, whose response to the transmitter depends on the types of DA receptors they express. DA stimulation of neurons containing $D_{1}$ or D5 receptors (so-called $D_{1}$-like receptors) results in activation of heterotrimeric Golf/Gs proteins, which activate the enzyme adenylyl cyclase, resulting in the synthesis of the second messenger CAMP. In contrast to this mechanism, DA stimulation of MSNs that express $D_{2}$, D3 or D4 (or $D_{2}$-like receptors) activate sheterotrimeric $\mathrm{Gi} / \mathrm{Go}$ proteins, which inhibit adenylyl cyclase activity to decrease CAMP. The level of intracellular CAMP controls the activation of protein kinase A, which regulates additional signaling molecules including dopamine- and CAMP-regulated neuronal phosphoprotein of $32 \mathrm{kDa}$ (DARPP-32) and the transcription factor CAMP response element binding (CREB) protein, both of which can modulate gene expression and additional cellular responses. The response to DA is generally terminated when DA is removed from the synapse by reuptake via the DA transporter (DAT). After reuptake, the transmitter can be repackaged into synaptic vesicles or may be degraded by the enzyme monoamine oxidase, resulting in the DA metabolite homovanillic acid. In addition, the enzyme catechol-o-methyltransferase (COMT) may also control DA levels by breaking down DA to 3-methoxytyramine (3-MT), AC, adenylyl cyclase; ATP; adensosine triphosphate; cAMP; cyclic adenosine monophosphate; HVA, homovanillic acid; MAO, monoamine oxidase; VTA, ventral tegmental area.

activity suggest that phasic, but not tonic, activation of VTA neurons is sufficient to drive behavioral conditioning to rewards and elicit DA transients [72], and thus indicates the likely importance of the frequency of VTA neuron firing activity.

\section{Potential molecular and cellular mechanisms underlying dysregulated reward systems}

Disruption of molecular, cellular, or circuitry mechanisms that are essential for the reward system may, in theory, result in aberrant reward-system function. Although a primary (or even common) molecular mechanism for dysregulating the reward system has yet to be identified, we briefly consider in the following section some of the potential molecules and mechanisms that may underlie abnormal reward processing.

Because the major neurotransmitter mediating mesolimbic transmission is DA, alterations in the synthesis, release, or reuptake of DA may result in an abnormally functioning reward system. Amphetamines and cocaine mediate their effects in the mesolimbic pathway by increasing the release of DA. Cocaine and amphetamines, both of which directly interact with the DAT, exert their effects, at least in part, by blocking (in the case of cocaine) or reversing the direction of (in the case of amphetamine) this transporter, resulting in increased synaptic DA [73]. Indeed, chronic administration of cocaine upregulates striatal DAT expression in rhesus monkeys, an effect that persists for more than 30 days after cocaine withdrawal [74]. Increased DA-transporter expression has also been shown in post-mortem analyses of brain tissue from human subjects addicted to cocaine [75]. Such studies indicate that alterations in DAT expression or function can result in an altered reward system in response to drugs of abuse. 
Similarly, alteration in the expression or regulation of DA receptors would also be expected to dysregulate reward-system functions. Altered DA receptor function could involve increased or decreased receptor expression or signaling responsiveness to DA thereby altering the reward system. For example, the DA hypothesis of schizophrenia suggests that excess mesolimbic DA levels may be pro-psychotic, and involve alterations in the activity of striatal $D_{2}$ receptors, which are the major site of action for typical antipsychotic medications [76]. There is clear evidence of dysregulated striatal DA function in schizophrenia [77], and a meta-analysis of multiple studies indicated a significant increase in striatal $D_{2}$ receptors in patients with schizophrenia who were not on medication [78]. Studies have also suggested an increased affinity of $\mathrm{D}_{2}$ receptors for DA in schizophrenia, which may produce $D_{2}$ receptor supersensitivity in the NAc, contributing to psychosis [79]. In an interesting animal model correlate to these studies, transient overexpression of $\mathrm{D}_{2}$ receptors in the striatum of mice resulted in deficits in prefrontal working memory, resembling some of the features of human schizophrenia [80]. Studies such as these indicate that alterations in DA receptor expression (or function) can result in a dysfunctional reward system.

Molecules that are activated downstream of DA receptor signaling in the NAc also play important roles in mediating reward responses and changes in their function may also dysregulate the reward system. These molecules include the heterotrimeric $G$ proteins activated by DA receptors and also the adenylyl cyclases. Interestingly, genetic knockout of adenylyl cyclase type 5 in mice prevents the reward response to opioids such as morphine [81]. Further down in the DA signaling pathway of MSNs is the DA- and cAMP-regulated phosphoprotein of $32 \mathrm{kDa}$ (DARPP32) (Figure 2). DARPP-32 is activated by $D_{1}$ receptor cAMP signaling in the NAc by protein kinase A phosphorylation, that regulates the activity of protein phosphatase (PP)-1 [82]. Phosphorylated DARPP-32, by inhibiting PP-1, acts in a combined manner with other protein kinases to increase the level of phosphorylation of various downstream effector proteins, and modulation of protein phosphorylation by DA is thought to play an important role in drug reward. DARPP-32 may thereby influence the long-term neuronal adaptations associated with natural rewards or with rewards from drugs of abuse $[83,84]$. Support for this concept is provided in genetic models in mice lacking the DARPP-32 gene, which results in decreased responses to cocaine in conditioned place preference behaviors [85]. Therefore, alterations in DARPP-32, PP-1, and the phosphoproteins that these regulate in $\mathrm{MSNs}$, may dysregulate the reward pathway.
Two transcription factors, $\triangle \mathrm{FosB}$ and cAMP response element binding protein (CREB), are activated by DA receptor signaling in the NAc, and both are important mediators of reward responses because they control the expression of numerous genes. One of the most dramatic examples of protein expression induction is in the transcription factor $\triangle F o s B$, a Fos family protein, which accumulates in the NAc after chronic exposure to drugs of abuse, including alcohol, amphetamine, cannabinoids, cocaine, nicotine, opiates, and phencyclidine [86,87]. Overexpression of $\triangle \mathrm{FosB}$ in the NAc increases behavioral responses to cocaine, opiates, sucrose and wheelrunning, including increased incentive drive for these rewards. Conversely, blockade of $\Delta$ FosB function in the NAc by overexpression of a dominant negative antagonist causes the opposite effects [88].

CREB is another transcription factor that is directly activated by protein kinase $\mathrm{A}$ in response to DA signaling in the NAc. Activation of CREB seems to produce similar behavioral responses to rewarding stimuli: in numerous experimental systems, increased CREB activity in the NAc is negatively related to behavioral responses to cocaine, opiates, and alcohol [86,88-90]. CREB is also induced in the NAc by natural rewards (such as sucrose), and similarly reduces an animal's sensitivity to the rewarding effects of sucrose [89]. Therefore, any changes in the activation and induction of CREB, $\triangle$ FosB, (and probably many other transcription factors) would be expected to regulate or dysregulate the reward system.

Finally, although the molecules highlighted here are clearly involved in DA mesolimbic transmission and reward responses, this represents only a brief overview and readers are encouraged to see other recent reviews of this topic [86,91-93].

\section{Considerations for animal models that focus on reward-system function}

Animal models, particularly those using rodents, have provided key mechanistic insights that have elucidated the neurobiology of the brain reward system. Although animal models cannot recapitulate the entire spectrum of phenotypes apparent in clinical presentations of illness, they provide powerful approaches for experimental studies using various environmental, genetic, pharmacological, and biological manipulations. With regard to studying behavior, a high degree of experimental control can be achieved by precisely controlling the animal's life experiences, environment, diet, and history of drug exposure, enabling inferences to be made concerning the causality of effects seen in experimental studies. However, for complex psychiatric disorders with largely unknown genetic etiologies, environmental insults, specific pathologies, or biomarkers, the building of animal models with high construct validity has not yet been possible 
[94]. With this limitation in mind, an alternative strategy has been to develop mouse genetic models (for example, knockout or transgenic mice) of psychiatric disorders with relevant behavioral phenotypes (face validity) that are responsive to pharmacotherapies that are clinically effective (predictive validity).

\section{Considerations for clinical studies that focus on reward-system function}

Primary rewards are vital to gene propagation, and thus responses to such stimuli have been shaped by evolution to elicit approach-oriented behaviors. These stimuli include food and sexual behavior (given that sustenance and procreation are crucial for the survival of a species $[95,96])$, and social interactions with conspecifics $[39,97]$. Nonclinical human neuroimaging studies indicate that the mesolimbic DA response to primary rewards may operate similarly in humans in response to more abstract, or secondary, rewards such as monetary incentives [98-100]. Recent evidence suggests a common 'neural currency' for coding monetary and primary (for example, food) rewards [101]. Thus, most clinical studies investigating responses to rewards have used monetary incentives as a proxy for primary rewards, because money is adaptable to the research environment, may be parametrically scaled, may be won or lost, and may be delivered at precise intervals.

It should be noted that few of the preclinical and clinical studies reviewed here involve longitudinal data collection, and it is difficult to make any inferences about the developmental nature of reward-processing systems in the disorders reviewed. In this regard, although our goal is to propose a possible common framework for conceptualizing a range of seemingly disparate phenotypes and possibly to ultimately identify novel biological markers and influence nosological classification, inferences about etiology must be appropriately cautious in the context of largely cross-sectional data.

\section{Psychiatric disorders}

\section{Substance-use disorders}

Perhaps the greatest convergence of empirical evidence supporting reward-network dysfunction in psychiatry emanates from research on substance-use disorders [102]. The 12-month prevalence estimates for substance-use and abuse disorder are about 3.8\% [103]. Contemporary theories addressing the pathophysiology of substanceuse disorders highlight altered motivational states, cognitive control, inhibitory function, and decision-making, mediated in large part by dysfunctional output of mesolimbic and mesocortical brain systems [104-107]. Although the scope of this review is constrained to a consideration of reward processes, rather than to related constructs such as inhibition and impulsivity, it should be noted that the 'impulsivity hypothesis' of addiction vulnerability stresses shared neurobiology and patterns of heritance between risk for addiction disorders and conduct disorder [108], including evidence of intergenerational transmission of both alcoholism risk and impulsivity in large-scale twin studies [109], and common patterns of enhanced behavioral sensitivities to reward stimuli [110] and risky decisions [111,112].

The rewarding effects of drugs of abuse derive in large part from the sizeable increases in extracellular DA in limbic regions, and in the NAc in particular, during drug use $[113,114]$. In addition, drug-induced increases in striatal DA have been linked with subjective feelings of euphoria $[115,116]$. The firing of DA cells that accompanies drug use encodes a number of reward properties, including reward expectancy [117], reward learning [118], and the consolidation of contextual memories [119]. All of these processes are believed to contribute to the intense motivation to attain drugs of abuse [120].

It has been proposed that the crucial mechanism for the development of addiction is drug-induced activation of DA transmission in the mesolimbic pathway, also referred to as the 'dopamine hypothesis of addiction' [121-123]. To better understand the neurobiology of drug abuse and addiction in humans, several animal models have been developed to investigate different aspects of drug addiction [122,124]. Among these, the models that incorporate self-administration of drugs are thought to best capture the human condition because animals voluntarily seek drugs and because drugs that are self-administered by animals correspond well with those that have abuse potential in humans.

Preclinical models From mechanistic neurobiological and behavioral studies in rodents, it has become clear that the mesolimbic pathway is a key component for the rewarding effect of drugs of abuse, and is essential for behaviors related to drug reward, salience, and motivation [122]. For example, using rodent models, researchers have determined that nearly all psychoactive drugs of abuse (for example, cocaine, amphetamines, alcohol, opiates, cannabinoids, nicotine) induce alterations in the transmission of DA within the mesolimbic pathway, with most of these drugs increasing extracellular concentrations of DA [122]. Studies using an in vivo microdialysis technique, which measures minute changes in brain neurotransmitter levels in the behaving animal, have shown that drugs of abuse can increase tonic DA concentrations in the NAc. In addition, studies using fast-scanning cyclic voltammetry, which can detect the level of DA release in the intact brain on a timescale of seconds, have shown an increased frequency of spontaneous phasic DA signals in the NAc in response to 
cannabinoids and nicotine in awake, behaving animals $[125,126]$, and also temporally distinct DA signals in response to cocaine [127].

Dopamine neurotransmission is strongly implicated in the reinforcement of self-administering drugs or electrical stimulation in animals. The seminal animal research by Olds and Milner [54] provided the initial foundation for our modern understanding of brainreward mechanisms. In those pioneering studies, rats were given the ability to self-administer electrical stimulation to various brain regions including the mesolimbic pathway. The rats persistently and repeatedly chose to stimulate the VTA mesolimbic DA pathway (but not other brain areas), often to the exclusion of other behaviors. Behavioral studies in rodents also indicate that DA is essential for the self-administration of drugs of abuse for which the mesolimbic pathway has been identified as a crucial substrate $[114,128]$. Drug self-administration is the 'gold standard' of animal models of drug abuse $[122,129]$. In the typical drug self-administration procedure, animals obtain a drug by performing a simple behavior (such as pressing a lever), and animals will readily self-administer the same drugs that are abused by humans [130].

The importance of mesolimbic DA transmission to drug self-administration is supported by pharmacological and lesion studies. Direct DA receptor agonists can mimic the effects of substances of abuse, and these agonists are self-administered both systemically and locally into the NAc in rats and monkeys [131-133]. By contrast, DA receptor antagonists administered systemically increase the rate of operant responding for cocaine in animals [134-136]. In addition, lesion or inactivation of the mesolimbic DA system in the VTA $[137,138]$ or in the NAc [139-143] decreases cocaine, amphetamine, heroin, and nicotine self-administration in rats. These findings indicate the crucial importance of the mesolimbic DA system in drug-taking.

Clinical studies There is a confluence of clinical evidence that substance-use disorders are characterized by relative hyperactivation of mesolimbic regions in response to drug cues (that is, increased reward motivation). This pattern is evident across various subtypes of substanceabuse disorders, suggesting the central involvement of striatal regions encoding reward prediction and/or anticipation in substance-abuse disorders. Wexler and colleagues [144] presented cocaine-addicted subjects with videotapes containing cocaine-associated cues, and reported relatively increased anterior cingulate cortex (ACC) activation during the presentation of the cocaine cues, despite decreased overall frontal lobe activation. Further, these effects were evident even in the absence of self-reported cravings, suggesting that brain-imaging effects did not simply recapitulate experiential responses to the cocaine cues "Buhler and colleagues" [145] assessed anticipatory responses to cues predicting cigarette and monetary rewards in nicotine-dependent smokers and non-dependent occasional smokers. The non-dependent group showed relatively increased mesocorticolimbic reactivity to stimuli predicting monetary reward compared with stimuli predicting cigarette rewards, and subsequently spent relatively more effort to obtain money relative to cigarettes. By contrast, the nicotinedependent group showed equivalent responses to both categories of reward cues, and anticipatory mesocorticolimbic activation predicted subsequent motivation to obtain both rewards, suggesting an imbalance in reward motivation in response to drug-predicting cues relative to monetary cues in those with nicotine dependence. Myrick and colleagues [146] reported that activation in the NAc, anterior cingulate, and left orbitofrontal cortex in response to alcohol images predicted cravings in alcoholics. Oberlin and colleagues [147] reported that the magnitude of striatal activation to alcohol cues (the odors of the preferred alcohol drink) in heavy drinkers was modulated by antisocial trait density. Finally, Filbey and colleagues [148] showed that regular marijuana users who abstained from use for 72 hours were characterized by relatively increased reward-circuitry activity, including the VTA, thalamus, ACC, insula, and amygdala, in response to tactile marijuana cues. These studies reflect the overall pattern of data in a range of substance-abuse disorders, which shows relatively increased mesolimbic activation in response to drug cues, accompanied by increased states of reward motivation in response to these cues [148].

In contrast to the hyperactive responses of reward circuitry to drug-related cues, there is evidence that substance-use disorders are alternatively characterized by a reduced motivation for non-drug rewards [106]. As a number of researchers have described $[106,149]$, substance-use disorders are typically accompanied by decreased reward motivation for typical and nonpathological rewards, a phenomenon that has been variously termed 'motivational toxicity' [150] and 'rewarddeficiency syndrome' [151]. For example, Asensio and collegues [152] reported hypoactivation of the dorsal and ventral striatum and the dorsomedial pre-frontal cortex when cocaine addicts viewed pleasant images not linked to substance cues. Gilman and Hommer [153] reported subjective hypoarousal to normative positive images in alcohol-dependent participants. Bühler and collegues [154] reported mesocorticolimbic hypoactivation during monetary-reward motivation in nicotinedependent participants, which predicted motivation to obtain rewards. Andrews and colleagues [155] reported decreased NAc activation to monetary-reward outcome 
that predicted family history of alcoholism. In a study using multi-modal psychophysiological measurements, Lubman and colleagues [156] reported decreased arousal ratings and physiological measures of reward motivation to pleasant pictures relative to drug-cue images in opiate-dependent participants. Luo and colleagues [157] found relatively decreased right ventral striatal activation during the anticipation of delayed relative to immediate monetary rewards in cigarette smokers (that is, decreased reward motivation for delayed monetary rewards). However, Jia et al. [158] reported that treatment-seeking adults with cocaine dependence were characterized by striatal hyperactivation during monetaryreward outcome and that striatal activation during reward motivation predicted treatment outcome.

Attenuated motivation for non-drug rewards has also been reported in younger populations at risk for substance abuse. Schneider and colleagues [159] found that adolescents with risky substance- use patterns had reduced striatal activity relative to low-risk adolescents during monetary-reward motivation [17][ Similarly, Peters and colleagues [160] reported reduced ventral striatal responses during the anticipation of food reward in adolescent smokers. Notably, Andrews and colleagues [155] found this effect in family members of those with substance abuse, suggesting that this pattern may be evident even in the absence of the direct effects of repeated drug use on the brain. Overall, these studies highlight that the effects of altered mesolimbic function in substance-use disorders may be characterized not only by increased reward motivation for substancerelated stimuli, but also by decreased reward motivation for natural rewards (but there are exceptions [161]), which may lead to increased drug-seeking behaviors. In this regard, Koob and Le Moal [162] described an allostatic mechanism through which the reward system may become desensitized with repeated exposure to addictive drugs, due to gradual modulation of an organism's 'set point' of responsivity to external rewards.

Molecular-imaging studies of substance-use disorders have focused on imaging the $\mathrm{D}_{2}$ post-synaptic receptor $[106,163]$. There are multiple lines of evidence that cocaine dependence is associated with a decrease in $\mathrm{D}_{2}$ receptor binding [164-167], a pattern that seems to persist after disease remission [165]. Decreases in $\mathrm{D}_{2}$ receptor binding have also been found in heroin addiction [168], alcohol dependence $[169,170]$, methamphetamine abuse $[171,172]$, prompting a number of researchers to posit that low $\mathrm{D}_{2}$ receptor availability may serve as a biomarker for substance abuse, potentially reflecting an altered sensitivity to various rewards [173-175]. Although these molecular-imaging studies suggest decreased reward motivation in addiction that is consistent with the 'reward-deficiency syndrome' hypothesis of addiction, functional brain-activation studies paint a less consistent picture, probably due to variability in samples, task demands, patient characteristics, and unknown effects of a history of addictive behavior on functional responses to reward stimuli. Future research that combines molecular and functional imaging approaches will be necessary to elucidate the causes and consequences of altered reward processing in substance-use disorders in at-risk individuals [176].

Dopaminergic treatments A number of agents that modulate functional output of DA systems are effective first-line treatments for substance-use disorders [177]. Modafinil is a non-amphetamine stimulant with DA and glutamatergic effects, and with moderate effectiveness for the treatment of cocaine dependence [178] and possibly methamphetamine dependence [179]. Bupropion is a DA and norepinephrine reuptake inhibitor that is an effective treatment to promote smoking cessation [180]. Dextroamphetamine causes release of DA (as well as norepinephrine and serotonin) and is an effective treatment for amphetamine abuse [181]. Finally, risperidone, a $\mathrm{D}_{2}$-receptor antagonist, has shown promise for the treatment of methamphetamine abuse [182], and aripiprizole, a partial $\mathrm{D}_{2}$ agonist is a promising treatment for amphetamine abuse [183].

\section{Affective disorders}

Unipolar major depressive disorder (MDD) is associated with significant psychosocial and medical morbidity and mortality [184-186], and has an estimated lifetime prevalence of $14.6 \%$ [187]. Anhedonia, the decreased response to pleasurable stimuli, is a defining symptom of the disorder to the extent that MDD may be diagnosed even in the absence of depressed mood if anhedonia and other secondary symptoms are present [1]. Anhedonia is also a central feature of a number of neurobiological theories of depression that posit that deficits in emotional and motivational responses to appetitive stimuli are core features of the disorder [188], and the anhedonic endophenotype of MDD is perhaps the most well supported [10].

Preclinical models Because anhedonia is a defining symptom of affective disorders, animal models of hedonic deficits have been addressed in preclinical models of affective disorders. Chronic mild stress has been reported to induce an anhedonic-like state in rodents, that resembles the affective disorder phenotypes in humans [189]. In particular, Willner and colleagues originally reported that chronic and sequential exposure of rats or mice to a mild stress regimen caused decreases in responsiveness to rewards [190,191], commonly reported as a decrease in the consumption of and preference for sucrose solutions, and a decrease in the rewarding properties of pharmacological and natural rewards in the place 
preference behavioral paradigm [189,192-194]. The chronic stress paradigm is considered to have a greater etiological relevance and face validity in mimicking MDD than other animal models, and therefore has become one of the most widely used preclinical paradigms of affective disorders [195]. Chronic mild stress causes significant reductions in absolute and relative sucrose intake in rats, that is associated with a decrease in striatal DA activity, and is reversed after chronic antidepressant administration with imipramine [196]. Decreased DA release to the NAc has been shown to occur after exposure to chronic repeated or an unavoidable stress regimen in rats $[189,197,198]$, suggesting that stress significantly reduces mesolimbic DA transmission in rodent models. Altered DA function may also be related to changes in $D_{1}$ receptors, which have been shown to alter functional output in the rat limbic system after chronic unpredictable stress [199]. Therefore, stress-induced neurochemical changes, including decreased DA activity in the mesolimbic pathway, contributes to decreased natural reward (sucrose)-seeking in this animal model of affective disorders.

\section{Clinical studies: unipolar major depressive disorder} Reward-system dysfunction in MDD is well established [200-202]. Behavioral studies have reliably found that individuals with MDD show a blunted response to a range of rewarding stimuli [203-205]. Reward learning has also been found to be impaired in MDD [206], and this impairment is correlated with the severity of anhedonic symptoms [207]. Additionally, the severity of MDD has been found to correlate strongly with the magnitude of the rewarding effects of administration of oral Damphetamine, which increases DA availability [208], and anhedonic symptoms in the general population predict rewarded effort-based decision-making [209].

Functional neuroimaging studies in MDD have consistently indicated hypoactivation in reward-processing regions, including the dorsal and ventral striatum [210214] and a host of other reward structures, including the medial prefrontal cortex $[215,216]$, the pregenual and subgenual anterior cingulate, and the medial frontal gyrus $[217,218]$.

Reduced mesolimbic activity in MDD has been found during reward anticipation and outcomes in both adults and children [210,219-227] and during reward learning [206]. For example, Smoski et al. [228] reported that during a gambling task, outpatients with unipolar MDD had reduced striatal activation during reward selection, reward anticipation, and reward feedback (but see Knutson et al. [229] for a report of intact striatal function but increased ACC activation in depression during reward anticipation). In a follow-up study, Dichter and colleagues [230] reported that when these same patients were treated with behavior-oriented psychotherapy designed to increase interactions with potentially rewarding situations, striatal regions showed increased functioning during reward anticipation, similar to results of Forbes et al. [231]. Finally, there is also evidence that reward-network function shows greater impairment in MDD while patients are processing pleasant images relative to monetary rewards [232].

Altered reward-network responsivity may also be characteristic of individuals with a history of MDD but without significant current symptoms, suggesting that anhedonia may represent a trait marker of MDD vulnerability, independent of current MDD state [233,234]. McCabe et al. [235] found decreased ventral striatal activation during reward outcome in response to the sight and flavor of chocolate in euthymic individuals with a history of depression, and Dichter and colleagues [236] reported rewardnetwork hyperactivation during reward anticipation and hypoactivation during reward outcomes in individuals with remitted unipolar MDD. Although studying patients with remitted depression is not sufficient to establish reward-processing deficit as a trait marker of depression, given that the effect of past illness and treatments on brain function may not be conclusively excluded, it is nevertheless a necessary initial step to identify this disease trait. It also has the advantage of mitigating the potential confounding effects of current mood state, illness severity, non-specific effects of chronic illness and stress, and effects of psychotropic medication usage $[237,238]$. Thus, examining linkages between brain function and a history of MDD holds the promise of ultimately aiding in the identification of trait-like endophenotypic vulnerability markers predictive of MDD onset before clinically impairing symptoms appear.

Further converging evidence of the crucial role that reward-network functioning plays in MDD is found in literature documenting the remarkable consistency with which antidepressant response is predicted by pretreatment functioning of the ACC. The ACC plays a central role in processing positively valenced emotions [239] and other rewards [240], and in coding value representations of anticipated rewards [241], as shown in studies of sleep deprivation [242-245], psychopharmacological intervention [246-250], cognitive behavioral therapy $[251,252]$ and a combined approach of therapy and psychopharmacological intervention [231].

Given the linkages between anhedonia, unipolar MDD, and mesolimbic dysfunction, and the prevalence of anhedonia in a number of other Axis I disorders, including bipolar disorder, schizophrenia, and post-traumatic stress disorder, an area of neglected study is the direct comparison between MDD and these other conditions. A notable exception is a study by Lawrence et al. [253], 
in which euthymic and depressed patients with bipolar disorder and patients with unipolar depression viewed faces with varying emotional intensities. Whereas the bipolar group was characterized by differential ventral striatal responses to nearly all emotion categories, the unipolar group was characterized by blunted response to happy but not sad stimuli, suggesting that diminished reward outcome to pleasant stimuli may uniquely characterize unipolar MDD relative to bipolar MDD. Future three-group studies comparing MDD with other disorders characterized by anhedonia are needed to distinguish similarities and differences between these conditions with respect to processing reward stimuli.

Molecular-imaging studies of unipolar depression have reported decreased monoamine signaling, which is consistent with functional brain-imaging data suggestive of altered reward processing [254]. In addition to a substantial body of literature on positron emission tomography (PET) addressing serotonin $(5-\mathrm{HT})_{2}$ receptor density in depression [255,256], DAT-binding potential has received considerable attention. Dunlop and Nemeroff [200] summarized the literature to date addressing molecular-imaging studies of DA signaling in MDD. These studies have indicated increased $\mathrm{D}_{2}$ receptor binding in the basal ganglia [257], striatum [258,259], and putamen [260], whereas other studies have reported lower [261] or no difference $[259,262,263]$ in striatal $D_{2}$ transporter binding potential.

Clinical studies: bipolar disorder Bipolar disorder is a mood disorder characterized by one or more episodes of mania, defined as abnormally increased energy levels, cognition, and mood [1], and has an estimated lifetime prevalence estimate of around 1\% [264]. Mania has been conceptualized as a tendency to show heightened response to positive emotions and rewards [265], along with excessive goal pursuit and unrealistically high expectancy of success. It has been suggested that these symptoms may reflect upregulation of the mesolimbic DA system in bipolar disorder [266]. Behavioral studies of response to rewards in bipolar disorder indicate deficits in behavioral adaptation to changing reward contingencies [267] and prolonged elevation of mood in response to monetary reward in euthymic patients with bipolar disorder [268]. Reward motivation is also atypical in individuals with bipolar disorder, as shown by a selfreport measure of reward responsivity [269] and in eyetracking studies of monetary gains and losses [270].

Although functional MRI studies have identified prefrontal dysfunction in bipolar disorder and manic psychosis, evidence for abnormalities in reward-related neural network function in mania is scarce [271-275]. Although several studies have suggested alterations in the shape [276], size [277,278] and function [274] of the basal ganglia in bipolar disorder, there are only three published functional neuroimaging research studies addressing responses to rewards in bipolar disorder. Abler et al. [279] reported decreased NAc activation during monetary-reward outcome, a pattern that was not evident in a group of patients with schizophrenia scanned using the same paradigm. Lawrence and colleagues [253] reported increased ventral striatal and ventral prefrontal cortical responses to mildly happy facial expressions in bipolar disorder. Finally, Jogia and colleagues [280] reported relative ACC hyperactivation during reward processing in bipolar disorder. The paucity of functional brain-imaging research on reward processing in bipolar disorder is striking, given the increasing recognition of reward-system dysfunction in the related conditions of unipolar MDD and schizophrenia, and the conceptual linkages between the symptoms of mania and functions of striatal DA that have been suggested for nearly 20 years [281].

Molecular-imaging studies of striatal DAT availability in bipolar disorder generally suggest increased functional DA throughput (but Suhara et al. reported an exception [282]). Amsterdam and Newberg [283] reported higher striatal DAT binding in the right posterior putamen and left caudate in a small number of patients with bipolar disorder; Chang and colleagues [284] reported that unmedicated euthymic subjects with bipolar disorder had significantly relatively higher whole striatal DAT binding; and Anand and colleagues [285] reported relatively lower DAT availability in the dorsal caudate nucleus (DCN) bilaterally. There is also evidence that the presence of psychosis may moderate patterns of DA receptor binding. Specifically, striatal $\mathrm{D}_{2}$ receptor signaling seems to be greater in psychotic patients with bipolar disorder [286,287], whereas no differences in $\mathrm{D}_{2}$ availability were found between non-psychotic patients with bipolar disorder and controls $[288,289]$.

Dopaminergic treatments Bupropion, a DA and norepinephrine reuptake inhibitor, is an effective antidepressant [290] that seems to specifically increase feelings of positive affect [291]. Other examples of DA agents effective in the treatment of MDD include the selective $D_{2} / D_{3}$ receptor agonists pramipexole [292] and piribedil [293] the catechol-O-methyltransferase inhibitor tolcapone, [294], and the preferential presynaptic DA antagonist amisulpride, [295]. Particularly relevant in the present context are previous reports [290,296,297] that although both DA and non-DA agents can be used to effectively treat mood disorders, DA agents generally have superior effects on symptoms of anhedonia, specifically when compared with non-DA agents [19,298-300]. Tremblay and colleagues [226] reported that depressed patients had relatively greater increases in striatal and 
orbitofrontal cortex activation in response to emotional pictures after administration of dextroamphetamine (a stimulant associated with increased DA release). This highlights the crucial role that the selection of rewardrelevant outcome measures will have for studies addressing the efficacy of DA agents in the treatment of mood disorders.

\section{Eating disorders \\ Preclinical models}

Feeding is a complex process that involves a sensory response to the sight and smell of food, previous feeding experiences, satiety signals elicited by ingestion, and hormonal signals related to energy balance. DA release in specific brain regions is associated with pleasurable and rewarding events, and the mesolimbic system is thought to reward positive aspects of feeding. Some of the most elegant and informative studies clarifying the involvement of DA in feeding and other neurobiological functions come from the studies of Palmiter and colleagues. Zhou and Palmiter [301] developed a DA-deficient mouse by genetically deleting tyrosine hydroxylase, the key enzyme required for the synthesis of L-3,4-dihydroxyphenylalanine (L-DOPA), the chemical precursor of catecholamines. These DA-deficient mice cannot make $\mathrm{DA}$, and are born normal but fail to thrive, have decreased food intake, gradually become hypoactive and hypophagic, and die at 3 weeks of age [301]. However, intervention and treatment of the mice with L-DOPA to restore striatal DA levels to $10 \%$ of the levels in normal mice is sufficient to elicit normal feeding behavior and animal survival [302]. Moreover, restoration of tyrosine hydroxylase gene expression using gene therapy was able rescue the deficient feeding behavior in these DAdeficient mice [303]. Using gene therapy to enable DA production within only the caudate putamen restored mouse feeding on regular chow diet, and also normal nest-building behavior, whereas restoration of DA production into the NAc only restored the exploratory behavior [304].

A salient result from these animal studies is that DA transduction in the central or lateral regions of the caudate putamen was sufficient to permanently rescue mice from the starvation that would occur inevitably without daily L-DOPA injections. However, restoration of DA into the NAc in these studies was not sufficient to rescue normal feeding behavior, but this may have been due to an inability to anatomically restore gene expression throughout the entire NAc [304]. Interestingly, when the DA-deficient mice are crossed with obese leptin $(\mathrm{Ob} / \mathrm{Ob})$-deficient mice, the lack of DA blocked the increased feeding behavior normally present in the leptin (Ob/Ob)-deficient mice [305]. Taken together, the DA- deficient mouse studies indicate the essential requirement of DA for normal feeding behavior and survival.

In addition, there is extensive experimental evidence in animal contexts supporting a role for the mesolimbic reward pathway on appetitive and motivational behaviors [306,307]. Mesolimboic DA release is associated with most pleasurable or rewarding events, and food is one type of reward that is often used during the training of animals. There is an increase in DA release (measured in awake, behaving animals by microdialysis or by fastscanning cyclic voltammetry) in the NAc in response to unexpected food rewards or stimuli that predict food rewards [72,308310]. Moreover, drugs that enhance operant responding for such food rewards, such as amphetamine, are most effective when administered into the NAc, whereas DA receptor antagonists administered into the NAc block the stimulant effects $[57,311]$. Pharmacological control of the output from the NAc shell can also have profound effects on food consumption [312,313], as does surgical or chemical lesion of the nigrostriatal or mesolimbic DA pathways. These results suggest that DA release in the striatum is required to integrate relevant signals for sustained feeding $[301,314,315]$. These studies emphasize the importance of DA transmission and the mesolimbic reward pathway for food consumption, feeding behavior, and food rewards in animal models.

Bulimia nervosa Bulimia nervosa $(\mathrm{BN})$ is an eating disorder characterized by recurrent binge eating followed by compensatory behaviors. It typically has its onset during adolescence, has an estimated prevalence of $1-2 \%$, is more common in females, and is characterized by, among other features, impulse-control dysregulation $[1,316]$. There is high comorbidity between $\mathrm{BN}$ and substance abuse, and there is a considerable body of data suggesting that disturbed appetitive behaviors for food in $\mathrm{BN}$ may reflect a dysregulation of reward mechanisms that is common to both $\mathrm{BN}$ and substance-abuse disorders [317]. Indeed, early hallmark preclinical studies by Hoebel and colleagues [318] highlighted commonalities between $\mathrm{BN}$ and addiction disorders in terms of neurobiology, psychopharmacology, neurochemistry, and behavior [319]. Binge eating has also been suggested to serve an emotion regulatory function, and thus has many qualities of reward-mediated behaviors [320].

Clinical studies There has been a small handful of functional neuroimaging studies of response to rewards in $\mathrm{BN}$, with a wide range of rewarding stimuli presented. It is important to note that functional brain imaging studies in eating disorders have the methodological challenge of confounds associated with nutritional imbalances in affected individuals. One way to overcome this is to focus on individuals who are recovered from these 
disorders at the time of scanning, but it is important to note that such an approach may minimize the extent of brain responsivity differences that would characterize individuals meeting current criteria for this disorder.

Several studies have reported reduced reward motivation for food rewards in eating disorders. Joos and colleagues [321] found reduced activation of the ACC in individuals with concurrent $\mathrm{BN}$ during the presentation of visual food cues, and Bohon and Stice [322] reported trends towards decreased right insular cortex activation to the anticipated receipt of chocolate milkshake solution and in the right posterior and dorsal insula in response to milkshake consumption in women with BN. Other studies have found atypical responses during reward outcome for monetary and food rewards. Wagner and colleagues [323] reported that women who had recovered from $\mathrm{BN}$ had equivalent DCN responses to monetary-reward outcomes, whereas $\mathrm{CN}$ responses in the control group were specifically linked to monetary gains relative to losses. Frank and colleagues [324] reported decreased ACC reward outcome responses to the blinded administration of glucose in participants who had recovered from bulimia. By contrast, Uher and colleagues [325] reported increased activation of the ACC, orbitofrontal cortex, occipital cortex, and cerebellum in response to food rewards in patients with bulimia; however, they did find hypoactivity in the lateral prefrontal cortex in patients with $\mathrm{BN}$ when compared with controls.

Several studies have included different patient groups relevant to eating disorders, allowing for identification of brain imaging patterns specific to different types of eating disorders. Schienle and colleagues [326] examined reward outcome by presenting food images to overweight and normal-weight controls, overweight individuals with binge-eating disorder, and normal-weight individuals with $\mathrm{BN}$. These authors reported increased medial orbital frontal cortex activation in the bingeeating disordered group, and greater cingulate cortex and insula activation in the bulimic group, relative to all other groups. Brooks et al. [327] compared neural responses to food-reward outcomes in individuals with $\mathrm{BN}$ and with anorexia nervosa (AN), and found that individuals with $\mathrm{BN}$ had relatively greater activation in the dorsolateral prefrontal cortex, the insular cortex, and the pre-central gyrus. These studies compliment candidate genetic behavior investigations in $\mathrm{BN}$ that have reported altered allelic frequencies for the DAT gene [328] and DA receptor genes [329,330] in individuals with bulimia.

Molecular-imaging data addressing striatal DA function in $\mathrm{BN}$ are lacking. In the only preliminary study to be published, Tauscher and colleagues [331] reported a $15 \%$ reduction in striatal DAT availability in $\mathrm{BN}$, although the study included only sub-threshold cases and an unmatched control group.

\section{Dopaminergic treatments}

Only fluoxetine, which primarily affects serotonin, is approved by the US FDA for the treatment for BN [332]. Of the numerous trials of the effects of psychopharmacologic agents for the treatment of $\mathrm{BN}$, none has been primarily a DA agent [333].

Anorexia nervosa AN is characterized by extremely low body weight, distorted body image, and fear of gaining weight, with an estimated prevalence of $0.7 \%[1,316]$. Watson and colleagues [334] outlined a framework delineating linkages between $\mathrm{AN}$ and reward-processing deficits. Their model stressed the highly social nature of eating, the overlapping reward circuitry of gustatory and social stimuli $[335,336]$, and the tendency of individuals with AN to deprive themselves of pleasure. Additionally, Zucker and colleagues [337] described commonalities between AN and ASD in social and interpersonal impairments, suggesting that impaired social function and social motivation may be a novel framework to conceptualize core deficits of AN.

\section{Clinical studies}

Individuals with $\mathrm{AN}$ report a heightened response to both punishment and reward outcome, even in the absence of clinically significant symptoms of anxiety or depression [338]. Fladung and colleagues [339] assessed responses to images depicting a female body with underweight, normal-weight, and overweight canonical wholebody features. They reported higher ventral striatal activation during processing of underweight images compared with normal-weight images in women with acute $\mathrm{AN}$, but the reverse pattern in the control group. Joos and colleagues [340] also reported hyper-reactive reward-outcome responses in anorexia during the processing of food-reward images.

A small handful of studies have directly compared reward responses in $\mathrm{AN}$ and bulimia. Wagner and colleagues [341] reported increased $\mathrm{CN}$ activation to monetaryreward outcomes in women recovered from anorexia, and relatively equivalent $\mathrm{CN}$ responses to monetary gains and losses (a strongly similar pattern of results to that found by Wagner et al. in bulimia in [323]), suggesting possible similarities in reward-circuitry response in AN and bulimia. Uher and colleagues [325] also found similar brainactivation patterns in individuals with $\mathrm{AN}$ and bulimia, with both groups showing hyperactivation relative to controls in areas relevant to reward processing, including the ACC and the orbitofrontal cortex.

However, other studies have emphasized brain-activation differences during reward outcome between anorexia and bulimia. Brooks and colleagues [327] found that in response to food-reward outcomes, individuals with anorexia had greater activation of the dorsolateral 
prefrontal cortex, the cerebellum, and the right precuneus relative to controls. They also had greater activation of the caudate, superior temporal gyrus, right insula, and supplementary motor area, and greater deactivation in the parietal lobe and dorsal posterior cingulate cortex relative to those with bulimia. It should be noted that this study did not include a non-foodreward condition, a design feature that would be necessary to assess the functional integrity of brain-reward systems to different classes of rewards.

Interestingly, individuals at risk for an eating disorder (that is, those with higher dietary restraint) have enhanced anticipatory responses to food rewards in the orbitofrontal cortex and the dorsolateral prefrontal cortex [342], suggesting that hyperactive functioning of anticipatory reward processing may be a risk factor for eating disorders. Complimenting these functional magnetic resonance imaging (fMRI) studies is a report of higher ${ }^{11} \mathrm{C}$-raclopride binding potential in the ventral striatum in women who were recovered from AN, suggesting that DA activity is enhanced in this population [343], and significant relations between multiple $\mathrm{DRD}_{2}$ polymorphisms and AN [344].

Dopaminergic treatments Psychopharmacologic treatments for AN have yielded only moderate success, and the majority of treatments are antidepressants that act primarily on non-DA systems [333]. A small number of double-blind trials have evaluated the effects of antipsychotics, with essentially non-significant effects [345-347].

\section{Neurodevelopmental disorders Schizophrenia}

Schizophrenia is a complex and debilitating disorder that typically emerges in late adolescence and early adulthood, and is characterized by hallucinations and delusions (positive symptoms), social withdrawal, alogia, and flat affect (negative symptoms), and cognitive disabilities [1], and has an estimated lifetime prevalence of $1 \%$ [348]. Anhedonia has been hypothesized to be a core feature of schizophrenia [349-351], and it has been suggested that individuals with high levels of social anhedonia are more likely to develop schizophrenia-spectrum disorders [352], although the link between anhedonia and the so-called schizophrenia prodrome has not been firmly established [353]. The centrality of incentive motivation deficits to schizophrenia is suggested by the long-standing hypotheses regarding the role of DA disturbances in the pathophysiology of the disorder [354-356].

Preclinical models The DA hypothesis of schizophrenia suggests that excess DA transmission may be propsychotic, and originally gained support from pharmacological evidence that drugs that decrease DA activity (for example, the phenothiazine neuroleptics) are antipsychotic, whereas drugs that promote DA activity (for example,, amphetamines) are psychotomimetic $[76,357]$. Indeed, the medications that have proven successful for treating schizophrenia/psychosis are drugs that primarily antagonize $D_{2}$ receptors [76,358]; however, most clinically effective antipsychotics also exhibit a myriad of other actions that contribute to both therapeutic and side-effect profiles $[359,360]$.

Current models of schizophrenia suggest that the disorder is due to both common and rare gene mutations, copy-number variations, and possibly epigenetic factors [361], all of which can affect multiple brain neurotransmitter systems and multiple risk genes [362-364]. Using pharmacological and genetic approaches, animal models have been developed for schizophrenia, which manipulate or alter mesolimbic DA transmission as a means to understand the disease and/or test therapeutic strategies.

In rodent models, hyperlocomotive behaviors and disruptions in the pre-pulse inhibition (PPI) response (a measure of sensorimotor gating) are generally viewed as being psychotomimetic, as both hyperlocomotion and disrupted PPI can be normalized and attenuated by antipsychotic medications [365]. However, no current behavioral paradigms truly capture the positive symptoms of schizophrenia (such as hallucinations and delusions). PPI is a cross-species measure that refers to the ability of a non-startling 'pre-stimulus' to inhibit the response to a startling stimulus [366]. There have been numerous reports of PPI deficits in patients with schizophrenia [367,368]; however, exactly which endophenotype in schizophrenia is manifested as disrupted PPI remains debated [365]. Swerdlow and colleagues [368] persuasively suggested that PPI deficits are a useful psychophysiological outcome for basic studies in humans and animals to probe neural circuitry and as a pharmacological screen. Indeed, PPI testing is commonly used in screening for potential antipsychotic drugs that act via antagonism of mesolimbic DA transmission. Studies in mice have indicated that administration of direct-acting DA agonists (such as apomorphine) and indirect DA agonists (such as cocaine) to mice disrupt PPI primarily via $D_{1}$ receptors [369], whereas $D_{2}$ receptors seem to modulate amphetamine-induced PPI deficits [370]. By contrast, both apomorphine-induced and amphetamine-induced PPI disruptions in rats are blocked by DA $\mathrm{D}_{2}$ antagonists [366]. In addition, normalizing PPI deficits in rodent models has enabled drug discovery for potential antipsychotic medications [371], some of which have proven successful in treating schizophrenia [368,372].

Mice lacking the DAT gene display markedly increased levels of DA in the mesolimbic system and striatum [373], that results in hyperlocomoter behaviors [373,374] 
and also deficits in PPI $[375,376]$. The DAT knockout mice phenotypes resemble amphetamine-like effects, and both hyperlocomotion and PPI deficits can be reversed with either $D_{1}$ or $D_{2}$ receptor antagonists [376], the atypical antipsychotics clozapine and quetiapine [377], various antidepressant drugs, and monoamine transporter inhibitors [378]. Thus, the DAT knockout mouse may be a useful animal model for predicting the efficacy of novel drugs for disorders such as schizophrenia that are characterized by a dysregulated limbic DA system.

In alignment with the DA hypothesis of schizophrenia, an increased level of striatal $D_{2}$ receptors has been seen in patients with schizophrenia who are not on medication [78], which may result in $\mathrm{D}_{2}$ receptor supersensitivity in the ventral striatum contributing to psychosis [79]. Kellendonk et al. [80] attempted to model this $\mathrm{D}_{2}$ receptor elevation in genetically engineered mice, in which they transiently and selectively overexpressed $\mathrm{D}_{2}$ receptors in the striatum including in the caudate putamen, the NAc, and olfactory tubercle. It was found that $30 \%$ of striatal MSNs overexpressed these engineered receptors, thereby elevating the $D_{2}$ receptor level to about $15 \%$ higher than that of normal mice. To study the behavioral consequences of $\mathrm{D}_{2}$ receptor upregulation in the striatum, the mice were analyzed using a battery of behavioral tasks, and were shown to have several abnormal cognitive phenotypes, including working-memory deficits, reversal-learning impairment and decreased social interactions. In a follow-up study, $\mathrm{Li}$ and colleagues [379] reported that this $\mathrm{D}_{2}$ receptor overexpression in the striatum causes an increase in the firing activity of layer $\mathrm{V}$ cortical pyramidal neurons, and also a decrease in both the frequency and amplitude of spontaneous inhibitory post-synaptic currents, indicating reduced inhibitory transmission in the prefrontal cortex. Taken together, the mouse model suggests that overexpression of $\mathrm{D}_{2}$ receptors (similar to that seen in some individuals with schizophrenia) will alter striatal MSN activity, resulting in dysregulated GABA transmission and inhibitory activity in the cortex [380]. Because a core symptom of schizophrenia is cognitive impairment (for example, deficits in working memory, attention, executive function), this mouse model may provide a link explaining how altered mesostriatal and mesolimbic DA receptors and DA transmission can alter cognitive processes in the frontal cortex, possibly by dysregulating circuit pathways that link connectivity between the striatum and pre-frontal cortex [381]. The reader is referred to other seminal reviews of schizophrenia animal models that highlight altered DA and reward-pathway transmission [382-385].

Clinical studies Patterns of responses to rewards by patients with schizophrenia are complex. Patients report normal intrapsychic emotional experience, but communicate symptoms of anhedonia during structured interview [386]. Individuals with schizophrenia show diminished positive and negative emotions in response to emotional movie clips [387], food [388], and social exchange [389-391], even when taking medication [388]. However, individuals with schizophrenia also report similar or heightened subjective emotional experience [392], including in response to movie clips [393], pictures [394], food [395], and even odors [396].

In contrast to the mixed self-report and interview profiles of hedonic capacity in schizophrenia, psychophysiological studies of patients with schizophrenia indicate comparable or more exaggerated facial responsivity to positive and negative stimuli, assessed via facial electromyography [397,398], skin conductance [399,400], and affective modulation of the startle eyeblink response $[401,402]$. These lines of evidence suggest that schizophrenia is characterized by deficits in the expression of pleasant emotions but not in the experiential or physiological components of emotions [390].

Studies that have differentiated between reward motivation and reward outcome in schizophrenia have found mixed results. Although some studies have found that individuals with schizophrenia are impaired during reward motivation and outcome [403-407], others have not found a selective impairment in reward motivation [386,408]. This discrepancy may be attributable to different levels of symptom severity in the patients sampled, as there is some evidence that the severity of clinical symptoms is correlated with reward motivation and outcome processing in schizophrenia [386,403].

Behavioral studies of reward learning have reported that sensitivity to reward is intact in schizophrenia, but deficits are evident in rapid reward learning on the basis of trial-to-trial feedback, such as reversal learning, and in reward-related decision-making [406,409-413]. However, reward learning may be typical in schizophrenia over longer learning trials [410], and in individuals with less severe symptoms [414]. Overall, however, studies of reward learning in individuals with schizophrenia are consistent with the framework that patients with schizophrenia have intact hedonic responses but impaired motivation and reward representation, leading to a failure to motivate their behavior for rewards [415].

Neuroimaging studies of responses to rewards in schizophrenia generally suggest decreased NAc activation during monetary-reward anticipation (but see [416] for an exception) in both patients taking medication and patients not taking medication [417-420]. However, there is also evidence that these effects may be mediated by the predictability or certainty of rewards, as individuals with schizophrenia have reduced activation of the ventral striatum to unexpected reward outcomes, but have 
enhanced responses to expected rewards [421]. There is also evidence of inverse relations between negative symptoms and NAc activation during reward anticipation $[416,420,422]$ and between lateral PFC activation during reward outcomes [420]. Waltz et al. [406] used computer simulations to show that the reward-processing deficits in schizophrenia are consistent with impaired functioning of DA. A handful of studies also suggest that striatal responses during monetary anticipation in schizophrenia are partially normalized by the antipsychotic, olanzapine $[279,417,423]$ but not by other antipsychotics [418], suggesting that this neural signature may be a state, rather than trait, marker of schizophrenia. Finally, Grimm and colleagues [424] reported reduced striatal activation in schizophrenia to food cues when medication dose and weight were used as covariates, highlighting a possible mechanism underlying weight gain in schizophrenia.

Molecular-imaging evidence indicates dysregulated striatal DA function in schizophrenia [77]. A metaanalysis of 17 studies found significant elevation of striatal $D_{2}$ receptors in patients with schizophrenia who were not being treated with medication, although no consistent clinical correlates of this pattern were evident [78]. Studies have also suggested an increased affinity of $\mathrm{D}_{2}$ receptors for DA in schizophrenia, that may produce a $D_{2}$ receptor supersensitivity in the NAc contributing to psychosis [79]. Additionally, a PET study found higher synaptic DA concentrations in the ventral striatum in schizophrenia [425].

Dopaminergic treatments First-line treatments for schizophrenia include DA $\mathrm{D}_{2}$ receptor antagonist agents that primarily treat so-called positive symptoms. Firstgeneration compounds, such as chlorpromazine and haloperidol, work primarily as $\mathrm{D}_{2}$ receptor antagonists [358]. Second-generation, or 'atypical', antipsychotics, such as clozapine (which has affinity for $\mathrm{D}_{2}$ and $\mathrm{D}_{4}$ receptors [426]), risperidone, olanzapine, and quetiapine, primarily affect DA and 5-HT systems, but with markedly reduced extrapyramidal side effects [427]. Finally, third-generation antipsychotics, such as aripiprizole, are partial $\mathrm{D}_{2}$ receptor agonists with high affinity and low intrinsic activity, and these drugs may act as 'DA stabilizers' because of their ability to stabilize, rather than simply upregulate or downregulate functional output of DA systems [428].

\section{Attention-deficit hyperactivity disorder}

ADHD is characterized by symptoms of inattention, hyperactivity, or impulsivity that produce impairment in cognitive, behavioral, and interpersonal domains [1] Although for many years ADHD was believed to be a disorder of childhood and adolescence, it is now recognized to occur also in adulthood [120].ADHD affects approximately 8 to $9 \%$ of school-aged children and 4 to $5 \%$ of adults [429-431]. ADHD is characterized by symptoms of age-inappropriate inattention, impulsiveness, and hyperactivity [1]. It disrupts academic and social development, and is associated with considerable psychiatric comorbidity [432], including impaired academic, occupational, and social functioning, increased rates of substance abuse and traffic accidents, and persistent neuropsychological impairments [433-436].

Dysregulated reward processing has been proposed as a central mechanism in prevailing theoretical models of ADHD [437,438]. The 'DA transfer deficit' theory of ADHD highlights altered phasic DA responses to cues that predict rewards, resulting in decreased conditioning to reward cues, blunted reward anticipation, weaker influence of rewards on behavior, and ultimately poorer behavioral control $[438,439]$. This model explains not only empirical brain-imaging data of reward processing in ADHD (reviewed below) but also the consequences of these processes on motivated behaviors.

Clinical genetics studies have indicated that multiple genes are important in the development of ADHD. Recent meta-analyses of candidate gene association studies have found consistent evidence of significant associations between ADHD and polymorphisms in several candidate genes that are almost exclusively involved in the regulation of dopaminergic and serotonergic transmission (including the dopamine transporter (DAT1) gene, the dopamine $\mathrm{D}_{4}$ receptor (DRD4) gene, the dopamine $\mathrm{D}_{5}$ receptor (DRD5) gene, the serotonin transporter (5-HTT) gene, the 5-hydroxytryptamine receptor $1 \mathrm{~B}\left(\mathrm{HTR}_{1 \mathrm{~B}}\right)$ gene, and synaptosomal-associated protein 25 (SNAP25) [440,441]. Among these, perhaps the most commonly replicated risk gene associations were reported for DAT1 and DRD4; however, even for these genes, substantial population heterogeneity is seen in ADHD.

Preclinical models Animal models of ADHD are expected to show phenomenological similarities to the clinical condition and mimic aspects of the three core symptoms of the disorder; that is, hyperactivity, impulsivity, and impaired sustained attention [442]. In addition, proof of predictive validity of ADHD animal models often includes evidence of improved behavioral outcome after treatment with effective ADHD therapeutics, including stimulants such as methylphenidate and amphetamine (reviewed below) which increase DA transmission and levels by reuptake inhibition of monoamine transporters.

Two commonly used ADHD rodent models are the DAT transgenic knockout mouse model and the spontaneous hypertensive rat (SHR) model, both of which 
exhibit altered mesostriatal DA transmission and model some aspects of ADHD behavior. Mice lacking DAT have increased dopaminergic tone and represent a genetic animal model in which certain endophenotypes of ADHD can be recapitulated [443]. In DAT knockout mice, DA is cleared very slowly from the synaptic cleft, causing a five fold elevation of extracellular DA in the striatum (that is, a hyperdopaminergic state). DAT knockout mice have been suggested to model ADHD because they are hyperactive $([443,444])$, have reduced extinction of responses in food reinforcement operant tasks [445], and also have impaired learning and memory $[444,446]$. However, DAT knockout mice provide an extreme model because only a mild reduction in midbrain DAT binding has been seen in human adolescents with ADHD [447], and the model also does not agree with several studies have that found increased DAT in the striatum of children and adults in ADHD [448,449]. Nonetheless, the DAT knockout mouse provides very useful information concerning the neurobiological consequences of impaired DAT function which present as ADHD-like behaviors.

The most widely studied rodent model of ADHD is the inbred SHR [450]. The SHR is a convincing model to study because these rats have been shown to display many behavioral characteristics apparent in ADHD, including poor performance in sustained attention tasks, hyperactivity, impulsivity, sensitivity to delay, and increased variation in performance of operant tasks [451-453]. Impulsivity is seen in SHR as an inability to inhibit a response during the extinction phase of an operant task, and an inability to delay a response in order to obtain a larger reward [452,454]. It seems that the SHR exhibits these ADHD-like behaviors due to a genetic alteration in the DAT gene. The SHR possesses a 160-bp insertion in the noncoding region upstream of exon 3 of the DAT gene [455], which is of significance because a variable number of tandem repeats in the 3 '-untranslated region of the DAT gene has been associated with ADHD in several family studies $[448,449,456]$. DAT gene expression is transiently reduced in the SHR midbrain during the first month after birth, and increased in adult SHR compared with controls [457], which results in abnormal mesostriatal DA transmission in the rats during postnatal development, and possibly in adulthood [458]. In addition, several other animal models have informed ADHD research; many of these models have implicated mesolimbic DA transmission as a feature underlying ADHDlike behaviors. The reader is encouraged to see other comprehensive reviews $[443,450]$.

Clinical studies Etiological models addressing cognitive dysfunction in ADHD have focused on altered reward sensitivity $[18,459,460]$, including diminished influence of reward on skills [460], now-versus-later decisionmaking [461,462], and altered sensitivities during reward learning [463]. Altered reward processes are mediated via alterations in DA and other catecholamine function in ADHD [438,464-467]. Individuals with ADHD display a range of reward deficits, including impaired behavioral modification to rewards [468]. A classic finding in childhood ADHD is hypersensitivity to reward delays (that is, "delay aversion" [462,469-474]), which is independent of inhibitory deficits [475] yet correlates with hyperactivity symptom severity [476]. The 'dynamic developmental theory' of ADHD put forth by Sagvolden and colleagues $[453,477]$ hypothesizes that downregulated frontolimbic DA results in lower tonic DA, a steeper and shorter delay-of reward gradient, and ultimately increased impulsivity and slower extinction of impulsivity. Longer delays between a behavior and its consequence then result in relatively reduced effects of the consequence for exerting control over the behavior in ADHD [453,459].

Although individuals with ADHD may report enhanced reward outcome responsivity [478], behaviorally, individuals with ADHD display a range of motivational deficits, including impaired behavioral modification in response to rewards [468], enhanced motivation for larger but riskier rewards [479], and decreased motivation for social rewards [480].

Although the majority of fMRI studies in ADHD have focused on attentional processes, such as cognitive control and response inhibition [481-483], a smaller subset of studies have focused on reward processing. Such studies have direct conceptual linkages to the constructs of impulsivity and delay aversion that are core features of the disorder. These studies have shown decreased ventral striatum activation during monetary-reward anticipation [484-487], atypical orbitofrontal activation during monetary-reward outcome [487,488], and decreased DCN and amygdala activation during delayed reward outcome $[485,489]$. Children with ADHD have reduced NAc activity when anticipating monetary rewards $[18,486,487]$, which is seen particularly in drug-naive children [490], in carriers of the DAT nine-repeat allele [491], and in response to seeking gains rather than avoiding losses [492]. This pattern is present during cues of both immediate and delayed rewards [485]. Plichta and colleagues [485] also found relations between striatal responsivity to immediate and delayed rewards and ADHD symptom severity. Furthermore, a negative correlation between NAc activation during reward motivation for a range of rewards (monetary, verbal feedback, and loss avoidance) and the number of reported ADHD symptoms was found in the general population [492]. Finally, a study by Wilbertz and colleagues [493] found decreased differentiation between high-incentive and 
low-incentive rewards in the medial orbitofrontal cortex and in physiological arousal in patients with ADHD that correlated with risky decision-making and delaydiscounting.

Molecular-imaging studies in ADHD suggest that impaired frontostriatal activation to rewards in ADHD may be linked to altered DA transmission. Ernst and colleagues [494] found relatively higher right midbrain accumulation of ${ }^{18} \mathrm{~F}$-DOPA in children with ADHD, that was correlated with symptom severity, and a study of children with ADHD by Volkow et al. [120] found lower specific DA binding to DATs and to $\mathrm{D}_{2}$ and $\mathrm{D}_{3}$ receptors in the NAc, midbrain, and left caudate, with $\mathrm{D}_{2}$ and $\mathrm{D}_{3}$ receptor binding in the NAc, midbrain, caudate, and hypothalamus significantly related to inattention symptoms. A follow-up study showed that decreased DA binding to these receptors was also correlated with lower scores of self-reported motivation [495]. Levels of tonic and phasic DA have also been found to be lower in individuals with ADHD [453,496] whereas the density of DATs, which downregulate DA activity, is higher in ADHD [448,449].

\section{Dopaminergic treatments}

Methylphenidate is the most commonly prescribed medication for childhood ADHD, and has binding affinity for both the DA and norepinephrine transporters [497]. D-amphetamine is the major pharmacological ingredient in dextroamphetamine and lisdexamfetamine dimesylate, and both are believed to exert their therapeutic actions by enhancing the function of noradrenaline and DA [498]. Finally, bupropion has been used off-label for treating ADHD, yet it has been shown to have only very moderate efficacy for treating core ADHD symptoms $[499,500]$.

\section{Obsessive-compulsive disorder}

OCD has an estimated prevalence of 1 to 3\% [501], and is characterized by recurrent anxiety-provoking thoughts or impulses (obsessions), typically followed by repetitive ritualistic behaviors to relieve anxiety (compulsions) [502]. Although OCD is formally classified as an anxiety disorder, it has many phenotypic features resembling addictive behaviors, including tolerance and withdrawallike behaviors, suggesting linkages between core symptoms and reward-circuitry processes. Indeed, it has been theorized that compulsive behaviors may persist at least in part due to the rewarding effects of anxiety-reduction that accompanies them [503], and that OCD should be labeled as a disorder of behavioral addiction rather than as an anxiety disorder in the DSM-V [504]. Although OCD is grouped here as a psychiatric disorder (rather than a neurodevelopmental disorder), it is important to note that it is commonly seen in both children and adults [505].

Preclinical models Animal models of OCD have focused on studying obsessive-like behaviors related to grooming and repetitive movements. In mice, the neural substrate for the stereotyped grooming sequence (whisker grooming or coat grooming) lies in several brain regions including the brain stem and the striatum [506], where the striatum is thought to regulate the initiation and modulation of these grooming behaviors [507].

Profiles of DAT knockout mice indicate involvement of altered mesolimbic DA transmission in OCD. DAT knockout mice show an overall increased level of DA transmission, resulting in increased DA tone, hypermotoric activity, and overall increased movement [373]. The DAT knockout mice also have stronger and more rigid self-grooming patterns, with mutants displaying sequential super-stereotypy, evidenced by having more stereotyped and predictable self-grooming sequences [508]. Synapse-associated protein 90/PSD-95-associated protein (SAPAP)3 is a post-synaptic scaffolding protein at excitatory synapses, that is expressed at high levels in the striatum. An engineered genetic knockout of SAPAP3 in mice increases anxiety and compulsive grooming behaviors, leading to facial hair loss and skin lesions [509], providing a genetic animal model for OCD-like behaviors. SAPAP3-deficient mice have dramatically increased grooming bouts, and spend significantly more time self-grooming than their genetically normal littermates. Physiological studies indicate that the mutant mice have multiple deficits in the excitatory synapses of the striatal MSNs, including increased striatal excitatory and NMDA-dependent neurotransmission.

Also related to genetic mouse models of OCD are the Slitrk 5 knockout mice. Genetic deletion of Slitrk 5 in mice also results in excessive grooming associated with facial hair loss and skin lesions and with impaired corticostriatal neurotransmission [510]. Although evidence for a direct disruption in mesolimbic transmission in SAPAP3 and Slitrk5 knockout mice has not been reported, the altered excitatory transmission apparent in the striatum may also dysregulate the reward pathways.

Clinical studies Behaviorally, patients with OCD show evidence of impaired reward learning [511] and impaired performance on gambling tasks that predict pharmacologic treatment response [512,513]. Despite the overlap of OCD and substance-use disorders in terms of phenotype, neurobiology, comorbidities, and neurochemistry [514], few empirical studies have directly assessed reward-system integrity in OCD. Using a monetary incentive-delay task, Jung et al. [515] found increased frontostriatal activation during monetary-reward 
outcome, and decreased lateral prefrontal and inferior parietal cortex activation during loss anticipation, but no group differences during monetary-reward anticipation. However, Figee and colleagues [516] did find relatively decreased NAc activity during reward anticipation in OCD, particularly in those patients with contamination fear. Finally, Pena-Garijo and colleagues [517] found that individuals with OCD had reduced activity in the ACC and the $\mathrm{CN}$ during a reward-learning task. Clearly, more research is needed in this area, in particular studies of mesolimbic responses to disease-relevant stimuli and studies of the relationships between brain function in response to reward stimuli and treatment outcomes.

A review of PET studies by Whiteside et al. [518] indicated differences in radiotracer uptake in the orbital gyrus and the head of the $\mathrm{CN}$ in patients with OCD, and a quantitative, voxel-level meta-analysis of functional MRI findings by Menzies and colleagues [519] reported abnormalities in the orbitofronto-striatal regions in OCD. A recent review and meta-analysis of in vivo imaging studies assessing striatal DA systems in OCD found evidence of reduced $D_{2}$ receptor binding in the neostriatum and ventral striatum, and reduced $\mathrm{D}_{1}$ striatal receptor binding [520].

Dopaminergic treatments Although the most widely prescribed agents to treat OCD are tricyclic antidepressants and selective serotonin reuptake inhibitors, these agents show a 40 to $60 \%$ inadequate response rate [521]. Recently, second-generation antipsychotic agents have shown benefit, either alone or as adjunctive therapy. Specifically, high-dose olanzapine [522], quetiapine [523], and risperidone [524] have all shown at least minimal clinical benefit relative to placebo treatment [525]. Finally, reports that the ventral striatum is an effective target for deep brain-stimulation treatment in OCD, particularly in patients identified as otherwise treatmentresistant, further implicates the mesolimbic DA system in OCD [526-528].

\section{Autism spectrum disorders}

ASDs affect up to $1 \%$ of the general population [529], and are characterized by a triad of symptoms that includes impaired communication, social impairments, and restricted and repetitive behaviors and interests [1].

Preclinical models Studies aimed at modeling, in animals, the core phenotypes associated with ASDs have focused on studying social and repetitive behaviors in mice [530-532] and pair-bonding behaviors in the prairie vole (Microtus ochrogaster) [533,534]. Although there is no clinical evidence supporting disordered attachment profiles in autism, these rodent models may provide a bridge to define and translate the neurobiology of mammalian social behavior into a better understanding of ASD [535]. As discussed in greater detail below, there is compelling evidence that the mesolimbic DA pathway is altered in a mouse model of FXS, and that DA signaling in the NAc is important for social pair bonding in the prairie vole, suggesting that altered reward processing can influence social behaviors.

The study of social bonding in the prarie vole is one animal model that has informed preclinical studies relevant to ASDs. Prairie voles display characteristics associated with a monogamous lifestyle, including a lack of sexual dimorphism, biparental care of offspring, and the formation of pair bonds between males and females [536]. In the laboratory, male and female prairie voles show a robust preference to pair-bond and associate with a familiar partner, and the neurobiology and behavior of this social-bonding attachment has been studied extensively [534]. Vole pair bonds can be assessed by testing for partner preference, a choice test in which pair-bonded voles regularly prefer their partner to a conspecific stranger. Several studies have indicated that mesolimbic DA pathways regulate vole pair-bonding and social behaviors [537]. After extended cohabitation with a female, male voles show behaviors indicative of pairbond maintenance, including selective aggression towards unfamiliar females. These voles also show a significant upregulation in NAc $D_{1}$-like receptors, and blockade of these receptors abolishes the selective aggression of the males toward unfamiliar females [538]. Mating between voles can facilitate partner preference formation, and is associated with increased extracellular DA in the NAc. This partner preference can be blocked by microinjection of the $\mathrm{D}_{2}$ antagonist eticlopride into the NAc (but not the prelimbic cortex), whereas the $D_{2}$ agonist quinpirole can facilitate formation of vole partner preferences [539]; decreasing NAc cAMP signaling probably underlies these effects of $\mathrm{D}_{2}$ receptors [540]. Interestingly, in a comparative study of monogamous versus promiscuous voles, the monogamous voles exhibited increased mesolimbic DA release into the NAc in response to amphetamine, suggesting increased DA release or clearance in the monogamous species [541]. However, when amphetamine or a selective $\mathrm{D}_{1}$ receptor agonist was administered systemically to male voles, this interfered with mating-induced pair bonding, and this disruption seems dependent on $\mathrm{D}_{1}$ receptor activation [542-544]. Taken together, these prairie-vole social-bonding studies indicate that the mesolimbic DA is essential for the social pair-bond with $\mathrm{D}_{2}$-like receptors in the NAc.

Other neurotransmitter systems seem to converge within the NAc to modulate and control vole socialbonding behavior. For example, activation of cortisolreleasing factor (CRF) receptors by microinjections of CRF directly into the NAc accelerates partner preference 
formation in male prairie voles [545]. Oxytocin transmission and oxytocin receptors in the NAc seem to facilitate maternal behavior in female voles [546]. Furthermore, prairie voles have higher densities of NAc oxytocin receptors than is found in nonmonogamous vole species, and blocking NAc oxytocin receptors prevents partner-preference formation [547]. These studies suggest that oxytocin facilitates affiliation and social attachment [548].

Although the challenge remains to translate these observations and mechanisms from rodents to human autism studies [549], these animal model findings have had a significant influence on our understanding of mammalian social behaviors, and have generated testable hypotheses about the reward system and underlying molecular neurobiology. The reward-system involvement in social engagement and social-bond formation may also have implications for understanding the core social deficits characterizing ASDs [535].

Clinical studies A number of theorists have suggested that the social-communication deficits that characterize ASDs reflect decreased motivation to engage in reciprocal social behaviors in infancy and early childhood, which may ultimately result in fewer experiences with social sources of information [550-552]. Because children with ASD may lack the motivation to participate in activities in which social skills are typically forged, the resulting relatively impoverished social environment may further compound the social impairment caused by low social motivation, and further negatively influence the development of social cognition and language skills $[553,554]$. Consistent with this model, very young children with ASD display decreased orienting to social stimuli [550,555], and atypical social orienting has been shown to predict decreased social competence in adolescents and young adults with ASDs [556]. There is also evidence that social motivation remains impaired in individuals with ASD despite growth in other areas of cognitive development. For instance, older children with ASDs report experiencing less pleasure from social rewards [557], and social stimuli are relatively less salient for individuals with ASD [558-560]. More generally, individuals with ASD have been found to report lower levels of reward responsivity [561], and behavioral studies have also found evidence for impaired reward learning in individuals with ASD [562].

However, despite the accumulating evidence for reward-processing deficits in ASD, relatively few published studies have assessed the neural bases of reward processing in this population, and results of these studies are decidedly mixed. Schmitz and colleagues [563] investigated the neural substrates of reward learning in the context of a sustained attention task with monetary rewards, and reported decreased activation in the left anterior cingulate gyrus and left midfrontal gyrus on rewarded trials in patients with ASD. They also found that activity in the anterior cingulate gyrus during this task was negatively correlated with social ability, supporting the hypothesized link between that reward-processing dysfunction and the core social impairments in ASD. ScottVan Zeeland and colleagues [564] investigated the neural correlates of implicit reward learning in children with ASDs using both social and monetary rewards. They found diminished ventral striatal response during socialreward outcomes and also, but to a lesser extent, with monetary-reward outcomes. Activity within the ventral striatum was found to predict social reciprocity within the control group but not the ASD group. This finding is consistent with previous research examining the effect of reward type on task performance, which indicates that children with ASD may be less motivated by social than non-social rewards [480,565-568]. Dichter and colleagues [569] recently reported results of an fMRI study of reward anticipation and outcome using monetary and social (faces) rewards within the context of an incentive-delay task. The ASD group displayed bilateral amygdala hyperactivation during face-reward anticipation and bilateral insular cortex hyperactivation during face-reward outcomes. Further, activation in the left and right amygdala during face anticipation predicted the severity of social impairments in the ASD sample.

EEG and event-related potential (ERP) studies have largely supported these fMRI findings. Kohls and colleagues [570] examined responses in children with ASDs during a rewarded go/no-go paradigm involving social (smiling faces) and monetary rewards, using an ERP marker of reward-system activity. In the ASD group, they found unimpaired behavioral task performance but a decreased response to reward conditions that required an active response for both social and monetary rewards A recent EEG study found evidence of relatively decreased left-sided frontal EEG activity in response to faces, a pattern suggestive of decreased motivational approach $[571,572]$ ) By contrast,, Larson and colleagues [573] reported that an ERP marker of reward processing was unimpaired in ASD, highlighting the need for future research to examine differential brain activation to reward gains and losses in ASD.

Restricted and repetitive behaviors and interests are also a core symptom of ASDs, and a number of etiologic models of repetitive behaviors highlight that rewardprocessing deficits may bias attention and exploration towards non-social aspects of the environment [552,559]. This general behavioral tendency may ultimately lead to the development of stereotyped movements and circumscribed interests that characterize ASDs [574]. To 
investigate the hypothesis that reward-processing dysfunction in ASD may contribute to the development of circumscribed interests, Dichter and colleagues [575] conducted a fMRI study in which stimuli reflecting circumscribed interests were presented to individuals with ASDs within the context of an incentive-delay task. The ASD group showed decreased NAc activation during monetary-reward anticipation, but ventromedial prefrontal cortex hyperactivation when viewing the circumscribed interest reward outcome, suggesting that ASDs are characterized by reward-circuitry hypoactivation in response to monetary incentives but by hyperactivation during circumscribed interest reward outcomes.

Manipulating the consistency, immediacy, or saliency of rewards has been a central feature of long-standing effective behavioral interventions for ASD [576-578]. Such programs are designed to scaffold reward understanding for children with ASD to ultimately alter behavior and enhance learning. Even with this scaffolding, however, reward-based interventions are not successful for all children with ASD [579-582], and there is some evidence that individual differences in reward motivation may predict differences in response to treatment [580]. Such variability suggests an urgent need to identify neurobiological markers to aid in the prediction of responses to reward-based behavioral interventions in ASD, and to understand how these markers may be functionally related to behaviors relevant to treatment success.

Aberrant serotonin function has consistently been linked to genetics, neuropharmacology, and brain metabolism of individuals with ASD [583]. There are few studies of striatal DA binding in ASD, and to date there has been no consistent evidence of striatal DAT-binding differences in ASD [584,585], although a recent study with a relatively large sample found evidence of higher DAT binding in the orbitofrontal cortex in ASD [586]. Ernst and colleagues [587] found reduced ventromedial prefrontal cortex DA metabolism in children with ASDs, whereas Nieminen-von Wendt and colleagues [588] found no such evidence. A small pilot study of 13 children with ASDs who received a 6-month course of fluoxetine treatment showed that good clinical responders had a significant decrease in striatal DAT binding [589], suggesting that studies of modulation of striatal DAT binding may be relevant to understand potential mechanisms of action of treatments for ASD, even when such treatments do not primarily affect DA systems.

Dopaminergic treatments Although SSRIs have been a promising class of agents to target repetitive behaviors in ASD [590-594] (but inefficacy has also been reported [595]), the only two drugs currently approved by the US FDA for the treatment of ASDs are the secondgeneration antipsychotic risperidone (a DA antagonist) and the third-generation antipsychotic aripiprazole $\left(\mathrm{a}_{2}\right.$ partial agonist). Although both are approved for the treatment of irritability, an associated ASD symptom, both have shown efficacy in reducing core symptoms as well. Specifically, randomized controlled trials of risperidone in individuals with ASD found significant reductions in challenging behaviors, such as irritability and hyperactivity [596-600], and significant improvement in core autism symptoms [601-604]. Randomized controlled trials of aripiprazole have also found a decrease in irritability and hyperactivity and decreased instances of repetitive behaviors in children with ASD over the course of treatment [604,605].

Other commonly used treatments for ASD include other antipsychotic agents [606-608], psychostimulants (for example, methylphenidate), which generally upregulate norepinephrine and/or DA function and reduce hyperactivity but have a relatively poor side-effect profile $[609,610]$, and naltrexone, a DA modulator $[607,611]$.

\section{Tourette's syndrome}

TS affects 0.3 to $0.8 \%$ of the population [612], and is characterized by motor and vocal tics (rapid, recurrent, stereotyped motor movements or vocalizations) performed in response to somatosensory or environmental cues [1]. This defining feature of TS suggests involvement of nigrostriatal DA motor control systems, and thus it is not unexpected that striatal systems linked to reward processing have been implicated in the disorder, through not using tasks assessing response to rewards.

Preclinical models Animal models relevant to TS have focused on rodent genetic models and behavioral phenotypes such as stereotypy. The DAT knockout mouse is one model involving hyperdopaminergia that results in increased levels of DA in striatal brain regions, which may model some of the motor abnormalities apparent in TS. Excessive sequential stereotypy of behavioral patterns (sequential super-stereotypy) in TS is thought to involve dysfunction in the nigrostriatal DA systems, and DAT knockout mice exhibit complex restricted patterns of stereotyped movements similar to the sequential super-stereotypy seen in TA [508]. The genetic factors underlying TS are largely unknown; however, a rare mutation in the gene SLITRK1 is associated with human TS $[613,614]$. The SLITRK1 protein is a single-pass transmembrane protein that displays similarities to the SLIT family of secreted ligands, which have roles in axonal repulsion and dendritic patterning in neurons, but its function and developmental expression remain largely unknown. A SLITRK1 knockout mouse model of TS has recently been developed. SLITRK1 knockout mice exhibit increased anxiety-like behavior in the elevated plus-maze test and neurochemical analyses identified 
increased levels of norepinephrine and its metabolite 3methoxy-4-hydroxyphenylglycol in the prefrontal cortex and NAc, but DA levels were not altered [615]. Administration of clonidine, an $\alpha 2$-adrenergic receptor agonist often used to treat patients with TS, attenuated the anxiety-like behavior of SLITRK 1-deficient mice, providing predictive validity in this TS mouse model. Interestingly, SLITRK 1 expression in mouse, monkey, and human brain is developmentally regulated in the neuroanatomical circuits most commonly implicated in TS [616]. In the striatum, SLITRK 1 expression is high in striosomes/patches during early brain development but significantly diminishes later, suggesting a possible role in establishing corticostriatal circuitry. In addition, SLITRK 1 expression is also restricted to striatal projection neurons of the direct pathway where it could influence striatal circuitry; however, to date, direct evidence of SLITRK 1 knockout affecting either mesolimbic or nigrostriatal DA pathways has not been reported.

Clinical studies The DA hypothesis of TS was originally proposed nearly 30 years ago [617], and has been corroborated by post-mortem data [618]; however the identification of an underlying DA deficit leading to dysfunction in TS has proven to be elusive [619]. Available evidence suggests that a phasic DA imbalance, similar to that seen in schizophrenia, may help to explain the pathophysiology of TS $[619,620]$. Supporting this framework, reward learning is enhanced in people with TS who are not on medication, and impaired in people with TS taking DA receptor antagonists [621].

Although there are no published functional neuroimaging studies of response to rewards in TS, a recent fMRI study of tic inhibition implicated the striatum and associated dorsal frontal regions during tic suppression [622], corroborating other evidence that the magnitude of basal ganglia and thalamus activation during voluntary tic suppression correlated inversely with the severity of tic symptoms [623]. Thus, a model has been proposed in which frequent prefrontal activation during tic suppression may produce compensatory prefrontal cortex hypertrophy that aids in tic suppression $[624,625]$, although it is not presently clear how such basal ganglia and prefrontal characteristics effects reward processing in TS. Variants in the DA receptor gene $D R D_{2}$ have also been associated with genetic risk for TS [626-628], but this finding is not consistent [629-633].

An early study of monozygotic twins discordant for TS severity found evidence in affected twins of increased $D_{2}$ receptor binding in the head of the $\mathrm{CN}$, but not putamen, which predicted disease severity [634]. Singlephoton emission computed tomography investigations in TS have found higher DAT binding in the right caudate [635], the striatum [636-639], the putamen after amphetamine challenge [640], and the basal ganglia [641]. However, a handful of studies have found no differences in striatal DAT binding in TS $[639,642-644]$.

Dopaminergic treatments Tetrabenazine is commonly used to treat hyperkinetic movement disorders, including TS [645]. Its mechanism of action is believed to involve the early metabolic degradation of monoamines, in particular DA [646]. The classes of medications with the most proven efficacy in treating tics are typical and atypical antipsychotics (DA receptor antagonists) including risperidone, ziprasidone, haloperidol, pimozide, and fluphenazine [647].

\section{Conduct disorder/oppositional defiant disorder}

$\mathrm{CD}$ is defined by a behavioral pattern involving the violation of others' rights and of societal rules along with antisocial behaviors before the age of 18 years, and ODD is characterized by recurrent patterns of defiant behaviors toward authority figures during childhood [1]. These externalizing disorders, known collectively as disruptive behavior disorders, are often comorbid, and there is debate over whether they represent differences in severity of symptom expression or two distinct conditions [648]. Prevalence estimates for both conditions are just over 3\% [649]. Although the preponderance of functional brain-imaging studies in these conditions has focused on cognitive switching and sustained attention [650], a significant subset of studies has focused on reward processing.

Clinical studies Results of functional brain-imaging studies of response to rewards in CD/ODD are not wholly consistent [17]. Rubia and colleagues [651] reported reduced orbitofrontal activation during a rewarded continuous performance task in adolescents with $\mathrm{CD}$, whereas Bjork et al. [652] reported increased subgenual cortex activation in adolescents with externalizing disorders during a monetary incentive-delay task. Finally, Crowley and colleagues [653] found that adolescents with $\mathrm{CD}$ and comorbid substance-use disorder displayed relative hypoactivation in the striatum and $\mathrm{ACC}$ during risky decision-making for rewards.

Despite evidence that the dopaminergic system plays a key role in aggression $[654,655]$, only a small handful of molecular genetic studies implicate DA candidate genes, including DAT1, $\mathrm{DRD}_{2}$, and DRD4, in the development of conduct problems [656-659], and no molecularimaging study to date has assessed striatal DA signaling in samples with CD/ODD who are not comorbid for other conditions.

Dopaminergic treatments Atypical antipsychotics, psychostimulants, mood stabilizers, and $\alpha 2$ agonist agents 
are commonly used to treat CD/ODD [660]) Divalproex was found it to be superior to placebo in treating explosive temper, mood lability [661], and CD [662] in adolescents. There is initial evidence in the form of open-label or retrospective chart review studies, of the efficacy of olanzapine, quetiapine, and aripiprazole in treating aggressive behavior [663]. Risperidone was found to be well-tolerated and superior to placebo in reducing aggressive behaviors in children with CD [664-666]. Two large controlled trials found risperidone to be superior to placebo in ameliorating hostile and aggressive behavior in lower-functioning children with disruptive behavioral disorders $[667,668]$.

\section{Genetic syndromes}

\section{Prader-Willi syndrome}

PWS is characterized by infantile hypotonia, mental retardation, short stature, hypogonadism, hyperphagia and early-onset morbid obesity [669]. It has an estimated prevalence of 1 in 10,000 to 1 in 30,000 births [670]. Approximately $70 \%$ of cases are due to a genetic deletion on chromosome 15 (15q11-13), $25 \%$ of cases are due to a maternal uniparental disomy of chromosome 15 , and the remaining cases result from imprinting defects [671,672]. Although to date there are no preclinical models of PWS that clearly implicate the mesolimbic reward system, a linkage between PWS and reward-processing deficits is suggested by hyperphagia (abnormally increased appetite for and consumption of food) and the high incidence of obesity in affected individuals. PWS is the most commonly recognized genetic cause of childhood obesity, and obesity is the primary basis of morbidity and mortality for individuals with the syndrome. If given access, individuals with PWS will consume three to six times as much food as individuals without the syndrome, and show delayed meal termination, and earlier return of hunger after a previous meal $[673,674]$. Children with PWS show enhanced behavioral responses to food cues, which do not diminish after receiving a favorite food [675], suggesting that the incentive salience of food is heightened in this population, and that this heightened motivation is not diminished with satiation [676]. Appetite disturbance in PWS has been attributed to the hypothalamic dysfunction that characterizes the disorder, which also causes growth-hormone deficiency, hypogonadism, and temperature dysregulation [677].

The enhanced response to food that characterized PWS suggests that the brain reward-circuitry response to food may be hyperactive. Indeed, several research groups have found greater activation in the ventromedial prefrontal cortex, amygdala, and orbitofrontal cortex during reward anticipation for food cues in PWS. Miller and colleagues [678] presented images of food, animals, and tools, and found that participants with PWS had relatively greater ventromedial prefrontal cortex activation to food compared with controls. Holsen and colleagues [679] scanned participants with PWS while they viewed images of food and animals, both before and after eating a standard meal. They found a group $\times$ time interaction, reflecting the increased activation in orbitofrontal cortex, medial prefrontal cortex, and insula at post-meal relative to pre-meal in the PWS groups that was not evident in the control group. Dimitropoulos and Schultz [680] reported increased activation in the hypothalamus and orbitofrontal cortex in PWS during highcalorie versus low-calorie food-reward outcomes.

These initial studies suggest that the hyperphagia in PWS may indeed be mediated by hyperactivation in brain-reward networks to food-related stimuli (but Hinton et al. [681] failed to replicate this finding). In support of these findings, Shapira and colleagues [682] showed that in patients with PWS that there was a temporal delay in response to glucose ingestion in the resting-state activity of a distributed network implicated in the regulation of hunger and satiation, namely the hypothalamus, insular cortex, ventral basal ganglia, and ventromedial prefrontal cortex.

To date there are no published molecular-imaging studies addressing striatal DA binding in PWS, and the first-line pharmacologic treatment for PWS is growthhormone therapy, which does not regulate DA function.

\section{Williams syndrome}

WS (also known as Williams-Beuren syndrome), with a prevalence of about 1 in 7,500 [683], is a neurodevelopmental condition caused by a hemizygous microdeletion on chromosome 7q11.23, and is characterized by hypersociality and being overly empathic $[684,685]$. Although to date there are no preclinical models of WS that clearly implicate the mesolimbic reward system, the highly social phenotype of WS suggests a poorly modulated reward-system response to social cues.

There are currently three models of social function in WS: 1) heightened drive towards non-specific social interaction (for example, social interactions with strangers) $[686,687]$, 2) heightened emotional responsiveness [685], and 3) social fearlessness [688]. Only two functional brain-imaging studies to date to have provided insight into reward processing in WS by assessing responses to happy and fearful faces. One such study found relations between amygdala responses to fearful faces specifically, and symptoms of social approach of strangers [689], supportive of the social fearlessness model. Another study found that individuals with WS show reduced amygdala activity in response to sad faces and comparable activity in the orbitofrontal cortex for happy and sad faces, whereas TS individuals show a heightened orbitofrontal cortex response to sad faces 
[690]. However, both of these studies did not report responses to the happy-face conditions. In this regard, it is currently unknown if the phenotype of hypersociality in WS reflects a hyperactive neurobiological response to social rewards specifically, or if such behavior is but one exemplar of indiscriminant heightened approach behaviors to a wider range of social-emotional stimuli.

There are no published studies of striatal DAT function in WS. WS is typically treated by anxiolytic and antipsychotic agents, but to date there are no systematic data on efficacy of DA agents to treat WS [691].

Angelman syndrome AS is characterized by intellectual disability, epilepsy, impaired coordination, and absence of speech [692]. However, individuals with AS also commonly exhibit a characteristic happy demeanor with prominent smiling, non-specific laughing, a general exuberance [693], and an attraction to water and certain types of paper and plastics [694], suggesting that the reward-system function may be a candidate system for study in this syndrome [695]. The syndrome is caused by mutations or deletions of the maternal copy of the gene Ube3a, an E3 ubquitin ligase enzyme that is involved in targeting proteins for degradation in cells. Although empirical evidence for altered reward-system function in individuals with AS is lacking, animal models suggest there may be some involvement. In elegant genetic studies using the fruit-fly Drosophila, overexpression or genetic knockout of the Drosophila homolog of $U b e 3 a$ respectively increased or decreased DA levels, potentially due to changes in the expression of tetrahydrobiopterin, the rate-limiting cofactor in monoamine synthesis in flies [696]. In addition, in a mouse model of AS, genetic loss of the Ube3a gene resulted in a loss of DA neurons in the substantia nigra [697], which may contribute to mechanisms that cause ataxia and motor deficits apparent in the mouse model of the disease. The severe developmental delay that characterizes the syndrome renders functional neuroimaging research challenging, and to date there are no functional brainimaging data on responses to rewards or molecular brain-imaging studies in AS.

Rett syndrome RS predominantly affects females and is caused by mutations in the gene encoding the methylCpG binding protein $(\mathrm{MeCP}) 2$, a transcriptional repressor involved in DNA remodeling and regulation of gene expression. In RS. both loss of function and gain in $\mathrm{MeCP} 2$ gene dosage lead to similar neurological phenotypes [698]. MeCP2 mutations result in a number of pathologies including microencephaly, general growth retardation, motor clumsiness, ataxia, and autistic features, including social withdrawal, loss of language, and stereotypy [699].
Preclinical models Although a connection between dysregulated mesolimbic DA reward systems and RS is not currently clear, several studies indicate altered DA levels and changes in the closely related nigrostriatal DA pathways in mouse models. It has been suggested that MeCP2 protein normally functions in the NAc to limit the rewarding properties of psychostimulants, and that psychostimulant or DA receptor-induced phosphorylation of MeCP2 may be involved in the rewarding properties of drugs of abuse such as amphetamines [700]. In an engineered MeCP2-deficient mouse model, a postnatal reduction of DA and its metabolite homovanillic acid was seen in the caudate putamen [701,702], suggesting that MAO and/or COMT levels might be impaired. Loss of MeCP2 also compromises the nigrostriatal DA pathway in mice, where the number of DA-synthesizing neurons is significantly decreased in the substantia nigra of RS model mice [701]. In addition, the DA neurons in the substantia nigra of MECP2 mutant mice have a decreased capacitance, total dendritic length, and resting membrane conductance as early as 4 weeks after birth, well before overt neurodevelopmental symptoms are seen in the mouse model [703]. These studies suggest that nigrostriatal DA deficits may underlie the origin of motor dysfunctions in RS. Although further studies are required, there may also be similar deficits in the closely associated mesolimbic pathway in RS model mice.

Clinical studies Because of the profound cognitive impairment associated with RS [699], there are no functional brain-imaging studies of individuals with this condition because of the cognitive demands of the functional brain-imaging environment. Molecularimaging studies have indicated increased $D_{2}$ receptor binding in the caudate and putamen [704], and in the striatum as a whole [705]. No DA agents are first-line treatments for RS.

\section{Fragile $X$ syndrome}

FXS is the most common inherited cause of intellectual disability, occurring in 1 in 4,000 males and 1 in 8,000 females [706], and is caused by a mutation of the FMR1 gene on the long arm of the $\mathrm{X}$ chromosome(locus Xq27.3; [707]). The FMR1 full mutation affects cognition, adaptive behavior, social abilities, and motor skills [708]. Specific areas of cognitive weaknesses include communication, mathematics, visual-spatial processing, executive function, and memory [709-711].

Preclinical models Fragile X model mice have been developed that encode an engineered mutation in the FMR1 gene [712], recapitulating the human mutation, resulting in an absence of FMR1 expression. To identify potentially related neurochemical mechanisms affected 
by this mutation, Fulks and colleagues [713] used fastscanning cyclic voltammetry to measure electrically evoked DA release in striatal brain slices. In adult mice, a decrease in stimulated extracellular DA release and reuptake was seen in FMR1 mutant mice, which was also associated with decreased repetitive movements/stereotypy. FMR1 has been suggested as important for DA signaling in both the prefrontal cortex and striatum, where it may interact with $\mathrm{G}$ protein-coupled receptor kinase 2, which regulates DA receptor signaling cascades [714]. In studies of FMR1 mutant mice, Zhuo and colleagues reported that cortical and striatal neurons from the mutant mice exhibit abnormal $D_{1}$ receptor signaling and disrupted synaptic plasticity in response to $D_{1}$ receptor activation. Remarkably, these neuronal deficits could be rescued by restoring the FMR1 gene to the mutant neurons [715]. FMR1 is also suggested to be important for $\mathrm{D}_{1}$ receptor-mediated synthesis of SAPAP3 in prefrontal cortex neurons; SAPAP3 is a post-synaptic neuronal scaffolding protein that regulates glutamate receptor trafficking and function [716]. Together, these studies indicate that FMR1 mutant mice have dysregulated striatal DA transmission and pre-frontal DA receptor function, and that these changes may contribute to the mechanisms underlying FXS.

Clinical studies No functional brain-imaging studies to date have assessed responses to rewarding stimuli in FXS. Rather, given that individuals with FXS display social impairments that may be similar to those seen in ASD $[717,718]$, it is not surprising that functional brainimaging studies of FXS have focused almost exclusively on responses to social stimuli. To the extent that, in neurotypical development, social stimuli such as faces are rewarding [719], these studies may indirectly address the integrity of reward-circuitry function in FXS, although future studies designed to investigate striatal response to other rewards in FXS are needed.

Garret and colleagues [720] reported relatively decreased activation of the fusiform gyrus and superior temporal sulcus and increased right insula activation to images of faces in FXS. The authors suggested that these results may reflect anxiety provoked by the face stimuli. Watson, Hoeft, Garrett et al. [721] showed this same stimulus set to boys with FXS, and replicated the finding of greater insula activation (although on the left side) to direct gaze. Holsen et al. [722] reported decreased cingulate and left insula activation in individuals with FXS in response to images of familiar fearful faces and inverse relations between social anxiety and activation in a number of regions, including a cluster in the left inferior frontal gyrus near the insula. These authors speculated that social anxiety in FXS has a cascading effect on multiple aspects of cognition. Finally, Dalton et al. [723] compared responses in groups with FXS and with autism during the processing of emotional faces, and found that in response to faces, the FXS group had higher activation in the right insula (among other regions) compared with both the autism and control groups, a finding that the authors suggested may be linked to social anxiety.

The only published molecular-imaging study of striatal DAT binding is a small investigation of four patients with parkinsonism carrying the FXS permutation, which found initial evidence of decreased striatal binding [724]. However, there is evidence that DA functioning may be atypical in FXS, as shown by high rates of comorbidity with tremor disorders [725], higher blink rates [726], and emerging preclinical models [714].

Dopaminergic treatments Children and adults with FXS are regularly prescribed stimulants, antidepressants, anticonvulsants, and antipsychotics [727-729]. Psychostimulants are the most often prescribed psychoactive medication to treat FXS [730], with initial randomized controlled trial data of response to methylphenidate and dextroamphetamine suggesting moderate response rates on attention and social skills [731]. Preliminary studies of aripiprazole in FXS have also found evidence for an improvement in clinical symptoms and irritability [732,733].

\section{Conclusions}

The central tenet of this review is that multiple neurodevelopmental and psychiatric disorders and genetic syndromes share a common neurobiological characteristic, namely, altered functional output of striatal DA systems mediating the processing of rewards. This framework suggests the need for new methods of phenotypic assessment that cut across traditional symptom-based surveys developed to assess functioning based on traditional, category-based classification systems such as DSM [1] and the International Classification of Diseases [734]. Given that a significant portion of the disorders reviewed here respond favorably to treatment by psychopharmacologic agents that primarily affect DA systems, investigations of reward-circuitry functioning in psychopathology may have direct relevance not only for etiological models of disease mechanisms, but for the potential mechanisms of effective interventions and the development of treatment agents. Although treatment effects do not necessarily indicate pathophysiological etiologies, the efficacy of dopaminergic agents represents supportive preliminary evidence of a potential common etiology in a number of conditions.

However, we recognize that the one-to-one linking of mesolimbic DA function with reward response is clearly overly simplistic [45]. The mesolimbic DA system represents only one component of a very complex and integrated set of circuits, and although DA is clearly a 
crucial neurotransmitter in the reward-processing system, non-DA systems clearly also modulate reward responsibility [19,735]. Additionally, there are multiple brain regions not addressed in this review that contribute to reward processing, including the subthalamic nucleus and ventral pallidum, the subiculum, the lateral habenula, and the extended amygdala [736,737]. Additionally, multiple non-DA compounds have shown efficacy in improving reward responses, such as agents that affect glutamate circuits involved in regulating monoamine systems [19]. Consequently, the purpose of this review is to serve as a starting point for consideration of DA-mediated reward-system dysfunction as a potential common etiologic factor in a range of conditions. Future research aimed at understanding linkages between disease phenotype, reward function, and treatment response will clearly have to consider other interacting systems and neurotransmitters.

A host of unanswered questions remain about how ascending DA projections and their forebrain targets contribute to aspects of reward processing [738,739]. For example, even within the context of DA systems, it is not clear whether increased and decreased reward-oriented motivation is a result of decreased or increased sensitivities of DA and associated systems [735,740]. Moreover, the striatum and associated DA systems play a prominent role in processing aversive stimuli and processing rewards $[741,742]$. Hence, the present review is intended to highlight initial evidence of the relevance of DA reward to neurodevelopmental and psychiatric disorders, but clearly future studies are needed to address other brain circuits, neurotransmitters, and motivating stimuli.

Another limitation of this line of research is that the majority of clinical studies summarized in this review assessed responses to standardized rewards, such as money or standard picture sets. This approach relies on the implicit assumption that standardized stimulus sets are a reasonable proxy for individual-specific stimuli. In the realm of nonclinical cognitive neuroscience, this assumption seems to be valid [97]; however, the concordance of results using standardized versus individual-specific stimuli is largely unknown in clinical contexts. Additionally, there are a number of contexts in which reward-system dysfunction in a given disorder may be contingent on a particular class of stimuli (for example,, addiction cues in substance abuse [148], food images in eating disorders [326], and sad pictures in unipolar depression [232]). Although this issue complicates cross-disorder comparisons, this variability in response-eliciting stimuli leads to distinct phenotypic expressions in different disorders.

Future research is needed to delineate linkages between laboratory measures of reward processing and real-life experiences of incentive motivation, positive affect, reward-seeking, and risk-taking tendencies. The few studies that have evaluated potential relations between mesolimbic neural activity and subjectively experienced reward [220] or motivation to work for rewards [154] have yielded promising initial results suggesting the external validity of laboratory-based measures of reward processes, but research on the ecological validity of rewardprocessing endophenotypic measures is needed. Additionally, the development of measures sensitive to rewardsystem integrity and suitably sensitive to change for intervention studies are also needed. Although self-report [743-745] and behavioral [209,746] measures of reward capacity have been developed, their association to neurobiological function has proven to be limited. As suggested by Treadway and Zald [19], an implication of clinical neurobiological research into reward-system dysfunction may be the modification of psychiatric interviews to frame and code questions to tap hedonic capacity and motivation towards certain classes of stimuli.

Another area in need of greater research is rewardcircuitry function in comorbid disorders. Given that the conditions reviewed here share mesolimbic dysfunction, it is perhaps not surprising that there are high rates of comorbidity between these disorders. For example, there are high rates of comorbidity between substance abuse and other Axis I conditions [747-749], schizophrenia and bipolar disorder [750], and ASD and mood and anxiety disorders [751]. A number of explanations for the high comorbidity rates have been suggested, including shared genetic etiology, self-medication of symptoms, and common socioenvironmental determinants $[752,753]$, but only multi-group studies that directly compare cases with comorbid disorders will be able to distinguish the nature of reward-circuitry dysfunction in these contexts.

Finally, as previously noted, the vast majority of clinical research into reward-circuitry function is crosssectional in nature, and has focused only on adults. Given the importance of brain development prior to adulthood, the study of reward-related processes during development will be crucial to disambiguate the proximal effects of altered reward-circuitry function from its more downstream effects on learning, motivation, and overall functioning [754-756]. There may be critical periods during early development when mesolimbic dysfunction creates a predisposition to any number of disorders, and understanding the factors that mediate these processes will be essential for treatment and the prevention of symptom onset.

Competing interests

The authors declare that they have no competing interests.

Authors' contributions

All three authors were major contributors in writing this manuscript, and have read and approved the final manuscript. 


\section{Acknowledgements}

We are grateful for helpful discussions with James W. Bodfish, C.J. Malanga, Joseph Piven, and the comments of two anonymous reviewers. Preparation of this manuscript was supported by K23 MH081285 (GSD), R01 MH073402 (GSD), and by a Weatherstone Predoctoral Fellowship from Autism Speaks (\#7413) (CAD).

\section{Author details}

${ }^{1}$ Carolina Institute for Developmental Disabilities, University of North Carolina at Chapel Hill School of Medicine, Chapel Hill, NC, USA. ${ }^{2}$ Department of Psychiatry, University of North Carolina at Chapel Hill School of Medicine, Chapel Hill, NC, USA. ${ }^{3}$ Department of Psychology, University of North Carolina at Chapel Hill, Chapel Hill, NC, USA. ${ }^{4}$ Neuroscience Research Unit Pfizer Global Research and Development, Groton CT 06340, USA. ${ }^{5}$ Department of Psychiatry, University of North Carolina School of Medicine, CB\# 7255, 101 Manning Drive, Chapel Hill, NC 275997255, USA.

Received: 6 February 2012 Accepted: 2 May 2012

Published: 6 July 2012

\section{References}

1. American Psychiatric Association: Diagnostic and statistical manual of mental disorders. 4th edition. Washington: DSM-IV; 1994.

2. Aupperle RL, Paulus MP: Neural systems underlying approach and avoidance in anxiety disorders. Dialogues Clin Neurosci 2010, 12(4): 517-531.

3. Murray EA, Wise SP, Drevets WC: Localization of dysfunction in major depressive disorder: prefrontal cortex and amygdala. Biol Psychiatr 2011, 69(12):e43.

4. Kerns JG, Cohen JD, MacDonald AW 3rd, Johnson MK, Stenger VA, Aizenstein H, Carter CS: Decreased conflict- and error-related activity in the anterior cingulate cortex in subjects with Schizophrenia. Am J Psychiatr 2005, 162(10):1833-1839.

5. Pannu Hayes J, Labar KS, Petty CM, McCarthy G, Morey RA: Alterations in the neural circuitry for emotion and attention associated with posttraumatic stress symptomatology. Psychiatr Res 2009, 172(1):7-15.

6. NIMH: The National Institute of Mental Health Strategic Plan. Bethesda: National Institute of Mental Health (NIH Publication 08-6368); 2008. http:// www.nimh.nih.gov/about/strategic-planning-reports/index.shtml.

7. Insel TR, Cuthbert BN: Endophenotypes: Bridging genomic complexity and disorder heterogeneity. Biol Psychiatr 2009, 66(11):988-989.

8. Miller G: Psychiatry. Beyond DSM: Seeking a brain-based classification of mental illness. Science 2010, 327(5972):1437.

9. Carter CS: Applying new approaches from cognitive neuroscience to enhance drug development for the treatment of impaired cognition in schizophrenia. Schizophr Bull 2005, 31(4):810-815.

10. Hasler G, Drevets WC, Manji HK, Charney DS: Discovering endophenotypes for major depression. Neuropsychopharmacology 2004, 29(10):1765-1781.

11. Jacob S, Landeros-Weisenberger A, Leckman JF: Autism spectrum and obsessive-compulsive disorders: OC behaviors, phenotypes and genetics. Autism Res 2009, 2(6):293-311.

12. Charney DS, Barlow DH, Botteron KN, Cohen JD, Goldman D, Gur RC: Neuroscience research agenda to guide development of a pathophysiologically based classification system. In A Research Agenda for DSM-V. Edited by Kupfer DJ, First MB, Regier DA. Washington: American Psychiatric Association; 2002:31-83.

13. Gottesman II, Gould TD: The endophenotype concept in psychiatry: etymology and strategic intentions. Am J Psychiatr 2003, 160(4):636-645.

14. Gottesman II, Shields J: Genetic theorizing and schizophrenia. $\mathrm{Br} J$ Psychiatr 1973, 122(566):15-30.

15. Ernst M, Daniele T, Frantz K: New perspectives on adolescent motivated behavior: Attention and conditioning. Deve Cognit Neurosci 2011, 1(4):377-389.

16. Gladwin TE, Figner B, Crone EA, Wiers RW: Addiction, adolescence, and the integration of control and motivation. Dev Cognit Neurosci 2011, 1(4):364-376.

17. Fairchild G: The developmental psychopathology of motivation in adolescence. Deve Cognit Neurosci 2011, 1(4):414-429.

18. Luman M, Tripp G, Scheres A: Identifying the neurobiology of altered reinforcement sensitivity in ADHD: A review and research agenda. Neurosci Biobehav Rev 2010, 34(5):744-754.
19. Treadway MT, Zald DH: Reconsidering anhedonia in depression: lessons from translational neuroscience. Neurosci Biobehav Rev 2011, 35(3):537-555.

20. Ernst M, Fudge JL: A developmental neurobiological model of motivated behavior: anatomy, connectivity and ontogeny of the triadic nodes. Neurosci Biobehav Rev 2009, 33(3):367-382.

21. Delgado MR: Reward-related responses in the human striatum. Ann N Y Acad Sci 2007, 1104:70-88.

22. Smith $\mathrm{KS}$, Berridge $\mathrm{KC}$, Aldridge JW: Disentangling pleasure from incentive salience and learning signals in brain reward circuitry. Proc Natl Acad Sci 2011, 108(27):E255

23. Barch DM, Dowd EC: Goal representations and motivational drive in schizophrenia: the role of prefrontal-striatal interactions. Schizophr Bull 2010, 36(5):919-934.

24. Delgado MR, Li J, Schiller D, Phelps EA: The role of the striatum in aversive learning and aversive prediction errors. Philosophical Transactions of the Royal Society of London. Ser B Biol Sci 2008, 363(1511):3787-3800.

25. Han S, Huettel SA, Raposo A, Adcock RA, Dobbins IG: Functional significance of striatal responses during episodic decisions: recovery or goal attainment? J Neurosci 2010, 30(13):4767-4775.

26. van der Schaaf ME, Warmerdamc E, Crone EA, Cools R: Distinct linear and non-linear trajectories of reward and punishment reversal learning during development: Relevance for dopamine's role in adolescent decision making. Dev Cognit Neurosci 2011, 1:578-590.

27. Aarts $E$, van Holstein $M$, Cools R: Striatal dopamine and the interface between motivation and cognition. Front Psychol 2011, 2:163.

28. Knutson B, Cooper JC: Functional magnetic resonance imaging of reward prediction. Curr Opin Neurol 2005, 18(4):411-417.

29. Schultz W: Reward signaling by dopamine neurons. Neuroscientist 2001, 7(4):293-302.

30. Kable JW, Glimcher PW: The neurobiology of decision: consensus and controversy. Neuron 2009, 63(6):733-745.

31. Platt ML, Huettel SA: Risky business: the neuroeconomics of decision making under uncertainty. Nat Neurosci 2008, 11(4):398-403.

32. Rangel A, Camerer C, Montague PR: A framework for studying the neurobiology of value-based decision making. Nat Rev Neurosci 2008, 9(7):545-556.

33. Hayes DJ, Greenshaw AJ: 5-HT receptors and reward-related behaviour: a review. Neurosci Biobehav Rev 2011, 35(6):1419-1449.

34. Park J, Wheeler RA, Fontillas K, Keithley RB, Carelli RM, Wightman RM: Catecholamines in the bed nucleus of the stria terminalis reciprocally respond to reward and aversion. Biol Psychiatr 2011, 71(4):327-334.

35. Cooper JR, Bloom FE, Roth RH: The Biochemical Basis of Neuropharmacology. Oxford: Oxford University Press; 2003. ISBN 8th.

36. Enoch MA: The role of GABA(A) receptors in the development of alcoholism. Pharmacol Biochem Behav 2008, 90(1):95-104.

37. Grueter BA, Rothwell PE, Malenka RC: Integrating synaptic plasticity and striatal circuit function in addiction. Curr Opin Neurobiol 2011. http://www. sciencedirect.com/science/article/pii/S095943881100153X.

38. Russo SJ, Dietz DM, Dumitriu D, Morrison JH, Malenka RC, Nestler EJ: The addicted synapse: mechanisms of synaptic and structural plasticity in nucleus accumbens. Trends Neurosci 2011, 33(6):267-276.

39. Berridge KC, Kringelbach ML: Affective neuroscience of pleasure: reward in humans and animals. Psychopharmacology (Berl) 2008, 199(3):457-480.

40. Berridge KC, Robinson TE: Parsing reward. Trends Neurosci 2003, 26(9):507-513.

41. Berridge $K C$, Robinson TE, Aldridge JW: Dissecting components of reward: 'liking', 'wanting', and learning. Curr Opin Pharmacol 2009, 9(1):65-73.

42. Graybiel AM: Habits, rituals, and the evaluative brain. Annu Rev Neurosci 2008, 31:359-387.

43. Salamone JD: Functions of mesolimbic dopamine: changing concepts and shifting paradigms. Psychopharmacol Berl 2007, 191(3):389.

44. Wise RA: Dopamine and reward: The anhedonia hypothesis 30 years on. Neurotoxicol Res 2008, 14(2-3):169-183.

45. Kringelbach ML, Berridge KC: Pleasures of the Brain. New York: Oxford University Press; 2009.

46. Rushworth MF, Noonan MP, Boorman ED, Walton ME, Behrens TE: Frontal cortex and reward-guided learning and decision-making. Neuron 2011, 70(6):1054-1069.

47. Graybiel AM: The basal ganglia. Curr Biol 2000, 10(14):R509-R511.

48. Yin $\mathrm{HH}$, Knowlton BJ: The role of the basal ganglia in habit formation. Nat Rev Neurosci 2006, 7(6):464-476. 
49. Hoebel BG, Avena NM, Rada P: Accumbens dopamine-acetylcholine balance in approach and avoidance. Curr Opin Pharmaco/ 2007, 7(6):617-627.

50. vblkemoto S, Panksepp J: The role of nucleus accumbens dopamine in motivated behavior: a unifying interpretation with special reference to reward-seeking. Brain Res Rev 1999, 31(1):6-41.

51. Salamone JD, Correa M, Farrar AM, Nunes EJ, Pardo M: Dopamine, behavioral economics, and effort. Front Behav Neurosci 2009, 3:13-15.

52. Berridge KC, Scherer $\mathrm{K}$ : Comparing the emotional brain of humans to other animals. In Handbook of Affective Sciences. Edited by Davidson RJ, Goldsmith HH. Oxford: Oxford University Press; 2003.

53. Davidson RJ, Sutton SK: Affective neuroscience: the emergence of a discipline. Curr Opin Neurobiol 1995, 5(2):217-224.

54. Olds J, Milner P: Positive reinforcement produced by electrical stimulation of septal area and other regions of rat brain. J Comp Physiol Psychol 1954, 47(6):419-427.

55. Wise RA: Addictive drugs and brain stimulation reward. Annu Rev Neurosci 1996, 19:319-340.

56. Haber SN: The primate basal ganglia: Parallel and integrative networks. J Chem Neuroanat 2003, 26(4):317-330.

57. McBride WJ, Murphy JM, Ikemoto S: Localization of brain reinforcement mechanisms: Intracranial self-administration and intracranial placeconditioning studies. Behav Brain Res 1999, 101(2):129-152.

58. Chau DT, Roth RM, Green Al: The neural circuitry of reward and its relevance to psychiatric disorders. Curr Psychiatr Rep 2004, 6(5):391-399.

59. Lindvall O, Bjorklund A: Dopamine- and norepinephine-containing neuron systems: Their anatomy in the rat brain. In Chemical Neuroanatomy. Edited by Emson PC. New York: Raven; 1983:229-255.

60. Swerdlow NR, Koob GF: Dopamine, schizophrenia, mania, and depression: toward a unified hypothesis of cortico-striato-pallido-thalamic function. Behav Brain Sci 1987, 10:197-245.

61. Haber SN, McFarland NR: The concept of the ventral striatum in nonhuman primates. Ann N Y Acad Sci 1999, 877:33-48.

62. McGinty JF: Advancing from the ventral striatum to the extended amygdala. Implications for neuropsychiatry and drug abuse. Introduction. Ann New York Acad Sci 1999, 877(McGinty JF):xii-xV.

63. Kalivas PW, Barnes CD: Limbic Motor Circuits and Neuropsychiatry. Boca Raton: CRC Press; 1993

64. Mogenson GJ, Jones DL, Yim CY: From motivation to action: Functional interface between the limbic system and the motor system. Progr Neurobiol 1980, 14(2-3):69-97.

65. Beaulieu JM, Gainetdinov RR: The physiology, signaling, and pharmacology of dopamine receptors. Pharmacol Rev 2011, 63(1):182-217.

66. Girault JA, Greengard P: The neurobiology of dopamine signaling. Arch Neurol 2004, 61(5):641-644

67. Neve KA, Seamans JK, Trantham-Davidson H: Dopamine receptor signaling. J Recept Signal Transduct Res 2004, 24(3):165-205

68. Mogenson GJ, Wu M, Jones DL: Locomotor activity elicited by injections of picrotoxin into the ventral tegmental area is attenuated by injections of GABA into the globus pallidus. Brain Res 1980, 191(2):569-571.

69. Nicola SM, Surmeier J, Malenka RC: Dopaminergic modulation of neuronal excitability in the striatum and nucleus accumbens. Annu Rev Neurosci 2000, 23:185-215.

70. Hopf FW, Cascini MG, Gordon AS, Diamond I, Bonci A: Cooperative activation of dopamine D1 and D2 receptors increases spike firing of nucleus accumbens neurons via G-protein betagamma subunits. $J$ Neurosci 2003, 23(12):5079-5087.

71. Cacciapaglia F, Wightman RM, Carelli RM: Rapid dopamine signaling differentially modulates distinct microcircuits within the nucleus accumbens during sucrose-directed behavior. J Neurosci 2011, 31(39):13860-13869.

72. Tsai HC, Zhang F, Adamantidis A, Stuber GD, Bonci A, de Lecea L, Deisseroth K: Phasic firing in dopaminergic neurons is sufficient for behavioral conditioning. Science 2009, 324(5930):1080-1084

73. Riddle EL, Fleckenstein $A E$, Hanson GR: Role of monoamine transporters in mediating psychostimulant effects. AAPS J 2005, 7(4):E847.

74. Beveridge TJ, Smith HR, Nader MA, Porrino LJ: Abstinence from chronic cocaine self-administration alters striatal dopamine systems in rhesus monkeys. Neuropsychopharmacology 2009, 34(5):1162-1171.

75. Little KY, Zhang L, Desmond T, Frey KA, Dalack GW, Cassin BJ: Striatal dopaminergic abnormalities in human cocaine users. Am J Psychiatr 1999, 156(2):238-245.
76. Seeman P, Lee T: Antipsychotic drugs: Direct correlation between clinical potency and presynaptic action on dopamine neurons. Science 1975, 188 (4194):1217-1219.

77. Guillin O, Abi-Dargham A, Laruelle M: Neurobiology of dopamine in schizophrenia. Int Rev Neurobiol 2007, 78:1-39.

78. Weinberger D, Laruelle M: Neurochemical and neuropharmachological imaging in schizophrenia. In Neuropsychopharmacology: The Fifth Generation of Progress. Edited by Davis KL, Charney DS, Coyle JT, Nemeroff C. New York: Lippincott, Williams, and Wilkins; 2001:833-856.

79. Seeman P: All roads to schizophrenia lead to dopamine supersensitivity and elevated dopamine D2(high) receptors. CNS Neurosci Therapy 2011, 17(2):118-132.

80. Kellendonk C, Simpson EH, Polan HJ, Malleret G, Vronskaya S, Winiger V, Moore H, Kandel ER: Transient and selective overexpression of dopamine D2 receptors in the striatum causes persistent abnormalities in prefrontal cortex functioning. Neuron 2006, 49(4):603-615.

81. Kim KS, Lee KW, Im JY, Yoo JY, Kim SW, Lee JK, Nestler EJ, Han PL: Adenylyl cyclase type $5(A C 5)$ is an essential mediator of morphine action. Proc Natl Acad Sci 2006, 103(10):3908-3913.

82. Greengard P: The neurobiology of dopamine signaling. Biosci Rep 2001, 21 (3):247-269.

83. Gould TD, Manji HK: DARPP-32: A molecular switch at the nexus of reward pathway plasticity. Proc Natl Acad Sci 2005, 102(2):253-254.

84. Valjent E, Pascoli V, Svenningsson P, Paul S, Enslen H, Corvol JC, Stipanovich A, Caboche J, Lombroso PJ, Nairn AC, Greengard P, Herve D, Girault JA: Regulation of a protein phosphatase cascade allows convergent dopamine and glutamate signals to activate ERK in the striatum. Proc Natl Acad Sci 2005, 102(2):491-496.

85. Zachariou V, Benoit-Marand M, Allen PB, Ingrassia P, Fienberg AA, Gonon F, Greengard P, Picciotto MR: Reduction of cocaine place preference in mice lacking the protein phosphatase 1 inhibitors DARPP 32 or Inhibitor 1. Biol Psychiatr 2002, 51(8):612-620.

86. Nestler EJ: Is there a common molecular pathway for addiction? Nat Neurosci 2005, 8(11):1445-1449.

87. Nestler EJ, Barrot M, Self DW: DeltaFosB: a sustained molecular switch for addiction. Proc Natl Acad Sci 2001, 98(20):11042-11046.

88. McClung CA, Nestler EJ: Regulation of gene expression and cocaine reward by CREB and DeltaFosB. Nat Neurosci 2003, 6(11):1208-1215.

89. Barrot M, Olivier JD, Perrotti LI, DiLeone RJ, Berton O, Eisch AJ, Impey S, Storm DR, Neve RL, Yin JC, Zachariou V, Nestler EJ: CREB activity in the nucleus accumbens shell controls gating of behavioral responses to emotional stimuli. Proc Natl Acad Sci 2002, 99(17):11435-11440.

90. Walters CL, Godfrey M, Li X, Blendy JA: Alterations in morphine-induced reward, locomotor activity, and thermoregulation in CREB-deficient mice. Brain Res 2005, 1032(1-2):193-199.

91. Chen BT, Hopf FW, Bonci A: Synaptic plasticity in the mesolimbic system: therapeutic implications for substance abuse. Ann N Y Acad Sci 2010, 1187:129-139.

92. De Biasi M, Dani JA: Reward, addiction, withdrawal to nicotine. Annu Rev Neurosci 2011, 34:105-130.

93. Maze I, Nestler EJ: The epigenetic landscape of addiction. Ann N Y Acad Sci 2011, 1216:99-113.

94. Nestler EJ, Hyman SE: Animal models of neuropsychiatric disorders. Nat Neurosci 2010, 13(10):1161-1169.

95. Nesse RM: Evolutionary biology: a basic science for psychiatry. World Psychiatr 2002, 1(1):7-9.

96. Panksepp J: Affective Neuroscience: the Foundations of Human and Animal Emotions. In. Oxford: Oxford University Press; 1998.

97. Hayden BY, Parikh PC, Deaner RO, Platt ML: Economic principles motivating social attention in humans. Proc R Soc Bio/ Sci 2007, 274 (1619):1751-1756.

98. Ernst M, Nelson EE, McClure EB, Monk CS, Munson S, Eshel N, Zarahn E, Leibenluft E, Zametkin A, Towbin K, Blair J, Charney D, Pine DS: Choice selection and reward anticipation: an fMRI study. Neuropsychologia 2004, 42(12):1585-1597.

99. Knutson B, Adams CM, Fong GW, Hommer D: Anticipation of increasing monetary reward selectively recruits nucleus accumbens. J Neurosci 2001, 211(16):RC159.

100. Zald DH, Boileau I, El-Dearedy W, Gunn R, McGlone F, Dichter GS, Dagher A: Dopamine transmission in the human striatum during monetary reward tasks. J Neurosci 2004, 24(17):4105-4112. 
101. Kim H, Shimojo S, O'Doherty JP: Overlapping responses for the expectation of juice and money rewards in human ventromedial prefrontal cortex. Cerebr Cortex 2010, 21(4):769-776.

102. Kalivas PW, Volkow ND: The neural basis of addiction: a pathology of motivation and choice. Am J Psychiatr 2005, 162(8):1403-1413.

103. Kessler RC, Chiu WT, Demler O, Merikangas KR, Walters EE: Prevalence, severity, and comorbidity of 12-month DSM-IV disorders in the National Comorbidity Survey Replication. Arch Gen Psychiatr 2005, 62 (6):617-627.

104. Bechara A: Decision making, impulse control and loss of willpower to resist drugs: a neurocognitive perspective. Nat Neurosci 2005, 8(11):1458-1463.

105. Bickel WK, Miller ML, Yi R, Kowal BP, Lindquist DM, Pitcock JA: Behavioral and neuroeconomics of drug addiction: competing neural systems and temporal discounting processes. Drug Alcohol Depend 2007, 90(Suppl 1): S85-S91.

106. Hommer DW, Bjork JM, Gilman JM: Imaging brain response to reward in addictive disorders. Ann N Y Acad Sci 2011, 1216(1):50-61.

107. Parvaz MA, Alia-Klein N, Woicik PA, Volkow ND, Goldstein RZ: Neuroimaging for drug addiction and related behaviors. Rev Neurosci 2011, 22(6): 609-624.

108. Jessor R: Jessor SL: Problem Behavior and Psychosocial Development: A Longitudinal Study of Youth. New York: Academic; 1977.

109. Pihl RO, Peterson J, Finn P: Inherited predisposition to alcoholism: characteristics of sons of male alcoholics. J Abnorm Psychol 1990, 99 (3):291-301.

110. Newman JP, Wallace JF: Diverse pathways to deficient self-regulation: implications for disinhibitory psychopathology in children. Clin Pschol Rev 1993, 13:699-720.

111. Fairchild G, van Goozen SH, Stollery SJ, Aitken MR, Savage J, Moore SC Goodyer IM: Decision making and executive function in male adolescents with early-onset or adolescence-onset conduct disorder and control subjects. Biol Psychiatr 2009, 66(2):162-168.

112. Lane SD, Cherek DR: Risk taking by adolescents with maladaptive behavior histories. Exp Clin Psychopharmacol 2001, 9(1):74-82.

113. Di Chiara G, Imperato A: Drugs abused by humans preferentially increase synaptic dopamine concentrations in the mesolimbic system of freely moving rats. Proc Nat Acad Sci 1988, 85(14):5274-5278.

114. Koob GF, Bloom FE: Cellular and molecular mechanisms of drug dependence. Science 1988, 242(4879):715-723.

115. Drevets WC, Gautier C, Price JC, Kupfer DJ, Kinahan PE, Grace AA, Price JL, Mathis CA: Amphetamine-induced dopamine release in human ventral striatum correlates with euphoria. Biol Psychiatr 2001, 49(2):81-96.

116. Volkow ND, Wang GJ, Fowler JS, Gatley SJ, Ding YS, Logan J, Dewey SL, Hitzemann R, Lieberman J: Relationship between psychostimulantinduced "high" and dopamine transporter occupancy. Proc Natl Acad Sci 1996, 93(19):10388-10392.

117. Volkow ND, Wang GJ, Ma Y, Fowler JS, Zhu W, Maynard L, Telang F, Vaska P, Ding YS, Wong C, Swanson JM: Expectation enhances the regional brain metabolic and the reinforcing effects of stimulants in cocaine abusers. $J$ Neurosci 2003, 23(36):11461-11468.

118. Volkow ND, Wang GJ, Telang F, Fowler JS, Logan J, Childress AR, Jayne M, Ma Y, Wong C: Cocaine cues and dopamine in dorsal striatum: mechanism of craving in cocaine addiction. J Neurosci 2006, 26(24): 6583-6588.

119. Waelti P, Dickinson A, Schultz W: Dopamine responses comply with basic assumptions of formal learning theory. Nature 2001, 412(6842):43-48.

120. Volkow ND, Fowler JS, Wang GJ, Baler R, Telang F: Imaging dopamine's role in drug abuse and addiction. Neuropharmacology 2009, 56(Suppl 1):3-8

121. Fibiger HC, LePiane FG, Jakubovic A, Phillips AG: The role of dopamine in intracranial self-stimulation of the ventral tegmental area. J Neurosci 1987, 7(12):3888-3896

122. Willuhn I, Wanat MJ, Clark JJ, Phillips PE: Dopamine signaling in the nucleus accumbens of animals self-administering drugs of abuse. Curr Top Behav Neurosci 2010, 3:29-71.

123. Wise RA, Bozarth MA: A psychomotor stimulant theory of addiction. Psychol Rev 1987, 94(4):469-492.

124. Koob GF, Le Moal M: Addiction and the brain antireward system. Annu Rev Psychol 2008, 59:29-53.

125. Cheer JF, Wassum KM, Heien ML, Phillips PE, Wightman RM: Cannabinoids enhance subsecond dopamine release in the nucleus accumbens of awake rats. J Neurosci 2004, 24(18):4393-4400.
126. Cheer JF, Wassum KM, Sombers LA, Heien ML, Ariansen JL, Aragona BJ, Phillips PE, Wightman RM: Phasic dopamine release evoked by abused substances requires cannabinoid receptor activation. J Neurosci 2007, 27 (4):791-795

127. Stuber GD, Wightman RM, Carelli RM: Extinction of cocaine selfadministration reveals functionally and temporally distinct dopaminergic signals in the nucleus accumbens. Neuron 2005, 46(4):661-669.

128. Ritz MC, Lamb RJ, Goldberg SR, Kuhar MJ: Cocaine receptors on dopamine transporters are related to self-administration of cocaine. Science 1987, 237(4819):1219-1223.

129. Panlilio LV, Goldberg SR: Self-administration of drugs in animals and humans as a model and an investigative tool. Addiction 2007, 102 (12):1863-1870.

130. Yokel R: Intravenous Self-Administration: Response Rates, the Effects of Pharmacological Challenges, and Drug Preference. New York: Springer; 1987.

131. Carlezon WA Jr, Devine DP, Wise RA: Habit-forming actions of nomifensine in nucleus accumbens. Psychopharmacol Berl 1995, 122(2):194-197.

132. Woolverton WL, Goldberg LI, Ginos JZ: Intravenous self-administration of dopamine receptor agonists by rhesus monkeys. J Pharmacol Exp Therapy 1984, 230(3):678-683.

133. Yokel RA, Wise RA: Amphetamine-type reinforcement by dopaminergic agonists in the rat. Psychopharmacol Berl 1978, 58(3):289-296.

134. Caine SB, Koob GF: Effects of dopamine D-1 and D-2 antagonists on cocaine self-administration under different schedules of reinforcement in the rat. J Pharmacol Exp Ther 1994, 270(1):209-218.

135. De Wit H, Wise RA: Blockade of cocaine reinforcement in rats with the dopamine receptor blocker pimozide, but not with the noradrenergic blockers phentolamine or phenoxybenzamine. Can J Psychol 1977, 31 (4):195-203

136. Ettenberg A, Pettit HO, Bloom FE, Koob GF: Heroin and cocaine intravenous self-administration in rats: Mediation by separate neural systems. Psychopharmacol Berl 1982, 78(3):204-209.

137. Roberts DC, Koob GF: Disruption of cocaine self-administration following 6-hydroxydopamine lesions of the ventral tegmental area in rats. Pharmacol Biochem Behav 1982, 17(5):901-904.

138. Xi ZX, Stein EA: Baclofen inhibits heroin self-administration behavior and mesolimbic dopamine release. J Pharmacol Exp Therapy 1999, 290(3): 1369-1374.

139. Corrigall WA, Franklin KB, Coen KM, Clarke PB: The mesolimbic dopaminergic system is implicated in the reinforcing effects of nicotine Psychopharmacol Berl 1992, 107(2-3):285-289.

140. Lyness WH, Friedle NM, Moore KE: Destruction of dopaminergic nerve terminals in nucleus accumbens: Effect on d-amphetamine selfadministration. Pharmacol Biochem Behav 1979, 11(5):553-556.

141. Pettit HO, Ettenberg A, Bloom FE, Koob GF: Destruction of dopamine in the nucleus accumbens selectively attenuates cocaine but not heroin self-administration in rats. Psychopharmacol Berl 1984, 84 (2):167-173

142. Roberts DC, Koob GF, Klonoff P. Fibiger HC: Extinction and recovery of cocaine self-administration following 6-hydroxydopamine lesions of the nucleus accumbens. Pharmacol Biochem Behav 1980, 12(5):781-787.

143. Shoaib M, Swanner LS, Beyer CE, Goldberg SR, Schindler CW: The GABAB agonist baclofen modifies cocaine self-administration in rats. Behav Pharmacol 1998, 9(3):195-206.

144. Wexler BE, Gottschalk CH, Fulbright RK, Prohovnik I, Lacadie CM, Rounsaville BJ, Gore JC: Functional magnetic resonance imaging of cocaine craving. Am J Psychiatr 2001, 158(1):86-95.

145. Buhler M, Vollstadt-Klein S, Kobiella A, Budde H, Reed LJ, Braus DF, Buchel C, Smolka MN: Nicotine Dependence Is Characterized by Disordered Reward Processing in a Network Driving Motivation. Biol Psychiatry 2009.

146. Myrick H, Anton RF, Li X, Henderson S, Drobes D, Voronin K, George MS: Differential brain activity in alcoholics and social drinkers to alcohol cues: relationship to craving. Neuropsychopharmacology 2004, 29(2): 393-402.

147. Oberlin BG, Dzemidzic M, Bragulat V, Lehigh CA, Talavage T, O'Connor SJ, Kareken DA: Limbic responses to reward cues correlate with antisocial trait density in heavy drinkers. Neuroimage 2011, 60(1):644-652.

148. Filbey FM, Schacht JP, Myers US, Chavez RS, Hutchison KE: Marijuana craving in the brain. Proc Natl Acad Sci 2009, 106(31):13016-13021.

149. Volkow ND, Wang GJ, Kollins SH, Wigal TL, Newcorn JH, Telang F, Fowler JS, Zhu W, Logan J, Ma Y, Pradhan K, Wong C, Swanson JM: Evaluating 
dopamine reward pathway in ADHD: Clinical implications. JAMA 2009, 302(10):1084-1091.

150. Bozarth MA: New perspectives on cocaine addiction: recent findings from animal research. Can J Physiol Pharmacol 1989, 67(9):1158-1167.

151. Comings DE, Blum K: Reward deficiency syndrome: genetic aspects of behavioral disorders. Progr Brain Res 2000, 126:325-341.

152. Asensio S, Romero MJ, Palau C, Sanchez A, Senabre I, Morales JL, Carcelen R, Romero FJ: Altered neural response of the appetitive emotional system in cocaine addiction: An fMRI Study. Addict Biol 2010, 15(4):504-516.

153. Gilman JM, Hommer DW: Modulation of brain response to emotional images by alcohol cues in alcohol-dependent patients. Addiction Biol 2008, 13(3-4):423-434.

154. Bühler M, Vollstadt-Klein S, Kobiella A, Budde H, Reed LJ, Braus DF, Buchel C, Smolka MN: Nicotine dependence is characterized by disordered reward processing in a network driving motivation. Biol Psychiatr 2010, 67(8): 745-752.

155. Andrews MM, Meda SA, Thomas AD, Potenza MN, Krystal JH, Worhunsky P, Stevens MC, O'Malley S, Book GA, Reynolds B, Pearlson GD: Individuals family history positive for alcoholism show functional magnetic resonance imaging differences in reward sensitivity that are related to impulsivity factors. Biol Psychiatr 2011, 69(8):675-683.

156. Lubman DI, Yucel M, Kettle JW, Scaffidi A, Mackenzie T, Simmons JG, Allen NB: Responsiveness to drug cues and natural rewards in opiate addiction: Associations with later heroin use. Arch Gen Psychiatr 2009, 66(2):205-212.

157. Luo S, Ainslie G, Giragosian L, Monterosso JR: Striatal hyposensitivity to delayed rewards among cigarette smokers. Drug Alcohol Depend 2011, 116(1-3):18-23.

158. Jia Z, Worhunsky PD, Carroll KM, Rounsaville BJ, Stevens MC, Pearlson GD, Potenza MN: An initial study of neural responses to monetary incentives as related to treatment outcome in cocaine dependence. Biol Psychiatr 2011, 70(6):553-560.

159. Schneider S, Peters J, Bromberg U, Brassen S, Miedl SF, Banaschewski T, Barker GJ, Conrod P, Flor H, Garavan H: Risk taking and the adolescent reward system: A potential common link to Substance abuse. Am J Psychiatr 2011, 169(1):39-46.

160. Peters J, Bromberg U, Schneider S, Brassen S, Menz M, Banaschewski T, Conrod PJ, Flor H, Gallinat J, Garavan H: Lower ventral striatal activation during reward anticipation in adolescent smokers. Am J Psychiatr 2011, 168(5):540.

161. Nestor L, Hester R, Garavan H: Increased ventral striatal BOLD activity during non-drug reward anticipation in cannabis users. Neuroimage 2010, 49(1):1133-1143.

162. Koob GF, Le Moal M: Plasticity of reward neurocircuitry and the 'dark side' of drug addiction. Nat Neurosci 2005, 8(11):1442-1444.

163. Martinez D, Narendran R: Imaging neurotransmitter release by drugs of abuse. Curr Top Behav Neurosci 2010, 3:219-245.

164. Martinez D, Broft A, Foltin RW, Slifstein M, Hwang DR, Huang Y, Perez A, Frankle WG, Cooper T, Kleber HD, Fischman MW, Laruelle M: Cocaine dependence and $\mathrm{d} 2$ receptor availability in the functional subdivisions of the striatum: Relationship with cocaine-seeking behavior. Neuropsychopharmacology 2004, 29(6):1190-1202.

165. Volkow ND, Fowler JS, Wang GJ, Hitzemann R, Logan J, Schlyer DJ, Dewey SL, Wolf AP: Decreased dopamine D2 receptor availability is associated with reduced frontal metabolism in cocaine abusers. Synapse 1993, 14(2):169-177.

166. Volkow ND, Fowler JS, Wolf AP, Schlyer D, Shiue CY, Alpert R, Dewey SL, Logan J, Bendriem B, Christman D, et al: Effects of chronic cocaine abuse on postsynaptic dopamine receptors. Am J Psychiatr 1990, 147(6):719-724.

167. Volkow ND, Wang GJ, Fowler JS, Logan J, Gatley SJ, Hitzemann R, Chen AD, Dewey SL, Pappas N: Decreased striatal dopaminergic responsiveness in detoxified cocaine-dependent subjects. Nature 1997, 386(6627):830-833.

168. Wang GJ, Volkow ND, Fowler JS, Logan J, Abumrad NN, Hitzemann RJ, Pappas NS, Pascani K: Dopamine D2 receptor availability in opiatedependent subjects before and after naloxone-precipitated withdrawal. Neuropsychopharmacology 1997, 16(2):174-182.

169. Hietala J, West C, Syvalahti E, Nagren K, Lehikoinen P, Sonninen P, Ruotsalainen U: Striatal D2 dopamine receptor binding characteristics in vivo in patients with alcohol dependence. Psychopharmacol (Berl) 1994, 116(3):285-290.

170. Volkow ND, Wang GJ, Fowler JS, Logan J, Hitzemann R, Ding YS, Pappas N, Shea C, Piscani K: Decreases in dopamine receptors but not in dopamine transporters in alcoholics. Alcoholism Clin Exp Res 1996, 20(9):1594-1598.
171. Volkow ND, Chang L, Wang GJ, Fowler JS, Ding YS, Sedler M, Logan J, Franceschi D, Gatley J, Hitzemann R, Gifford A, Wong C, Pappas N: Low level of brain dopamine $\mathrm{D} 2$ receptors in methamphetamine abusers: association with metabolism in the orbitofrontal cortex. Am J Psychiatr 2001, 158(12):2015-2021.

172. Volkow ND, Wang G, Fowler JS, Logan J, Gerasimov M, Maynard L, Ding Y, Gatley SJ, Gifford A, Franceschi D: Therapeutic doses of oral methylphenidate significantly increase extracellular dopamine in the human brain. J Neurosci 2001, 21(2):RC121.

173. Melis M, Spiga S, Diana M: The dopamine hypothesis of drug addiction: Hypodopaminergic state. Int Rev Neurobiol 2005, 63:101-154.

174. Volkow ND, Fowler JS, Wang GJ: Role of dopamine in drug reinforcement and addiction in humans: results from imaging studies. Behav Pharmacol 2002, 13(5-6):355-366.

175. Volkow ND, Wang GJ, Fowler JS, Thanos PP, Logan J, Gatley SJ, Gifford A, Ding YS, Wong C, Pappas N: Brain DA D2 receptors predict reinforcing effects of stimulants in humans: replication study. Synapse 2002, 46(2): 79-82.

176. Schott BH, Minuzzi L, Krebs RM, Elmenhorst D, Lang M, Winz OH, Seidenbecher $\mathrm{Cl}$, Coenen HH, Heinze HJ, Zilles K, Duzel E, Bauer A: Mesolimbic functional magnetic resonance imaging activations during reward anticipation correlates with reward-related ventral striatal dopamine release. J Neurosci 2008, 28(52):14311-14319.

177. Karila L, Weinstein A, Aubin HJ, Benyamina A, Reynaud M, Batki SL: Pharmacological approaches to methamphetamine dependence: A focused review. Br J Clin Pharmacol 2010, 69(6):578-592.

178. Anderson AL, Reid MS, Li SH, Holmes T, Shemanski L, Slee A, Smith EV, Kahn R, Chiang N, Vocci F, Ciraulo D, Dackis C, Roache JD, Salloum IM, Somoza E, Urschel HC 3rd, Elkashef AM: Modafinil for the treatment of cocaine dependence. Drug Alcohol Depend 2009, 104(1-2):133-139.

179. McElhiney MC, Rabkin JG, Rabkin R, Nunes EV: Provigil (modafinil) plus cognitive behavioral therapy for methamphetamine use in HIV + gay men: a pilot study. Am J Drug Alcohol Abuse 2009, 35(1):34-37.

180. Garrett BE, Rose CA, Henningfield JE: Tobacco addiction and pharmacological interventions. Expet Opin Pharmacother 2001, 2(10): 1545-1555.

181. Grabowski J, Rhoades H, Schmitz J, Stotts A, Daruzska LA, Creson D, Moeller FG: Dextroamphetamine for cocaine-dependence treatment: a double-blind randomized clinical trial. J Clin Psychopharmacol 2001, 21 (5):522-526.

182. Meredith CW, Jaffe C, Yanasak E, Cherrier M, Saxon AJ: An open-label pilot study of risperidone in the treatment of methamphetamine dependence. J Psychoactive Drugs 2007, 39(2):167-172.

183. Stoops WW, Lile JA, Glaser PE, Rush CR: A low dose of aripiprazole attenuates the subject-rated effects of d-amphetamine. Drug Alcohol Depend 2006, 84(2):206-209.

184. Brent DA, Maalouf FT: Pediatric depression: is there evidence to improve evidence-based treatments? J Child Psychol Psychiatr 2009, 50(1-2): 143-152.

185. Kovacs M: Presentation and course of major depressive disorder during childhood and later years of the life span. J Am Acad Child Adolesc Psychiatr 1996, 35(6):705-715.

186. Rohde P, Beevers CG, Stice E, O'Neil K: Major and minor depression in female adolescents: Onset, course, symptom presentation, and demographic associations. J Clin Psychol 2009, 65(12):1339-1349.

187. Bromet E, Andrade LH, Hwang I, Sampson NA, Alonso J, de Girolamo G, de Graaf R, Demyttenaere K, Hu C, Iwata N, Karam AN, Kaur J, Kostyuchenko S, Lepine JP, Levinson D, Matschinger H, Mora ME, Browne MO, Posada-Villa J, Viana MC, Williams DR, Kessler RC: Cross-national epidemiology of DSM-IV major depressive episode. BMC Med 2011, 9:90.

188. Davidson RJ: Affective style and affective disorders: Perspectives from affective neuroscience. Cognit Emot 1998, 12(3):307-330.

189. Willner P: Chronic mild stress (CMS) revisited: Consistency and behavioural-neurobiological concordance in the effects of CMS. Neuropsychobiology 2005, 52(2):90-110.

190. Willner P: Validity, reliability and utility of the chronic mild stress model of depression: A 10-year review and evaluation. Psychopharmacol Berl 1997, 134(4):319-329.

191. Willner P, Towell A, Sampson D, Sophokleous S, Muscat R: Reduction of sucrose preference by chronic unpredictable mild stress, and its 
restoration by a tricyclic antidepressant. Psychopharmacol Berl 1987, 93 (3):358-364.

192. Muscat R, Papp M, Willner P: Reversal of stress-induced anhedonia by the atypical antidepressants, fluoxetine and maprotiline. Psychopharmacol (Berl) 1992, 109(4):433-438.

193. Papp M, Muscat R, Willner P: Subsensitivity to rewarding and locomotor stimulant effects of a dopamine agonist following chronic mild stress. Psychopharmacol Berl 1993, 110(1-2):152-158.

194. Papp M, Willner P, Muscat R: Behavioural sensitization to a dopamine agonist is associated with reversal of stress-induced anhedonia. Psychopharmacol Berl 1993, 110(1-2):159-164.

195. Strekalova T, Couch Y, Kholod N, Boyks M, Malin D, Leprince P, Steinbusch HM: Update in the methodology of the chronic stress paradigm: internal control matters. Behav Brain Funct 2011, 7:9.

196. Bekris S, Antoniou K, Daskas S, Papadopoulou-Daifoti Z: Behavioural and neurochemical effects induced by chronic mild stress applied to two different rat strains. Behav Brain Res 2005, 161(1):45-59.

197. Imperato A, Angelucci L, Casolini P, Zocchi A, Puglisi-Allegra S: Repeated stressful experiences differently affect limbic dopamine release during and following stress. Brain Res 1992, 577(2):194-199.

198. Mangiavacchi S, Masi F, Scheggi S, Leggio B, De Montis MG, Gambarana C: Long-term behavioral and neurochemical effects of chronic stress exposure in rats. J Neurochem 2001, 79(6):1113-1121.

199. Ossowska G, Nowa G, Kata R, Klenk-Majewska B, Danilczuk Z, ZebrowskaLupina I: Brain monoamine receptors in a chronic unpredictable stress model in rats. J Neural Transm 2001, 108(3):311-319.

200. Dunlop BW, Nemeroff CB: The role of dopamine in the pathophysiology of depression. Arch Gen Psychiatr 2007, 64(3):327-337.

201. Eshel N, Roiser JP: Reward and punishment processing in depression. Biol Psychiatr 2010, 68(2):118-124.

202. Hasler G, Northoff G: Discovering imaging endophenotypes for major depression. Mol Psychiatr 2011, 16(6):604-619.

203. Henriques JB, Davidson RJ: Decreased responsiveness to reward in depression. Cognit Emot 2000, 14(5):711-724.

204. McFarland BR, Klein DN: Emotional reactivity in depression: diminished responsiveness to anticipated reward but not to anticipated punishment or to nonreward or avoidance. Depress Anxiety 2009, 26(2):117-122.

205. Pizzagalli DA, losifescu D, Hallett LA, Ratner KG, Fava M: Reduced hedonic capacity in major depressive disorder: evidence from a probabilistic reward task. J Psychiatr Res 2008, 43(1):76-87.

206. Robinson OJ, Cools R, Carlisi CO, Sahakian BJ, Drevets WC: Ventral striatum response during reward and punishment reversal learning in unmedicated major depressive disorder. Am J Psychiatr 2011, 169(2): 152-159.

207. Liu W, Chan RCK, Wang L, Huang J, Cheung EFC, Gong Q, Gollan JK: Deficits in sustaining reward responses in subsyndromal and syndromal major depression. Progr Neuro Psychopharmacol Biol Psychiatr 2011, 35 (4):1045-1052

208. Tremblay LK, Naranjo CA, Cardenas L, Herrmann N, Busto UE: Probing brain reward system function in major depressive disorder: Altered response to dextroamphetamine. Arch Gen Psychiatr 2002, 59(5):409-416.

209. Treadway MT, Buckholtz JW, Schwartzman AN, Lambert WE, Zald DH: Worth the 'EEfRT'? The effort expenditure for rewards task as an objective measure of motivation and anhedonia. PLoS One 2009, 4(8): e6598.

210. Epstein J, Pan $H$, Kocsis JH, Yang Y, Butler T, Chusid J, Hochberg H, Murrough J, Strohmayer E, Stern E, Silbersweig DA: Lack of ventral striatal response to positive stimuli in depressed versus normal subjects. Am J Psychiatr 2006, 163(10):1784-1790.

211. Keedwell PA, Andrew C, Williams SC, Brammer MJ, Phillips ML: The neural correlates of anhedonia in major depressive disorder. Biol Psychiatr 2005 58:843-853.

212. Kumar P, Waiter G, Ahearn T, Milders M, Reid I, Steele JD: Abnormal temporal difference reward-learning signals in major depression. Brain 2008, 131(8):2084-2093.

213. Mitterschiffthaler MT, Kumari V, Malhi GS, Brown RG, Giampietro VP, Brammer MJ, Suckling J, Poon L, Simmons A, Andrew C, Sharma T: Neural response to pleasant stimuli in anhedonia: an $\mathrm{fMRI}$ study. Neuroreport 2003, 14(2):177-182.

214. Schaefer HS, Putnam KM, Benca RM, Davidson RJ: Event-related functional magnetic resonance imaging measures of neural activity to positive social stimuli in pre- and post-treatment depression. Biol Psychiatr 2006, 60(9):974-986.

215. Kumari V, Mitterschiffthaler MT, Teasdale JD, Malhi GS, Brown RG, Giampietro V, Brammer MJ, Poon L, Simmons A, Williams SC, Checkley SA, Sharma T: Neural abnormalities during cognitive generation of affect in treatment-resistant depression. Biol Psychiatr 2003, 54(8):777-791.

216. Ochsner KN, Ray RD, Cooper JC, Robertson ER, Chopra S, Gabrieli JD, Gross JJ: For better or for worse: neural systems supporting the cognitive downand up-regulation of negative emotion. Neuroimage 2004, 23(2):483-499.

217. Keedwell PA, Andrew C, Williams SCR, Brammer MJ, Zelaya F, Phillips ML: The neural correlates of depression. Biol Psychiatr 2003, 53:171S.

218. Liotti M, Mayberg HS, McGinnis S, Brannan SL, Jerabek P: Unmasking disease-specific cerebral blood flow abnormalities: mood challenge in patients with remitted unipolar depression. Am J Psychiatr 2002, 159 (11):1830-1840.

219. Forbes EE, Christopher May J, Siegle GJ, Ladouceur CD, Ryan ND, Carter CS, Birmaher B, Axelson DA, Dahl RE: Reward-related decision-making in pediatric major depressive disorder: An fMRI study. J Child Psychol Psychiatr 2006, 47(10):1031-1040.

220. Forbes EE, Hariri AR, Martin SL, Silk JS, Moyles DL, Fisher PM, Brown SM, Ryan ND, Birmaher B, Axelson DA, Dahl RE: Altered striatal activation predicting real-world positive affect in adolescent major depressive disorder. Am J Psychiatr 2009, 166(1):64-73.

221. Forbes EE, Olino TM, Ryan ND, Birmaher B, Axelson D, Moyles DL, Dahl RE: Reward-related brain function as a predictor of treatment response in adolescents with major depressive disorder. Cognit Affect Behav Neurosci 2010, 10(1):107-118.

222. Olino TM, McMakin DL, Dahl RE, Ryan ND, Silk JS, Birmaher B, Axelson DA, Forbes EE: "I won, but I'm not getting my hopes up": depression moderates the relationship of outcomes and reward anticipation. Psychiatr Res 2011, 194(3):393-395.

223. Osuch EA, Bluhm RL, Williamson PC, Theberge J, Densmore M, Neufeld RW: Brain activation to favorite music in healthy controls and depressed patients. Neuroreport 2009, 20(13):1204-1208.

224. Pizzagalli DA, Holmes AJ, Dillon DG, Goetz EL, Birk JL, Bogdan R, Dougherty DD, losifescu DV, Rauch SL, Fava M: Reduced caudate and nucleus accumbens response to rewards in unmedicated individuals with major depressive disorder. Am J Psychiatr 2009, 166(6):702-710.

225. Steele J, Kumar $P$, Ebmeier K: Blunted response to feedback information in depressive illness. Brain 2007, 130(9):2367.

226. Tremblay LK, Naranjo CA, Graham SJ, Herrmann N, Mayberg HS, Hevenor S, Busto UE: Functional neuroanatomical substrates of altered reward processing in major depressive disorder revealed by a dopaminergic probe. Arch Gen Psychiatr 2005, 62(11):1228.

227. Wacker J, Dillon DG, Pizzagalli DA: The role of the nucleus accumbens and rostral anterior cingulate cortex in anhedonia: Integration of resting EEG, fMRI, and volumetric techniques. Neuroimage 2009, 46(1):327-337.

228. Smoski MJ, Felder J, Bizzell J, Green SR, Ernst M, Lynch TR, Dichter GS: fMRI of alterations in reward selection, anticipation, and feedback in major depressive disorder. J Affect Disord 2009, 118(1-3):69-78.

229. Knutson B, Bhanji JP, Cooney RE, Atlas LY, Gotlib IH: Neural responses to monetary incentives in major depression. Biol Psychiatr 2008, 63(7):686-692.

230. Dichter GS, Felder JN, Petty C, Bizzell J, Ernst M, Smoski MJ: The effects of psychotherapy on neural responses to rewards in major depression. Biol Psychiatr 2009, 66(9):886-897.

231. Forbes EE, Ryan ND, Phillips ML, Manuck SB, Worthman CM, Moyles DL, Tarr JA, Sciarrillo SR, Dahl RE: Healthy adolescents' neural response to reward: associations with puberty, positive affect, and depressive symptoms. J Am Acad Child Adolesc Psychiatr 2010, 49(2):162-172.

232. Smoski MJ, Rittenberg A, Dichter GS: Major depressive disorder is characterized by greater reward network activation to monetary than pleasant image rewards. Psychiatr Res Neuroimaging 2011, 194(3):263-270

233. Alloy LB, Ambramson LY, Raniere D, Dyller IM: Research methods in adult psychopathology. In Handbook of Research Methods in Clinical Psychology. 2nd edition. Edited by Kendall PC, Butcher JN, Holmbeck GN. New York: Wiley; 1999:466-498.

234. Mednick SA, McNeil TF: Current methodology in research on the etiology of schizophrenia: serious difficulties which suggest the use of the highrisk-group method. Psychol Bull 1968, 70(6):681-693.

235. McCabe C, Cowen PJ, Harmer CJ: Neural representation of reward in recovered depressed patients. Psychopharmacol (Berl) 2009, 205(4):667-677. 
236. Dichter GS, Kozink RV, McClernon FJ, Smoski MJ: Remitted major depression is characterized by reward network hyperactivation during reward anticipation and hypoactivation during reward outcomes. J Affect Disord 2012, 136(3):1126-1134.

237. Kerestes R, Ladouceur CD, Meda S, Nathan PJ, Blumberg HP, Maloney K, Ruf B, Saricicek A, Pearlson GD, Bhagwagar Z, Phillips ML: Abnormal prefrontal activity subserving attentional control of emotion in remitted depressed patients during a working memory task with emotional distracters. Psychol Med 2012, 42:29-40.

238. McCabe C, Mishor Z, Cowen PJ, Harmer CJ: Diminished neural processing of aversive and rewarding stimuli during selective serotonin reuptake inhibitor treatment. Biol Psychiatr 2010, 67(5):439-445.

239. Etkin A, Egner $T$, Kalisch R: Emotional processing in anterior cingulate and medial prefrontal cortex. Trends Cognit Sci 2011, 15(2):85-93.

240. Liu X, Hairston J, Schrier M, Fan J: Common and distinct networks underlying reward valence and processing stages: a meta-analysis of functional neuroimaging studies. Neurosci Biobehav Rev 2011, 35(5): 1219-1236.

241. Wallis JD, Kennerley SW: Heterogeneous reward signals in prefrontal cortex. Curr Opin Neurobiol 2010, 20(2):191-198.

242. Ebert D, Feistel $H$, Barocka A: Effects of sleep deprivation on the limbic system and the frontal lobes in affective disorders: a study with Tc99 m-HMPAO SPECT. Psychiatr Res 1991, 40(4):247-251.

243. Ebert D, Feistel H, Kaschka W, Barocka A, Pirner A: Single photon emission computerized tomography assessment of cerebral dopamine D2 receptor blockade in depression before and after sleep deprivation-preliminary results. Biol Psychiatr 1994, 35(11):880-885

244. Wu J, Buchsbaum MS, Gillin JC, Tang C, Cadwell S, Wiegand M, Najafi A, Klein E, Hazen K, Bunney WE Jr, Fallon JH, Keator D: Prediction of antidepressant effects of sleep deprivation by metabolic rates in the ventral anterior cingulate and medial prefrontal cortex. Am J Psychiatr 1999, 156(8):1149-1158.

245. Wu JC, Gillin JC, Buchsbaum MS, Hershey T, Johnson JC, Bunney WE Jr: Effect of sleep deprivation on brain metabolism of depressed patients. Am J Psychiatr 1992, 149(4):538-543.

246. Brody AL, Saxena S, Mandelkern MA, Fairbanks LA, Ho ML, Baxter LR: Brain metabolic changes associated with symptom factor improvement in major depressive disorder. Biol Psychiatr 2001, 50(3):171-178.

247. Brody AL, Saxena S, Silverman DH, Alborzian S, Fairbanks LA, Phelps ME, Huang SC, Wu HM, Maidment K, Baxter LR Jr: Brain metabolic changes in major depressive disorder from pre- to post-treatment with paroxetine. Psychiatr Res 1999, 91(3):127-139.

248. Mayberg HS: Limbic-cortical dysregulation: a proposed model of depression. J Neuropsychiatr Clin Neurosci 1997, 9(3):471-481.

249. Mayberg HS, Brannan SK, Tekell JL, Silva JA, Mahurin RK, McGinnis S, Jerabek PA: Regional metabolic effects of fluoxetine in major depression: Serial changes and relationship to clinical response. Biol Psychiatr 2000, 48 (8):830-843.

250. Pizzagalli D, Pascual-Marqui RD, Nitschke JB, Oakes TR, Larson CL, Abercrombie HC, Schaefer SM, Koger JV, Benca RM, Davidson RJ: Anterior cingulate activity as a predictor of degree of treatment response in major depression: Evidence from brain electrical tomography analysis. Am J Psychiatr 2001, 158(3):405-415.

251. Kennedy SH, Evans KR, Kruger S, Mayberg HS, Meyer JH, McCann S, Arifuzzman Al, Houle S, Vaccarino FJ: Changes in regional brain glucose metabolism measured with positron emission tomography after paroxetine treatment of major depression. Am J Psychiatr 2001, 158 (6):899-905.

252. Smith GS, Reynolds CF 3rd, Pollock B, Derbyshire S, Nofzinger E, Dew MA, Houck PR, Milko D, Meltzer CC, Kupfer DJ: Cerebral glucose metabolic response to combined total sleep deprivation and antidepressant treatment in geriatric depression. Am J Psychiatr 1999, 156(5):683-689.

253. Lawrence NS, Williams AM, Surguladze S, Giampietro V, Brammer MJ, Andrew C, Frangou S, Ecker C, Phillips ML: Subcortical and ventral prefrontal cortical neural responses to facial expressions distinguish patients with bipolar disorder and major depression. Biol Psychiatr 2004, 55(6):578-587

254. Meyer JH, Ginovart N, Boovariwala A, Sagrati S, Hussey D, Garcia A, Young T, Praschak-Rieder N, Wilson AA, Houle S: Elevated monoamine oxidase a levels in the brain: An explanation for the monoamine imbalance of major depression. Arch Gen Psychiatr 2006, 63(11):1209-1216.
255. Meltzer CC, Price JC, Mathis CA, Greer PJ, Cantwell MN, Houck PR, Mulsant BH, Ben-Eliezer D, Lopresti B, DeKosky ST, Reynolds CF 3rd: PET imaging of serotonin type $2 \mathrm{~A}$ receptors in late-life neuropsychiatric disorders. Am $J$ Psychiatr 1999, 156(12):1871-1878.

256. Meyer JH, Kapur S, Houle S, DaSilva J, Owczarek B, Brown GM, Wilson AA, Kennedy SH: Prefrontal cortex 5-HT2 receptors in depression: An [18 F] setoperone PET imaging study. Am J Psychiatr 1999, 156(7):1029-1034.

257. D'Haenen HA, Bossuyt A: Dopamine D2 receptors in depression measured with single photon emission computed tomography. Biol Psychiatr 1994, 35(2):128-132.

258. Brunswick DJ, Amsterdam JD, Mozley PD, Newberg A: Greater availability of brain dopamine transporters in major depression shown by [99 $\mathrm{m} \mathrm{Tc}$ ] TRODAT-1 SPECT imaging. Am J Psychiatr 2003, 160(10):1836-1841.

259. Parsey RV, Oquendo MA, Zea-Ponce Y, Rodenhiser J, Kegeles LS, Pratap M, Cooper TB, Van Heertum R, Mann JJ, Laruelle M: Dopamine D(2) receptor availability and amphetamine-induced dopamine release in unipolar depression. Biol Psychiatr 2001, 50(5):313-322.

260. Meyer JH, McNeely HE, Sagrati S, Boovariwala A, Martin K, Verhoeff NP, Wilson AA, Houle S: Elevated putamen $\mathrm{D}(2)$ receptor binding potential in major depression with motor retardation: An [11 C]raclopride positron emission tomography study. Am J Psychiatr 2006, 163(9):1594-1602.

261. Meyer JH, Kruger S, Wilson AA, Christensen BK, Goulding VS, Schaffer A, Minifie C, Houle S, Hussey D, Kennedy SH: Lower dopamine transporter binding potential in striatum during depression. Neuroreport 2001, 12 (18):4121-4125.

262. Ebert D, Feistel H, Loew T, Pirner A: Dopamine and depression-striatal dopamine D2 receptor SPECT before and after antidepressant therapy. Psychopharmacol Berl 1996, 126(1):91-94.

263. Klimke A, Larisch R, Janz A, Vosberg H, Muller-Gartner HW, Gaebel W: Dopamine D2 receptor binding before and after treatment of major depression measured by [123I]IBZM SPECT. Psychiatr Res 1999, 90(2):91-101.

264. Perala J, Suvisaari J, Saarni SI, Kuoppasalmi K, Isometsa E, Pirkola S, Partonen T, Tuulio-Henriksson A, Hintikka J, Kieseppa T, Harkanen T, Koskinen S, Lonnqvist J: Lifetime prevalence of psychotic and bipolar I disorders in a general population. Arch Gen Psychiatr 2007, 64(1):19-28.

265. Gruber J: A review and synthesis of positive emotion and reward disturbance in bipolar disorder. Clin Psychol Psychother 2011, 18(5):356-365.

266. Johnson SL: Mania and dysregulation in goal pursuit: A review. Clin Psychol Rev 2005, 25(2):241-262.

267. Gorrindo T, Blair RJ, Budhani S, Dickstein DP, Pine DS, Leibenluft E: Deficits on a probabilistic response-reversal task in patients with pediatric bipolar disorder. Am J Psychiatr 2005, 162(10):1975-1977.

268. Farmer A, Lam D, Sahakian B, Roiser J, Burke A, O'Neill N, Keating S, Smith GP, McGuffin P: A pilot study of positive mood induction in euthymic bipolar subjects compared with healthy controls. Psychol Med 2006, 36 (9):1213-1218

269. Meyer B, Johnson S, Winters R: Responsiveness to threat and incentive in bipolar disorder: relations of the BIS/BAS scales with symptoms. $J$ Psychopathol Behav Assess 2001, 23(3):133-143.

270. Mueller SC, Ng P, Temple V, Hardin MG, Pine DS, Leibenluft E, Ernst M: Perturbed reward processing in pediatric bipolar disorder: An antisaccade study. J Psychopharmacol 2010, 24(12):1779.

271. Blumberg HP, Martin A, Kaufman J, Leung HC, Skudlarski P, Lacadie C, Fulbright RK, Gore JC, Charney DS, Krystal JH, Peterson BS: Frontostriatal abnormalities in adolescents with bipolar disorder: Preliminary observations from functional MRI. Am J Psychiatr 2003, 160(7):1345-1347.

272. Cerullo MA, Adler CM, Delbello MP, Strakowski SM: The functional neuroanatomy of bipolar disorder. Int Rev Psychiatr 2009, 21(4):314-322.

273. Marchand WR, Yurgelun-Todd D: Striatal structure and function in mood disorders: a comprehensive review. Bipolar Disord 2010, 12(8):764-785.

274. Strakowski SM, Delbello MP, Adler CM: The functional neuroanatomy of bipolar disorder: a review of neuroimaging findings. Mol Psychiatr 2005, 10(1):105-116

275. Yurgelun-Todd DA, Ross AJ: Functional magnetic resonance imaging studies in bipolar disorder. CNS Spectr 2006, 11(4):287-297.

276. Hwang J, Lyoo IK, Dager SR, Friedman SD, Oh JS, Lee JY, Kim SJ, Dunner DL, Renshaw PF: Basal ganglia shape alterations in Bipolar disorder. Am J Psychiatr 2006, 163(2):276-285.

277. Liu IY, Howe M, Garrett A, Karchemskiy A, Kelley R, Alegria D, Reiss A, Chang K: Striatal volumes in pediatric bipolar patients with and without comorbid ADHD. Psychiatr Res Neuroimaging 2011, 194(1):14-20. 
278. Strakowski SM, Adler CM, DelBello MP: Volumetric MRI studies of mood disorders: do they distinguish unipolar and bipolar disorder? Bipolar Disorder 2002, 4(2):80-88

279. Abler B, Greenhouse I, Ongur D, Walter H, Heckers S: Abnormal reward system activation in mania. Neuropsychopharmacology 2008, 33(9): 2217-2227.

280. Jogia J, Dima D, Kumari V, Frangou S: Frontopolar cortical inefficiency may underpin reward and working memory dysfunction in bipolar disorder. World J Biol Psychiatr 2011. http://informahealthcare.com/doi/abs/10.3109/ 15622975.2011.585662.

281. Miller R: Striatal dopamine in reward and attention: a system for understanding the symptomatology of acute schizophrenia and mania. Int Rev Neurobiol 1993, 35:161-278.

282. Suhara T, Nakayama K, Inoue O, Fukuda H, Shimizu M, Mori A, Tateno Y: D dopamine receptor binding in mood disorders measured by positron emission tomography. Psychopharmacol Berl 1992, 106(1):14-18.

283. Amsterdam JD, Newberg AB: A preliminary study of dopamine transporter binding in bipolar and unipolar depressed patients and healthy controls. Neuropsychobiology 2007, 55(3-4):167-170.

284. Chang TT, Yeh TL, Chiu NT, Chen PS, Huang HY, Yang YK, Lee IH, Lu RB: Higher striatal dopamine transporters in euthymic patients with bipolar disorder: A SPECT study with [TC] TRODAT-1. Bipolar Disord 2010, 12 (1):102-106.

285. Anand A, Barkay G, Dzemidzic M, Albrecht D, Karne H, Zheng QH, Hutchins GD, Normandin MD, Yoder KK: Striatal dopamine transporter availability in unmedicated bipolar disorder. Bipolar Disord 2011, 13(4):406-413.

286. Pearlson GD, Wong DF, Tune LE, Ross CA, Chase GA, Links JM, Dannals RF, Wilson AA, Ravert HT, Wagner HN Jr, et al: In vivo D2 dopamine receptor density in psychotic and nonpsychotic patients with bipolar disorder. Arch Gen Psychiatr 1995, 52(6):471-477.

287. Wong DF, Pearlson GD, Tune LE, Young LT, Meltzer CC, Dannals RF, Ravert HT, Reith J, Kuhar MJ, Gjedde A: Quantification of neuroreceptors in the living human brain: IV. Effect of aging and elevations of D2-like receptors in schizophrenia and bipolar illness. J Cerebr Blood Metabol 1997, 17(3):331-342

288. Anand A, Verhoeff $P$, Seneca N, Zoghbi SS, Seibyl JP, Charney DS, Innis RB: Brain SPECT imaging of amphetamine-induced dopamine release in euthymic bipolar disorder patients. Am J Psychiatr 2000, 157(7):1108-1114.

289. Yatham LN, Liddle PF, Shiah IS, Lam RW, Ngan E, Scarrow G, Imperial M, Stoessl J, Sossi V, Ruth TJ: PET study of [(18)F]6-fluoro-L-dopa uptake in neuroleptic- and mood-stabilizer-naive first-episode nonpsychotic mania: effects of treatment with divalproex sodium. Am J Psychiatr 2002, 159 (5):768-774.

290. Thase ME, Haight BR, Richard N, Rockett CB, Mitton M, Modell JG, VanMeter S, Harriett AE, Wang Y: Remission rates following antidepressant therapy with bupropion or selective serotonin reuptake inhibitors: $A$ meta-analysis of original data from 7 randomized controlled trials. $J$ Clin Psychiatr 2005, 66(8):974-981.

291. Dichter GS, Tomarken AJ, Shelton RC, Freid C, Addington S: Effects of Bupropion SR on dimensions of mood. New Orleans, Louisiana: Poster presented at the annual meeting of The American Psychiatric Association; 2001.

292. Ostow M: Pramipexole for depression. Am J Psychiatr 2002, 159(2):320-321.

293. Post RM, Gerner RH, Carman JS, Gillin JC, Jimerson DC, Goodwin FK, Bunney WE Jr: Effects of a dopamine agonist piribedil in depressed patients: Relationship of pretreatment homovanillic acid to antidepressant response. Arch Gen Psychiatr 1978, 35(5):609-615.

294. Moroz G, Magni G, Fava M: Update on "open study of the catechol-Omethyltransferase inhibitor tolcapone in major depressive disorder". Clin Psychopharmacol 2000, 20(2):285.

295. Montgomery SA: Dopaminergic deficit and the role of amisulpride in the treatment of mood disorders. Int Clin Psychopharmacol 2002, 17(Suppl 4): discussion S16-17.

296. Corrigan MH, Denahan AQ, Wright CE, Ragual RJ, Evans DL: Comparison of pramipexole, fluoxetine, and placebo in patients with major depression. Depress Anxiety 2000, 11(2):58-65.

297. Weihs KL, Settle EC Jr, Batey SR, Houser TL, Donahue RM, Ascher JA: Bupropion sustained release versus paroxetine for the treatment of depression in the elderly. J Clin Psychiatr 2000, 61(3):196-202.

298. Bodkin JA, Lasser RA, Wines JD Jr, Gardner DM, Baldessarini RJ: Combining serotonin reuptake inhibitors and bupropion in partial responders to antidepressant monotherapy. J Clin Psychiatr 1997, 58 (4):137-145

299. Jamerson BD, Krishnan KR, Roberts J, Krishen A, Modell JG: Effect of bupropion SR on specific symptom clusters of depression: Analysis of the 31-item Hamilton Rating Scale for depression. Psychopharmacol Bull 2003, 37(2):67-78

300. Tomarken AJ, Dichter GS, Freid C, Addington S, Shelton RC: Assessing the effects of Bupropion SR on mood dimensions of depression. J Affect Disord 2004, 78(3):235-241.

301. Zhou QY, Palmiter RD: Dopamine-deficient mice are severely hypoactive, adipsic, and aphagic. Cell 1995, 83(7):1197-1209.

302. Szczypka MS, Mandel RJ, Donahue BA, Snyder RO, Leff SE, Palmiter RD: Viral gene delivery selectively restores feeding and prevents lethality of dopamine-deficient mice. Neuron 1999, 22(1):167-178.

303. Szczypka MS, Rainey MA, Kim DS, Alaynick WA, Marck BT, Matsumoto AM, Palmiter RD: Feeding behavior in dopamine-deficient mice. Proc Natl Acad Sci 1999, 96(21):12138-12143.

304. Szczypka MS, Kwok K, Brot MD, Marck BT, Matsumoto AM, Donahue BA, Palmiter RD: Dopamine production in the caudate putamen restores feeding in dopamine-deficient mice. Neuron 2001, 30(3):819-828.

305. Szczypka MS, Rainey MA, Palmiter RD: Dopamine is required for hyperphagia in Lep(ob/ob) mice. Nat Genet 2000, 25(1):102-104.

306. Kelley AE: Functional specificity of ventral striatal compartments in appetitive behaviors. Ann N Y Acad Sci 1999, 877:71-90.

307. Koob GF: Drugs of abuse: anatomy, pharmacology and function of reward pathways. Trends Pharmacol Sci 1992, 13(5):177-184.

308. Phillips AG, Atkinson LJ, Blackburn JR, Blaha CD: Increased extracellular dopamine in the nucleus accumbens of the rat elicited by a conditional stimulus for food: an electrochemical study. Can J Physiol Pharmacol 1993, 71(5-6):387-393.

309. Schultz W, Dickinson A: Neuronal coding of prediction errors. Annu Rev Neurosci 2000, 23:473-500.

310. Wilson C, Nomikos GG, Collu M, Fibiger HC: Dopaminergic correlates of motivated behavior: importance of drive. J Neurosci 1995, 15(7 Pt 2): 5169-5178.

311. Phillips GD, Robbins TW, Everitt BJ: Bilateral intra-accumbens selfadministration of $d$-amphetamine: antagonism with intra-accumbens SCH-23390 and sulpiride. Psychopharmacol Berl 1994, 114(3):477-485.

312. Pecina $S$, Berridge KC: Opioid site in nucleus accumbens shell mediates eating and hedonic 'liking' for food: Map based on microinjection Fos plumes. Brain Res 2000, 863(1-2):71-86.

313. Stratford TR, Kelley AE: GABA in the nucleus accumbens shell participates in the central regulation of feeding behavior. J Neurosci 1997, 17 (11):4434-4440.

314. White NM: Control of sensorimotor function by dopaminergic nigrostriatal neurons: influence on eating and drinking. Neurosci Biobehav Rev 1986, 10(1):15-36.

315. Zigmond MJ, Stricker EM: Deficits in feeding behavior after intraventricular injection of 6-hydroxydopamine in rats. Science 1972, 177(4055):1211-1214

316. Fairburn CG, Harrison PJ: Eating disorders. Lancet 2003, 361(9355):407-416.

317. Volkow ND, Wang GJ, Fowler JS, Telang F: Overlapping neuronal circuits in addiction and obesity: evidence of systems pathology. Philosophical Transactions of the Royal Society of London. Ser B Biol Sci 2008, 363 (1507):3191-3200.

318. Hoebel BG, Hernandez L, Schwartz DH, Mark GP, Hunter GA: Microdialysis studies of brain norepinephrine, serotonin, and dopamine release during ingestive behavior. Theoretical and clinical implications. Ann N Y Acad Sci 1989, 575:171-191.

319. Broft Al, Berner LA, Martinez D, Walsh BT: Bulimia nervosa and evidence for striatal dopamine dysregulation: a conceptual review. Physiol Behav 2011, 104(1):122-127.

320. Huebner HF: Endorphins, Eating Disorders, and Other Addictive Behaviors. 1st edition. New York: Norton; 1993.

321. Joos AAB, Saum B, van Elst LT, Perlov E, Glauche V, Hartmann A, Freyer T, Tüscher $O$, Zeeck $A$ : Amygdala hyperreactivity in restrictive anorexia nervosa. Psychiatr Res Neuroimaging 2011, 191(3):189-195.

322. Bohon C, Stice E: Reward abnormalities among women with full and subthreshold bulimia nervosa: a functional magnetic resonance imaging study. Int J Eat Disord 2011, 44(7):585-595.

323. Wagner A, Aizenstein H, Venkatraman VK, Bischoff-Grethe A, Fudge J, May JC, Frank GK, Bailer UF, Fischer L, Putnam K, Kaye WH: Altered striatal 
response to reward in bulimia nervosa after recovery. Int J Eat Disord 2010, 43(4):289-294.

324. Frank GK, Wagner A, Achenbach S, McConaha C, Skovira K, Aizenstein H, Carter CS, Kaye WH: Altered brain activity in women recovered from bulimic-type eating disorders after a glucose challenge: a pilot study. Int J Eat Disord 2006, 39(1):76-79.

325. Uher R, Murphy T, Brammer MJ, Dalgleish T, Phillips ML, Ng WW, Andrew CM, Williams SCR, Campbell IC, Treasure J: Medial prefrontal cortex activity associated with symptom provocation in eating disorders. Am J Psychiatr 2004, 161(7):1238-1246.

326. Schienle A, Schafer A, Hermann A, Vaitl D: Binge-eating disorder: Reward sensitivity and brain activation to images of food. Biol Psychiatr 2009, 65 (8):654-661.

327. Brooks SJ, Owen G, Uher R, Friederich HC, Giampietro V, Brammer M, Williams SCR, Schiöth HB, Treasure J, Campbell IC: Differential neural responses to food images in women with bulimia versus Anorexia Nervosa. PLoS One 2011, 6(7):e22259.

328. Davis C, Levitan RD, Kaplan AS, Carter J, Reid C, Curtis C, Patte K, Kennedy $J$ L: Dopamine transporter gene (DAT1) associated with appetite suppression to methylphenidate in a case-control study of binge eating disorder. Neuropsychopharmacology 2007, 32(10):2199-2206.

329. Kaplan AS, Levitan RD, Yilmaz Z, Davis C, Tharmalingam S, Kennedy JL: A DRD4/BDNF gene-gene interaction associated with maximum $B M I$ in women with bulimia nervosa. Int J Eat Disord 2008, 41(1):22-28.

330. Nisoli E, Brunani A, Borgomainerio E, Tonello C, Dioni L, Briscini L, Redaelli G, Molinari E, Cavagnini F, Carruba MO: D2 dopamine receptor (DRD2) gene Taq1A polymorphism and the eating-related psychological traits in eating disorders (Anorexia Nervosa and Bulimia) and obesity. Eat Weight Disord 2007, 12(2):91-96.

331. Tauscher J, Pirker W, Willeit M, de Zwaan M, Bailer U, Neumeister A, Asenbaum S, Lennkh C, Praschak-Rieder N, Brucke T, Kasper S: [123I] beta-CIT and single photon emission computed tomography reveal reduced brain serotonin transporter availability in bulimia nervosa. Biol Psychiatr 2001, 49(4):326-332

332. Alexander W: Prozac wins new indication for bulimia nervosa. Drug Topics 1997, 141(6):34.

333. Jackson CW, Cates M, Lorenz R: Pharmacotherapy of eating disorders. Nutr Clin Pract 2010, 25(2):143-159.

334. Watson KK, Werling DM, Zucker NL, Platt ML: Altered social reward and attention in anorexia nervosa. Front Psychol 2010, 1:36.

335. Kringelbach ML, O'Doherty J, Rolls ET, Andrews C: Activation of the human orbitofrontal cortex to a liquid food stimulus is correlated with its subjective pleasantness. Cerebr Cortex 2003, 13(10):1064-1071.

336. O'Doherty J, Winston J, Critchley H, Perrett D, Burt DM, Dolan RJ: Beauty in a smile: The role of medial orbitofrontal cortex in facial attractiveness. Neuropsychologia 2003, 41(2):147-155.

337. Zucker NL, Losh M, Bulik CM, LaBar KS, Piven J, Pelphrey KA: Anorexia nervosa and autism spectrum disorders: guided investigation of social cognitive endophenotypes. Psychol Bull 2007, 133(6):976-1006.

338. Jappe LM, Frank GKW, Shott ME, Rollin MDH, Pryor T, Hagman JO, Yang TT, Davis E: Heightened sensitivity to reward and punishment in anorexia nervosa. Int J Eat Disord 2011, 44(4):317-324.

339. Fladung AK, Gron G, Grammer K, Herrnberger B, Schilly E, Grasteit S, Wolf $\mathrm{RC}$, Walter $\mathrm{H}$, von Wietersheim J: A neural signature of anorexia nervosa in the ventral striatal reward system. Am J Psychiatr 2010, 167(2):206-212.

340. Joos AAB, Saum B, Zeeck A, Perlov E, Glauche V, Hartmann A, Freyer T, Sandholz A, Unterbrink T, van Elst LT, Tüscher O: Frontocingular dysfunction in Bulimia Nervosa when confronted with disease-specific stimuli. Eur Eat Disord Rev 2011, 19(5):447-453.

341. Wagner A, Aizenstein H, Venkatraman VK, Fudge J, May JC, Mazurkewicz L, Frank GK, Bailer UF, Fischer L, Nguyen V, Carter C, Putnam K, Kaye WH: Altered reward processing in women recovered from anorexia nervosa. Am J Psychiatr 2007, 164(12):1842-1849.

342. Burger KS, Stice E: Relation of dietary restraint scores to activation of reward-related brain regions in response to food intake, anticipated intake, and food pictures. Neuroimage 2011, 55(1):233-239.

343. Frank GK, Bailer UF, Henry SE, Drevets W, Meltzer CC, Price JC, Mathis CA, Wagner A, Hoge J, Ziolko S, Barbarich-Marsteller N, Weissfeld L, Kaye WH: Increased dopamine D2/D3 receptor binding after recovery from anorexia nervosa measured by positron emission tomography and [11c] raclopride. Biol Psychiatr 2005, 58(11):908-912.
344. Bergen AW, Yeager M, Welch RA, Haque K, Ganjei JK, van den Bree MB, Mazzanti C, Nardi I, Fichter MM, Halmi KA, Kaplan AS, Strober M, Treasure J, Woodside DB, Bulik CM, Bacanu SA, Devlin B, Berrettini WH, Goldman D, Kaye WH: Association of multiple DRD2 polymorphisms with anorexia nervosa. Neuropsychopharmacology 2005, 30(9):1703-1710.

345. Brambilla F, Garcia CS, Fassino S, Daga GA, Favaro A, Santonastaso P, Ramaciotti C, Bondi E, Mellado C, Borriello R, Monteleone P: Olanzapine therapy in anorexia nervosa: Psychobiological effects. Int Clin Psychopharmacol 2007, 22(4):197-204.

346. Brambilla F, Monteleone P, Maj M: Olanzapine-induced weight gain in anorexia nervosa: Involvement of leptin and ghrelin secretion? Psychoneuroendocrinology 2007, 32(4):402-406.

347. Mondraty N, Birmingham CL, Touyz S, Sundakov V, Chapman L, Beumont P: Randomized controlled trial of olanzapine in the treatment of cognitions in anorexia nervosa. Aust New Zeal J Psychiatr 2005, 13(1):72-75.

348. McGrath J, Saha S, Chant D, Welham J: Schizophrenia: A concise overview of incidence, prevalence, and mortality. Epidemiol Rev 2008, 30:67-76.

349. Blanchard JJ, Mueser KT, Bellack AS: Anhedonia, positive and negative affect, and social functioning in schizophrenia. Schizophr Bull 1998, 24 (3):413-424

350. Meehl P: Schizotaxia, schizotypy, and schizophrenia. Am Psychol 1962, $17: 827-838$

351. Rado S: Psychoanalysis of Behavior: The Collected Papers of Sandor Rado (Vol 2). New York: Grune \& Stratton; 1962.

352. Kwapil TR: Social anhedonia as a predictor of the development of schizophrenia-spectrum disorders. J Abnorm Psychol 1998, 107(4):558-565.

353. Broome MR, Woolley JB, Tabraham P, Johns LC, Bramon E, Murray GK, Pariante C, McGuire PK, Murray RM: What causes the onset of psychosis? Schizophr Res 2005, 79(1):23-34.

354. Abi-Dargham A, Rodenhiser J, Printz D, Zea-Ponce Y, Gil R, Kegeles LS, Weiss R, Cooper TB, Mann JJ, Van Heertum RL, Gorman JM, Laruelle M: Increased baseline occupancy of D2 receptors by dopamine in schizophrenia. Proc Natl Acad Sci 2000, 97(14):8104-8109.

355. Stone JM, Morrison PD, Pilowsky LS: Glutamate and dopamine dysregulation in schizophrenia-a synthesis and selective review. J Psychopharmacol 2007, 21(4):440-452.

356. Ziauddeen $H$, Murray GK: The relevance of reward pathways for schizophrenia. Curr Opin Psychiatr 2010, 23(2):91-96.

357. Meltzer HY, Stahl SM: The dopamine hypothesis of schizophrenia: A review. Schizophr Bull 1976, 2(1):19-76.

358. Creese I, Burt DR, Snyder SH: Dopamine receptor binding predicts clinical and pharmacological potencies of antischizophrenic drugs. Science 1976, 192(4238):481-483.

359. Allen JA, Roth BL: Strategies to discover unexpected targets for drugs active at G protein-coupled receptors. Annu Rev Pharmacol Toxicol 2011, 51:117-144.

360. Roth BL, Sheffler DJ, Kroeze WK: Magic shotguns versus magic bullets: Selectively non-selective drugs for mood disorders and schizophrenia. Nat Rev Drug Discov 2004, 3(4):353-359.

361. Gejman PV, Sanders AR, Kendler KS: Genetics of schizophrenia: new findings and challenges. Annu Rev Genom Hum Genet 2011, 12:121-144.

362. Allen JA, Yadav PN, Setola V, Farrell M, Roth BL: Schizophrenia risk gene CAV1 is both pro-psychotic and required for atypical antipsychotic drug actions in vivo. Translational Psychiatr 2011, 1:e33.

363. Brandon NJ, Millar JK, Korth C, Sive H, Singh KK, Sawa A: Understanding the role of DISC1 in psychiatric disease and during normal development. J Neurosci 2009, 29(41):12768-12775.

364. Marder SR, Roth B, Sullivan PF, Scolnick EM, Nestler EJ, Geyer MA, Welnberger DR, Karayiorgou M, Guidotti A, Gingrich J, Akbarian S, Buchanan RW, Lieberman JA, Conn PJ, Haggarty SJ, Law AJ, Campbell B, Krystal JH, Moghaddam B, Saw A, Caron MG, George SR, Allen JA, Solis M: Advancing drug discovery for schizophrenia. Ann N Y Acad Sci 2011, 1236 (1):30-43.

365. Powell SB, Zhou X, Geyer MA: Prepulse inhibition and genetic mouse models of schizophrenia. Behav Brain Res 2009, 204(2):282-294.

366. Geyer MA, Krebs-Thomson K, Braff DL, Swerdlow NR: Pharmacological studies of prepulse inhibition models of sensorimotor gating deficits in schizophrenia: A decade in review. Psychopharmacol (Berl) 2001, 156(2-3) 117-154.

367. Braff DL, Geyer MA, Light GA, Sprock J, Perry W, Cadenhead KS, Swerdlow NR: Impact of prepulse characteristics on the detection of sensorimotor gating deficits in schizophrenia. Schizophr Res 2001, 49(1-2):171-178. 
368. Swerdlow NR, Weber M, Qu Y, Light GA, Braff DL: Realistic expectations of prepulse inhibition in translational models for schizophrenia research. Psychopharmacol Berl 2008, 199(3):331-388.

369. Ralph-Williams RJ, Lehmann-Masten V, Geyer MA: Dopamine D1 rather than D2 receptor agonists disrupt prepulse inhibition of startle in mice. Neuropsychopharmacology 2003, 28(1):108-118.

370. Ralph RJ, Varty GB, Kelly MA, Wang YM, Caron MG, Rubinstein M, Grandy DK, Low MJ, Geyer MA: The dopamine D2, but not D3 or D4, receptor subtype is essential for the disruption of prepulse inhibition produced by amphetamine in mice. J Neurosci 1999, 19(11):4627-4633.

371. Kozikowski AP, Cho SJ, Jensen NH, Allen JA, Svennebring AM, Roth BL: HTS and rational drug design to generate a class of 5-HT(2 C)-selective ligands for possible use in schizophrenia. ChemMedChem 2010, 5(8):1221-1225.

372. Castagne V, Moser PC, Porsolt RD: Preclinical behavioral models for predicting antipsychotic activity. Adv Pharmacol 2009, 57:381-418.

373. Giros B, Jaber M, Jones SR, Wightman RM, Caron MG: Hyperlocomotion and indifference to cocaine and amphetamine in mice lacking the dopamine transporter. Nature 1996, 379(6566):606-612.

374. Gainetdinov RR, Wetsel WC, Jones SR, Levin ED, Jaber M, Caron MG: Role of serotonin in the paradoxical calming effect of psychostimulants on hyperactivity. Science 1999, 283(5400):397-401.

375. Barr AM, Lehmann-Masten V, Paulus M, Gainetdinov RR, Caron MG, Geyer MA: The selective serotonin-2A receptor antagonist M100907 reverses behavioral deficits in dopamine transporter knockout mice. Neuropsychopharmacology 2004, 29(2):221-228.

376. Ralph RJ, Paulus MP, Fumagalli F, Caron MG, Geyer MA: Prepulse inhibition deficits and perseverative motor patterns in dopamine transporter knock-out mice: differential effects of D1 and D2 receptor antagonists. J Neurosci 2001, 21(1):305-313.

377. Powell SB, Young JW, Ong JC, Caron MG, Geyer MA: Atypical antipsychotics clozapine and quetiapine attenuate prepulse inhibition deficits in dopamine transporter knockout mice. Behav Pharmacol 2008, 19(5-6):562-565.

378. Yamashita M, Fukushima S, Shen HW, Hall FS, Uhl GR, Numachi Y, Kobayashi $H$, Sora I: Norepinephrine transporter blockade can normalize the prepulse inhibition deficits found in dopamine transporter knockout mice. Neuropsychopharmacology 2006, 31(10):2132-2139.

379. Li YC, Kellendonk C, Simpson EH, Kandel ER, Gao WJ: D2 receptor overexpression in the striatum leads to a deficit in inhibitory transmission and dopamine sensitivity in mouse prefrontal cortex. Proc Natl Acad Sci 2011, 108(29):12107-12112.

380. Kellendonk C: Modeling excess striatal D2 receptors in mice. Progr Brain Res 2009, 179:59-65.

381. Simpson EH, Kellendonk C, Kandel E: A possible role for the striatum in the pathogenesis of the cognitive symptoms of schizophrenia. Neuron 2010, 65(5):585-596

382. Kellendonk C, Simpson EH, Kandel ER: Modeling cognitive endophenotypes of schizophrenia in mice. Trends Neurosci 2009, 32 (6):347-358.

383. Maia TV, Frank MJ: From reinforcement learning models to psychiatric and neurological disorders. Nat Neurosci 2011, 14(2):154-162

384. Ward RD, Simpson EH, Kandel ER, Balsam PD: Modeling motivational deficits in mouse models of schizophrenia: Behavior analysis as a guide for neuroscience. Behav Process 2011, 87(1):149-156.

385. Young JW, Zhou X, Geyer MA: Animal models of schizophrenia. Curr Top Behav Neurosci 2010, 4:391-433.

386. Trémeau F, Antonius D, Cacioppo JT, Ziwich R, Butler P, Malaspina D, Javitt DC: Anticipated, on-line and remembered positive experience in schizophrenia. Schizophr Res 2009, 122(1-3):199-205.

387. Earnst KS, Kring AM: Emotional responding in deficit and non-deficit schizophrenia. Psychiatr Res 1999, 88(3):191-207.

388. Berenbaum H, Oltmanns TF: Emotional experience and expression in schizophrenia and depression. J Abnorm Psychol 1992, 101(1):37-44.

389. Aghevli MA, Blanchard JJ, Horan WP: The expression and experience of emotion in schizophrenia: A study of social interactions. Psychiatr Res 2003, 119(3):261-270.

390. Kring AM, Moran EK: Emotional response deficits in schizophrenia: Insights from affective science. Schizophr Bull 2008, 34(5):819-834.

391. Trémeau F: A review of emotion deficits in schizophrenia. Dialogues Clin Neurosci 2006, 8(1):59-70.
392. Cohen AS, Minor KS: Emotional experience in patients with schizophrenia revisited: Meta-analysis of laboratory studies. Schizophr Bull 2008, 36 (1):143-150.

393. Kring AM, Kerr SL, Smith DA, Neale JM: Flat affect in schizophrenia does not reflect diminished subjective experience of emotion. J Abnorm Psychol 1993, 102(4):507-517.

394. Burbridge JA, Barch DM: Anhedonia and the experience of emotion in individuals with schizophrenia. J Abnorm Psychol 2007, 116(1):30-42.

395. Berlin I, Givry-Steiner L, Lecrubier Y, Puech AJ: Measures of anhedonia and hedonic responses to sucrose in depressive and schizophrenic patients in comparison with healthy subjects. Eur Psychiatr 1998, 13(6):303-309.

396. Schneider F, Habel U, Reske M, Toni I, Falkai P, Shah NJ: Neural substrates of olfactory processing in schizophrenia patients and their healthy relatives. Psychiatr Res 2007, 155(2):103-112.

397. Earnst KS, Kring AM, Kadar MA, Salem JE, Shepard DA, Loosen PT: Facial expression in schizophrenia. Biol Psychiatr 1996, 40(6):556-558.

398. Kring AM, Kerr SL, Earnst KS: Schizophrenic patients show facial reactions to emotional facial expressions. Psychophysiology 1999, 36(2):186-192.

399. Kring AM, Neale JM: Do schizophrenic patients show a disjunctive relationship among expressive, experiential, and psychophysiological components of emotion? J Abnorm Psychol 1996, 105(2):249-257.

400. Venables PH, Wing JK: Level of arousal and the subclassification of schizophrenia. Arch Gen Psychiatr 1962, 7:114-119.

401. Curtis CE, Lebow B, Lake DS, Katsanis J, lacono WG: Acoustic startle reflex in schizophrenia patients and their first-degree relatives: evidence of normal emotional modulation. Psychophysiology 1999, 36(4):469-475.

402. Schlenker R, Cohen R, Hopmann G: Affective modulation of the startle reflex in Schizophrenic patients. Eur Arch Psychiatr Clin Neurosci 1995, 245 (6):309-318.

403. Chan RCK, Wang Y, Huang J, Shi Y, Hong X, Ma Z, Li Z, Lai M, Kring AM: Anticipatory and consummatory components of the experience of pleasure in schizophrenia: Cross-cultural validation and extension. Psychiatr Res 2010, 175(1-2):181-183.

404. Gard DE, Kring AM, Gard MG, Horan WP, Green MF: Anhedonia in schizophrenia: distinctions between anticipatory and consummatory pleasure. Schizophr Res 2007, 93(1-3):253-260.

405. Loas G, Monestes JL, Ameller A, Bubrovszky M, Yon V, Wallier J, Berthoz S, Corcos M, Thomas P, Gard D, Loas G, Monestes JL, Ameller A, Bubrovszky M, Yon V, Wallier J, Berthoz S, Corcos M, Thomas P, Gard D: Traduction et étude de validation de la version française de l'échelle d'expérience temporelle du plaisir (EETP, Temporal Experience of Pleasure Scale [TEPS], Gard et al., 2006): étude chez 125 étudiants et chez 162 sujets présentant un trouble psychiatrique. Traduction et étude de validation 2009, 167(9):641-648.

406. Waltz JA, Frank MJ, Wiecki TV, Gold JM: Altered probabilistic learning and response biases in schizophrenia: Behavioral evidence and neurocomputational modeling. Neuropsychology 2011, 25(1):86

407. Wynn JK, Horan WP, Kring AM, Simons RF, Green MF: Impaired anticipatory event-related potentials in schizophrenia. Int J Psychophysiol 2010, 77 (2):141-149.

408. Strauss GP, Wilbur RC, Warren KR, August SM, Gold JM: Anticipatory vs. consummatory pleasure: What is the nature of hedonic deficits in schizophrenia? Psychiatr Res 2011, 187(1-2):36-41.

409. Elliott R, McKenna PJ, Robbins TW, Sahakian BJ: Neuropsychological evidence for frontostriatal dysfunction in schizophrenia. Psychol Med 1995, 25(3):619-630.

410. Gold JM, Waltz JA, Prentice KJ, Morris SE, Heerey EA: Reward processing in schizophrenia: a deficit in the representation of value. Schizophr Bull 2008, 34(5):835.

411. Koch K, Schachtzabel C, Wagner G, Schikora J, Schultz C, Reichenbach JR, Sauer H, Schlösser RGM: Altered activation in association with rewardrelated trial-and-error learning in patients with schizophrenia. Neuroimage 2010, 50(1):223-232.

412. Strauss MM, Makris N, Aharon I, Vangel MG, Goodman J, Kennedy DN, Gasic GP, Breiter HC: fMRI of sensitization to angry faces. Neuroimage 2005, 26 (2):389-413.

413. Waltz JA, Gold JM: Probabilistic reversal learning impairments in schizophrenia: Further evidence of orbitofrontal dysfunction. Schizophr Res 2007, 93(1-3):296-303.

414. Somlai Z, Moustafa AA, Kéri S, Myers CE, Gluck MA: General functioning predicts reward and punishment learning in schizophrenia. Schizophr Res 2011, 127(1-3):131-136. 
415. Yarkoni T, Gray JR, Chrastil ER, Barch DM, Green L, Braver TS: Sustained neural activity associated with cognitive control during temporally extended decision making. Brain Res Cognit Brain Res 2005, 23(1):71-84.

416. Simon JJ, Biller A, Walther S, Roesch-Ely D, Stippich C, Weisbrod M, Kaiser S Neural correlates of reward processing in schizophrenia-Relationship to apathy and depression. Schizophr Res 2009, 118(1-3):154-161.

417. Juckel G, Schlagenhauf F, Koslowski M, Filonov D, Wustenberg T, Villringer A, Knutson B, Kienast T, Gallinat J, Wrase J, Heinz A: Dysfunction of ventral striatal reward prediction in schizophrenic patients treated with typical, not atypical, neuroleptics. Psychopharmacol Berl 2006, 187(2):222-228.

418. Kirsch P, Ronshausen S, Mier D, Gallhofer B: The influence of antipsychotic treatment on brain reward system reactivity in Schizophrenia patients. Pharmacopsychiatry 2007, 40(5):196-198.

419. Waltz JA, Schweitzer JB, Gold JM, Kurup PK, Ross TJ, Salmeron BJ, Rose EJ, McClure SM, Stein EA: Patients with schizophrenia have a reduced neural response to both unpredictable and predictable primary reinforcers. Neuropsychopharmacology 2009, 34(6):1567-1577.

420. Waltz JA, Schweitzer JB, Ross TJ, Kurup PK, Salmeron BJ, Rose EJ, Gold JM, Stein EA: Abnormal responses to monetary outcomes in cortex, but not in the basal ganglia, in schizophrenia. Neuropsychopharmacology 2010, 35:2427-2439.

421. Morris R, Vercammen A, Lenroot R, Moore L, Langton J, Short B, Kulkarni J, Curtis J, O'Donnell M, Weickert C: Disambiguating ventral striatum fMRIrelated bold signal during reward prediction in schizophrenia. $\mathrm{Mol}$ Psychiatr 2011, 17:280-289.

422. Juckel G, Schlagenhauf F, Koslowski M, Wustenberg T, Villringer A, Knutson $B$, Wrase J, Heinz A: Dysfunction of ventral striatal reward prediction in schizophrenia. Neuroimage 2006, 29(2):409-416.

423. Schlagenhauf F, Juckel G, Koslowski M, Kahnt T, Knutson B, Dembler T, Kienast T, Gallinat J, Wrase J, Heinz A: Reward system activation in schizophrenic patients switched from typical neuroleptics to olanzapine. Psychopharmacol Berl 2008, 196(4):673-684.

424. Grimm O, Vollstadt-Klein S, Krebs L, Zink M, Smolka MN: Reduced striatal activation during reward anticipation due to appetite-provoking cues in chronic schizophrenia: A fMRI study. Schizophr Res 2011, 134(2-3):151-157.

425. Kegeles LS, Abi-Dargham A, Frankle WG, Gil R, Cooper TB, Slifstein M, Hwang D-R, Huang Y, Haber SN, Laruelle M: Increased synaptic dopamine function in associative regions of the striatum in schizophrenia. Arch Gen Psychiatr 2010, 67(3):231-239

426. Lieberman JA: Understanding the mechanism of action of atypical antipsychotic drugs. A review of compounds in use and development. $\mathrm{Br}$ J Psychiatr 1993, 22:7-18. Suppl.

427. Mailman RB, Murthy $\mathrm{V}$ : Third generation antipsychotic drugs: partial agonism or receptor functional selectivity? Curr Pharm Des 2010, 16 (5):488-501.

428. Stahl SM: Dopamine system stabilizers, aripiprazole, and the next generation of antipsychotics, part 1, "Goldilocks" actions at dopamine receptors. J Clin Psychiatr 2001, 62(11):841-842.

429. Froehlich TE, Lanphear BP, Epstein JN, Barbaresi WJ, Katusic SK, Kahn RS: Prevalence, recognition, and treatment of attention-deficit/hyperactivity disorder in a national sample of US children. Arch Pediatr Adolesc Med 2007, 161(9):857-864.

430. Kessler RC, Adler L, Barkley R, Biederman J, Conners CK, Demler O, Faraone SV, Greenhill LL, Howes MJ, Secnik K, Spencer T, Ustun TB, Walters EE, Zaslavsky AM: The prevalence and correlates of adult ADHD in the United States: results from the National Comorbidity Survey Replication. Am J Psychiatr 2006, 163(4):716-723.

431. Visser SN, Lesesne CA, Perou R: National estimates and factors associated with medication treatment for childhood Attention-Deficit/Hyperactivity disorder. Pediatrics 2007, 119(Suppl 1):S99-S106.

432. Spencer TJ, Biederman J, Mick E: Attention-deficit/hyperactivity disorder: Diagnosis, lifespan, comorbidities, and neurobiology. J Pediatr Psychol 2007, 32(6):631-642.

433. Biederman J, Faraone SV: Attention-deficit hyperactivity disorder. Lancet 2005, 366(9481):237-248.

434. Donnelly M, Haby MM, Carter R, Andrews G, Vos T: Cost-effectiveness of dexamphetamine and methylphenidate for the treatment of childhood attention deficit hyperactivity disorder. Aust New Zeal J Psychiatr 2004, 38 (8):592-601.

435. Secnik K, Swensen A, Lage MJ: Comorbidities and costs of adult patients diagnosed with attention-deficit hyperactivity disorder.

Pharmacoeconomics 2005, 23(1):93-102.
436. Taylor E, Chadwick O, Heptinstall E, Danckaerts M: Hyperactivity and conduct problems as risk factors for adolescent development. J Am Acad Adolesc Psychiatr 1996, 35(9):1213-1226.

437. Sagvolden T, Johansen EB, Aase H, Russell VA: A dynamic developmental theory of attention-deficit/hyperactivity disorder (ADHD) predominantly hyperactive/impulsive and combined subtypes. Behav Brain Sci 2005, 28 (3):397-418.

438. Tripp G, Wickens JR: Research review: Dopamine transfer deficit: a neurobiological theory of altered reinforcement mechanisms in ADHD. J Child Psychol Psychiatr 2008, 49(7):691-704.

439. Tripp G, Wickens JR: Neurobiology of ADHD. Neuropharmacology 2009, 57 (7-8):579-589.

440. Gizer IR, Ficks C, Waldman ID: Candidate gene studies of ADHD: a metaanalytic review. Hum Genet 2009, 126(1):51-90.

441. Khan SA, Faraone SV: The genetics of ADHD: a literature review of 2005. Curr Psychiatr Rep 2006, 8(5):393-397.

442. Arime $Y$, Kubo $Y$, Sora I: Animal models of attention-deficit/hyperactivity disorder. Biol Pharmacol Bull 2011, 34(9):1373-1376.

443. Gainetdinov RR: Strengths and limitations of genetic models of ADHD. Attention Deficit Hyperactive Disord 2010, 2(1):21-30.

444. Trinh JV, Nehrenberg DL, Jacobsen JP, Caron MG, Wetsel WC: Differential psychostimulant-induced activation of neural circuits in dopamine transporter knockout and wild type mice. Neuroscience 2003, 118:297-310.

445. Hironaka N, Ikeda K, Sora I, Uhl GR, Niki H: Food-reinforced operant behavior in dopamine transporter knockout mice: Enhanced resistance to extinction. Ann N Y Acad Sci 2004, 1025:140-145.

446. Gainetdinov RR, Caron MG: Genetics of childhood disorders: XXIV. ADHD, Part 8: hyperdopaminergic mice as an animal model of ADHD. J Am Acad Child Adolesc Psychiatr 2001, 40:380-382.

447. Jucaite A, Fernell E, Halldin C, Forssberg H, Farde L: Reduced midbrain dopamine transporter binding in male adolescents with attention-deficit/ hyperactivity disorder: Association between striatal dopamine markers and motor hyperactivity. Biol Psychiatr 2005, 57:229-238.

448. Dougherty DD, Bonab AA, Spencer TJ, Rauch SL, Madras BK, Fischman AJ: Dopamine transporter density in patients with attention deficit hyperactivity disorder. Lancet 1999, 354(9196):2132-2133.

449. Krause KH, Dresel SH, Krause J, Kung HF, Tatsch K: Increased striatal dopamine transporter in adult patients with attention deficit hyperactivity disorder: Effects of methylphenidate as measured by single photon emission computed tomography. Neurosci Lett 2000, 285(2):107-110.

450. Russell VA: Overview of animal models of attention deficit hyperactivity disorder (ADHD). Curr Protoc Neurosci 2011, 54.

451. Johansen EB, Killeen PR, Sagvolden T: Behavioral variability, elimination of responses, and delay-of-reinforcement gradients in SHR and WKY rats. Behav Brain Funct 2007, 3:60.

452. Sagvolden T: Behavioral validation of the spontaneously hypertensive rat (SHR) as an animal model of attention-deficit/hyperactivity disorder (AD/ HD). Neurosci Biobehav Rev 2000, 24:31-39.

453. Sagvolden T, Russell VA, Aase $H$, Johansen EB, Farshbaf M: Rodent models of attention-deficit/hyperactivity disorder. Biol Psychiatr 2005, 57: 1239-1247.

454. Bull E, Reavill C, Hagan JJ, Overend P, Jones DN: Evaluation of the spontaneously hypertensive rat as a model of attention deficit hyperactivity disorder: acquisition and performance of the DRL-60s test. Behav Brain Res 2000, 109:27-35.

455. Mill J, Sagvolden T, Asherson P: Sequence analysis of Drd2, Drd4, and Dat1 in SHR and WKY rat strains. Behav Brain Funct 2005, 1:24.

456. Cook EH Jr, Stein MA, Krasowski MD, Cox NJ, Olkon DM, Kieffer JE, Leventhal BL: Association of attention-deficit disorder and the dopamine transporter gene. Am J Hum Genet 1995, 56:993-998.

457. Watanabe Y, Fujita M, Ito Y, Okada T, Kusuoka H, Nishimura T: Brain dopamine transporter in spontaneously hypertensive rats. J Nucl Med 1997, 38:470-474.

458. Leo D, Sorrentino E, Volpicelli F, Eyman M, Greco D, Viggiano D, Di PU, Perrone-Capano C: Altered midbrain dopaminergic neurotransmission during development in an animal model of ADHD. Neurosci Biobehav Rev 2003, 27:661-669.

459. Johansen EB, Killeen PR, Russell VA, Tripp G, Wickens JR, Tannock R, Williams $J$, Sagvolden T: Origins of altered reinforcement effects in ADHD. Behav Brain Funct 2009, 5:7 
460. Luman M, Oosterlaan J, Sergeant JA: The impact of reinforcement contingencies on AD/HD: A review and theoretical appraisal. Clin Psychol Rev 2005, 25(2):183-213.

461. Drechsler R, Rizzo P, Steinhausen HC: Decision-making on an explicit risk-taking task in preadolescents with attention-deficit/hyperactivity disorder. J Neural Transm 2008, 115(2):201-209.

462. Sonuga-Barke EJ, Taylor E, Sembi S, Smith J: Hyperactivity and delay aversion-. The effect of delay on choice.I. J Psychol Psychiatr 1992, 33 (2):387-398.

463. Luman M, Oosterlaan J, Hyde C, van Meel CS, Sergeant JA: Heart rate and reinforcement sensitivity in ADHD. J Psychol Psychiatr 2007, 48(9):890-898.

464. Brennan AR, Arnsten AF: Neuronal mechanisms underlying attention deficit hyperactivity disorder: the influence of arousal on prefrontal cortical function. Ann N Y Acad Sci 2008, 1129:236-245.

465. Brocki K, Fan J, Fossella J: Placing neuroanatomical models of executive function in a developmental context: Imaging and imaging-genetic strategies. Ann N Y Acad Sci 2008, 1129:246-255.

466. Prince J: Catecholamine dysfunction in attention-deficit/hyperactivity disorder: An update. J Clin Psychopharmacol 2008, 28(3 Suppl 2):S39.

467. Wilens TE: Effects of methylphenidate on the catecholaminergic system in attention-deficit/hyperactivity disorder. J Clin Psychopharmacol 2008, 28 (3 Suppl 2):S46-S53.

468. Kollins SH, Lane SD, Shapiro SK: The experimental analysis of childhood psychopathology. Psychol Record 1997, 47(1):25-44.

469. Bitsakou P, Psychogiou L, Thompson M, Sonuga-Barke EJ: Delay aversion in Attention Deficit/Hyperactivity Disorder: An empirical investigation of the broader phenotype. Neuropsychologia 2009, 47(2):446-456.

470. Kuntsi J, Oosterlaan J, Stevenson J: Psychological mechanisms in hyperactivity: I. Response inhibition deficit, working memory impairment, delay aversion, or something else? J Child Psychol Psychiatr 2001, 42(2):199-210.

471. Marco R, Miranda A, Schlotz W, Melia A, Mulligan A, Muller U, Andreou P, Butler L, Christiansen H, Gabriels I, Medad S, Albrecht B, Uebel H, Asherson P, Banaschewski T, Gill M, Kuntsi J, Mulas F, Oades R, Roeyers H, Steinhausen HC, Rothenberger A, Faraone SV, Sonuga-Barke EJ: Delay and reward choice in ADHD: An experimental test of the role of delay aversion. Neuropsychology 2009, 23(3):367-380.

472. Neef NA, Bicard DF, Endo S: Assessment of impulsivity and the development of self-control in students with attention deficit hyperactivity disorder. J Appl Behav Anal 2001, 34(4):397-408.

473. Rapport MD, Tucker SB, DuPaul GJ, Merlo M, Stoner G: Hyperactivity and frustration: The influence of control over and size of rewards in delaying gratification. J Abnorm Child Psychol 1986, 14(2):191-204.

474. Tripp G, Alsop B: Sensitivity to reward delay in children with Attention Deficit Hyperactivity disorder (ADHD). J Child Psychol Psychiatr 2001, 42 (5):691-698.

475. Solanto MV, Abikoff H, Sonuga-Barke E, Schachar R, Logan GD, Wigal T, Hechtman L, Hinshaw S, Turkel E: The ecological validity of delay aversion and response inhibition as measures of impulsivity in AD/HD: A supplement to the NIMH multimodal treatment study of AD/HD. J Abnorm Child Psychol 2001, 29(3):215-228.

476. Scheres A, Tontsch C, Thoeny AL, Kaczkurkin A: Temporal reward discounting in attention-deficit/hyperactivity disorder: The contribution of symptom domains, reward magnitude, and session length. Biol psychiatr 2010, 67(7):641-648.

477. Johansen EB, Aase H, Meyer A, Sagvolden T: Attention-deficit/hyperactivity disorder (ADHD) behaviour explained by dysfunctioning reinforcement and extinction processes. Behav Brain Res 2002, 130(1-2):37-45.

478. Luman M, van Meel CS, Oosterlaan J, Geurts HM: Reward and punishment sensitivity in children with ADHD: validating the sensitivity to punishment and sensitivity to reward questionnaire for children (SPSRQ-C). J Abnorm Child Psychol 2011, 40:1-13.

479. Drechsler R, Rizzo P, Steinhausen HC: Decision making with uncertain reinforcement in children with attention deficit/hyperactivity disorde (ADHD). Child Neuropsychol 2010, 16(2):145-161.

480. Demurie E, Roeyers H, Baeyens D, Sonuga Barke E: Common alterations in sensitivity to type but not amount of reward in ADHD and autism spectrum disorders. J Child Psychol Psychiatr 2011, 52:1164-1173.

481. Rubia K, Overmeyer S, Taylor E, Brammer M, Williams SC, Simmons A, Bullmore ET: Hypofrontality in attention deficit hyperactivity disorder during higher-order motor control: A study with functional MRI. Am J Psychiatr 1999, 156(6):891-896.
482. Vaidya CJ, Austin G, Kirkorian G, Ridlehuber HW, Desmond JE, Glover GH, Gabrieli JD: Selective effects of methylphenidate in attention deficit hyperactivity disorder: A functional magnetic resonance study. Proc Natl Acad Sci 1998, 95(24):14494-14499.

483. Zang YF, Jin Z, Weng XC, Zhang L, Zeng YW, Yang L, Wang YF, Seidman LJ, Faraone SV: Functional MRI in attention-deficit hyperactivity disorder: Evidence for hypofrontality. Brain Dev 2005, 27(8):544-550.

484. Carmona S, Hoekzema E, Ramos Quiroga JA, Richarte V, Canals C, Bosch R, Rovira M, Carlos Soliva J, Bulbena A, Tobeña A: Response inhibition and reward anticipation in medication naïve adults with attention deficit/ hyperactivity disorder: A within subject case control neuroimaging study. Hum Brain Mapp 2011. http://onlinelibrary.wiley.com/doi/10.1002/ hbm.21368/abstract

485. Plichta MM, Vasic N, Wolf RC, Lesch K-P, Brummer D, Jacob C, Fallgatter AJ, Grön G: Neural hyporesponsiveness and hyperresponsiveness during immediate and delayed reward processing in adult Attention-Deficit/ Hyperactivity Disorder. Biol Psychiatr 2009, 65(1):7-14.

486. Scheres A, Milham MP, Knutson B, Castellanos FX: Ventral striatal hyporesponsiveness during reward anticipation in attention-deficit/ hyperactivity disorder. Biol Psychiatr 2007, 61(5):720-724.

487. Strohle A, Stoy M, Wrase J, Schwarzer S, Schlagenhauf F, Huss M, Hein J, Nedderhut A, Neumann B, Gregor A, Juckel G, Knutson B, Lehmkuhl U, Bauer M, Heinz A: Reward anticipation and outcomes in adult males with Attention-Deficit/Hyperactivity disorder. Neuroimage 2008, 39(3):966-972.

488. Cubillo A, Halari R, Smith A, Taylor E, Rubia K: Attention Deficit Hyperactivity Disorder (ADHD) and new evidence for dysfunction in adults with ADHD during motivation and attention. Cortex 2011, 48(2):194-215.

489. Paloyelis Y, Mehta MA, Kuntsi J, Asherson P: Functional MRI in ADHD: a systematic literature review. Expet Rev Neurotherapy 2007, 7(10):1337-1356.

490. Stoy M, Schlagenhauf F, Schlochtermeier L, Wrase J, Knutson B, Lehmkuhl U, Huss M, Heinz A, Strohle A: Reward processing in male adults with childhood ADHD-a comparison between drug-naive and methylphenidatetreated subjects. Psychopharmacol Berl 2011, 215(3):467-481.

491. Hahn T, Heinzel S, Dresler T, Plichta MM, Renner TJ, Markulin F, Jakob PM, Lesch KP, Fallgatter AJ: Association between reward-related activation in the ventral striatum and trait reward sensitivity is moderated by dopamine transporter genotype. Hum Brain Mapp 2011, 32(10):1557-1565.

492. Stark R, Bauer E, Merz CJ, Zimmermann M, Reuter M, Plichta MM, Kirsch P, Lesch KP, Fallgatter AJ, Vaitl D, Herrmann MJ: ADHD related behaviors are associated with brain activation in the reward system. Neuropsychologia 2011, 49(3):426-434.

493. Wilbertz G, van Elst LT, Delgado MR, Maier S, Feige B, Philipsen A, Blechert J: Orbitofrontal reward sensitivity and impulsivity in adult attention deficit hyperactivity disorder. Neuroimage 2011, 60(1):353-361.

494. Ernst M, Zametkin AJ, Matochik JA, Pascualvaca D, Jons PH, Cohen RM: High midbrain [18 F]DOPA accumulation in children with attention deficit hyperactivity disorder. Am J Psychiatr 1999, 156(8):1209-1215.

495. Volkow N, Wang G, Newcorn J, Kollins S, Wigal T, Telang F, Fowler J, Goldstein R, Klein N, Logan J: Motivation deficit in ADHD is associated with dysfunction of the dopamine reward pathway. Mol Psychiatr 2010, 16:1147-1154

496. Madras BK, Miller GM, Fischman AJ: The dopamine transporter and attention-deficit/hyperactivity disorder. Biol Psychiatr 2005, 57(11):1397-1409.

497. Yano M, Steiner H: Methylphenidate and cocaine: The same effects on gene regulation? Trends Pharmacol Sci 2007, 28(11):588-596.

498. Heal DJ, Cheetham SC, Smith SL: The neuropharmacology of ADHD drugs in vivo: Insights on efficacy and safety. Neuropharmacology 2009, 57(7-8):608-618.

499. Conners CK, Casat CD, Gualtieri CT, Weller E, Reader M, Reiss A, Weller RA, Khayrallah M, Ascher J: Bupropion hydrochloride in attention deficit disorder with hyperactivity. J Am Acad Child Adolesc Psychiatr 1996, 35 (10):1314-1321.

500. Kuperman S, Perry PJ, Gaffney GR, Lund BC, Bever-Stille KA, Arndt S, Holman TL, Moser DJ, Paulsen JS: Bupropion SR vs. methylphenidate vs. placebo for attention deficit hyperactivity disorder in adults. Ann Clin Psychiatr 2001, 13(3):129-134.

501. Ruscio AM, Stein DJ, Chiu WT, Kessler RC: The epidemiology of obsessive-compulsive disorder in the National Comorbidity Survey Replication. Mol Psychiatr 2010, 15(1):53-63. 
502. Cavedini P, Gorini A, Bellodi L: Understanding obsessive-compulsive disorder: Focus on decision making. Neuropsychol Rev 2006, 16(1):3-15.

503. Denys D, Zohar J, Westenberg HG: The role of dopamine in obsessive-compulsive disorder: Preclinical and clinical evidence. J Clin Psychiatr 2004, 65(Suppl 14):11-17.

504. Holden C: Psychiatry. Behavioral addictions debut in proposed DSM-V. Science 2010, 327(5968):935.

505. Geller DA, Biederman J, Faraone S, Agranat A, Cradock K, Hagermoser L, Kim G, Frazier J, Coffey BJ: Developmental aspects of obsessive compulsive disorder: findings in children, adolescents, and adults. J Nerv Ment Dis 2001, 189:471-477.

506. Yang XW, Lu XH: Molecular and cellular basis of obsessive-compulsive disorder-like behaviors: Emerging view from mouse models. Curr Opin Neurol 2011, 24(2):114-118.

507. Feusner JD, Hembacher E, Phillips KA: The mouse who couldn't stop washing: Pathologic grooming in animals and humans. CNS Spectr 2009, 14(9):503-513.

508. Berridge KC, Aldridge JW, Houchard KR, Zhuang X: Sequential super-stereotypy of an instinctive fixed action pattern in hyper-dopaminergic mutant mice: A model of obsessive compulsive disorder and Tourette's. BMC Biol 2005, 3:4

509. Welch JM, Lu J, Rodriguiz RM, Trotta NC, Peca J, Ding JD, Feliciano C, Chen M, Adams JP, Luo J, Dudek SM, Weinberg RJ, Calakos N, Wetsel WC, Feng G: Cortico-striatal synaptic defects and OCD-like behaviours in Sapap3-mutant mice. Nature 2007, 448(7156):894-900.

510. Shmelkov SV, Hormigo A, Jing D, Proenca CC, Bath KG, Milde T, Shmelkov E, Kushner JS, Baljevic M, Dincheva I, Murphy AJ, Valenzuela DM, Gale NW, Yancopoulos GD, Ninan I, Lee FS, Rafii S: Slitrk5 deficiency impairs corticostriatal circuitry and leads to obsessive-compulsive-like behaviors in mice. Nat Med 2010, 16(5):598-602.

511. Nielen MM, den Boer JA, Smid HG: Patients with obsessive-compulsive disorder are impaired in associative learning based on external feedback. Psychol Med 2009, 39(9):1519-1526.

512. Cavedini P, Riboldi G, D'Annucci A, Belotti P, Cisima M, Bellodi L: Decision-making heterogeneity in obsessive-compulsive disorder: Ventromedial prefrontal cortex function predicts different treatment outcomes. Neuropsychologia 2002, 40(2):205-211.

513. Saxena S, Brody AL, Schwartz JM, Baxter LR: Neuroimaging and frontal-subcortical circuitry in obsessive-compulsive disorder. $\mathrm{Br} J$ Psychiatr 1998, 35:26-37. Suppl.

514. Fontenelle LF, Oostermeijer S, Harrison BJ, Pantelis C, Yucel M: Obsessivecompulsive disorder, impulse control disorders and drug addiction: common features and potential treatments. Drugs 2011, 71(7):827-840.

515. Jung WH, Kang DH, Han JY, Jang JH, Gu BM, Choi JS, Jung MH, Choi CH, Kwon JS: Aberrant ventral striatal responses during incentive processing in unmedicated patients with obsessive-compulsive disorder. Acta Psychiatr Scand 2010, 123(5):376-386.

516. Figee $M$, Vink $M$, de Geus F, Vulink $N$, Veltman DJ, Westenberg $H$, Denys D: Dysfunctional reward circuitry in obsessive-compulsive disorder. Biol Psychiatr 2011, 69(9):867-874.

517. Pena-Garijo J, Barros-Loscertales A, Ventura-Campos N, Ruiperez-Rodriguez M, Edo-Villamon S, Avila C: Involvement of the thalamic-cortical-striatal circuit in patients with obsessive-compulsive disorder during an inhibitory control task with reward and punishment contingencies. Rev Neurol 2011, 53(2):77.

518. Whiteside SP, Port JD, Abramowitz JS: A meta-analysis of functional neuroimaging in obsessive-compulsive disorder. Psychiatr Res 2004, 132(1):69-79.

519. Menzies L, Chamberlain SR, Laird AR, Thelen SM, Sahakian BJ, Bullmore ET: Integrating evidence from neuroimaging and neuropsychological studies of obsessive-compulsive disorder: The orbitofronto-striatal model revisited. Neurosci Biobehav Rev 2008, 32(3):525-549.

520. Nikolaus S, Antke C, Beu M, Muller HW: Cortical GABA, striatal dopamine and midbrain serotonin as the key players in compulsive and anxiety disorders-results from in vivo imaging studies. Rev Neurosci 2010, 21 (2):119-139

521. Pallanti S, Quercioli L: Treatment-refractory obsessive-compulsive disorder: Methodological issues, operational definitions and therapeutic lines. Progr Neuropsychopharmacol Biol Psychiatr 2006, 30(3):400-412

522. Bystritsky A, Ackerman DL, Rosen RM, Vapnik T, Gorbis E, Maidment KM, Saxena S: Augmentation of serotonin reuptake inhibitors in refractory obsessive-compulsive disorder using adjunctive olanzapine: A placebocontrolled trial. J Clin Psychiatr 2004, 65(4):565-568.

523. Carey PD, Vythilingum B, Seedat S, Muller JE, van Ameringen M, Stein DJ: Quetiapine augmentation of SRIs in treatment refractory obsessive-compulsive disorder: a double-blind, randomised, placebocontrolled study. BMC Psychiatr 2005, 5:5.

524. Hollander E, Baldini Rossi N, Sood E, Pallanti S: Risperidone augmentation in treatment-resistant obsessive-compulsive disorder: A double-blind, placebo-controlled study. Int J Neuropsychopharmacol 2003, 6(4):397-401.

525. Komossa K, Depping AM, Meyer M, Kissling W, Leucht S: Second-generation antipsychotics for obsessive compulsive disorder. Cochrane Database Sys Rev 2010, 12:CD008141.

526. Denys $D$, Mantione M, Figee $M$, van den Munckhof $P$, Koerselman F, Westenberg H, Bosch A, Schuurman R: Deep brain stimulation of the nucleus accumbens for treatment-refractory obsessive-compulsive disorder. Arch Gen Psychiatr 2010, 67(10):1061-1068.

527. Huff W, Lenartz D, Schormann M, Lee SH, Kuhn J, Koulousakis A, Mai J, Daumann J, Maarouf M, Klosterkotter J, Sturm V: Unilateral deep brain stimulation of the nucleus accumbens in patients with treatment-resistant obsessive-compulsive disorder: Outcomes after one year. Clin Neurol Neurosurg 2010, 112(2):137-143.

528. Sturm V, Lenartz D, Koulousakis A, Treuer H, Herholz K, Klein JC, Klosterkotter $\mathrm{J}$ : The nucleus accumbens: A target for deep brain stimulation in obsessive-compulsive- and anxiety-disorders. J Chem Neuroanat 2003, 26 (4):293-299.

529. Kogan MD, Blumberg SJ, Schieve LA, Boyle CA, Perrin JM, Ghandour RM, Singh GK, Strickland BB, Trevathan E, van Dyck PC: Prevalence of parent-reported diagnosis of autism spectrum disorder among children in the US. Pediatrics 2009, 124(5):1395-1403.

530. Moy SS, Nadler JJ, Perez A, Barbaro RP, Johns JM, Magnuson TR, Piven J, Crawley JN: Sociability and preference for social novelty in five inbred strains: an approach to assess autistic-like behavior in mice. Gene Brain Behav 2004, 3(5):287-302.

531. Moy SS, Nadler JJ, Young NB, Nonneman RJ, Grossman AW, Murphy DL, D'Ercole AJ, Crawley JN, Magnuson TR, Lauder JM: Social approach in genetically engineered mouse lines relevant to autism. Gene Brain Behav 2009, 8(2):129-142.

532. Smith SE, Zhou YD, Zhang G, Jin Z, Stoppel DC, Anderson MP: Increased gene dosage of Ube3a results in autism traits and decreased glutamate synaptic transmission in mice. Sci Translational Med 2011, 3(103):103ra197-103ra197.

533. Nair HP, Young LJ: Vasopressin and pair-bond formation: Genes to brain to behavior. Physiol (Bethesda) 2006, 21:146-152.

534. Young KA, Gobrogge KL, Liu Y, Wang Z: The neurobiology of pair bonding: Insights from a socially monogamous rodent. Front Neuroendocrinol 2010, 32(1):53-69.

535. Bishop SL, Lahvis GP: The autism diagnosis in translation: shared affect in children and mouse models of ASD. Autism Res 2011, 4(5):317-335.

536. Carter CS, Getz LL: Monogamy and the prairie vole. Sci Am Am 1993, 268 (6):100-106.

537. Curtis JT, Wang Z: Ventral tegmental area involvement in pair bonding in male prairie voles. Physiol Behav 2005, 86(3):338-346.

538. Aragona BJ, Liu Y, Yu YJ, Curtis JT, Detwiler JM, Insel TR, Wang Z: Nucleus accumbens dopamine differentially mediates the formation and maintenance of monogamous pair bonds. Nat Neurosci 2006, 9(1): 133-139.

539. Gingrich B, Liu Y, Cascio C, Wang Z, Insel TR: Dopamine D2 receptors in the nucleus accumbens are important for social attachment in female prairie voles (Microtus ochrogaster). Behav Neurosci 2000, 114(1):173-183.

540. Aragona BJ, Wang Z: Opposing regulation of pair bond formation by CAMP signaling within the nucleus accumbens shell. J Neurosci 2007, 27 (48):13352-13356.

541. Curtis JT, Wang Z: Amphetamine effects in microtine rodents: $A$ comparative study using monogamous and promiscuous vole species. Neuroscience 2007, 148(4):857-866.

542. Hostetler CM, Harkey SL, Krzywosinski TB, Aragona BJ, Bales KL: Neonatal exposure to the D1 agonist SKF38393 inhibits pair bonding in the adult prairie vole. Behav Pharmacol 2011, 22(7):703-710.

543. Liu H, Dong F, Meng Z, Zhang B, Tan J, Wang Y: Evaluation of Tourette's syndrome by $(99 \mathrm{~m})$ Tc-TRODAT-1 SPECT/CT imaging. Ann Nucl Med 2010, 24(7):515-521. 
544. Liu Y, Young KA, Curtis JT, Aragona BJ, Wang Z: Social bonding decreases the rewarding properties of amphetamine through a dopamine D1 receptor-mediated mechanism. J Neurosci 2011, 31(22):7960-7966.

545. Lim MM, Liu Y, Ryabinin AE, Bai Y, Wang Z, Young LJ: CRF receptors in the nucleus accumbens modulate partner preference in prairie voles. Horm Behav 2007, 51(4):508-515.

546. Olazabal DE, Young LJ: Oxytocin receptors in the nucleus accumbens facilitate "spontaneous" maternal behavior in adult female prairie voles. Neuroscience 2006, 141(2):559-568.

547. Young $\amalg$, Lim MM, Gingrich B, Insel TR: Cellular mechanisms of social attachment. Horm Behav 2001, 40(2):133-138.

548. Insel TR: The challenge of translation in social neuroscience: $A$ review of oxytocin, vasopressin, and affiliative behavior. Neuron 2010, 65(6):768-779.

549. Hammock EA, Young LJ: Oxytocin, vasopressin and pair bonding: implications for autism. Philosophical Transactions of the Royal Society of London. Ser B Biol Sci 2006, 361(1476):2187-2198.

550. Dawson G, Meltzoff AN, Osterling J, Rinaldi J, Brown E: Children with autism fail to orient to naturally occurring social stimuli. J Autism Dev Disord 1998, 28(6):479-485.

551. Dawson G, Webb SJ, McPartland J: Understanding the nature of face processing impairment in autism: Insights from behavioral and electrophysiological studies. Dev Neuropsychol 2005, 27(3):403-424.

552. Schultz RT: Developmental deficits in social perception in autism: The role of the amygdala and fusiform face area. Int J Dev Neurosci 2005, 23 (2-3):125-141.

553. Kuhl PK, Coffey-Corina S, Padden D, Dawson G: Links between social and linguistic processing of speech in preschool children with autism: Behavioral and electrophysiological measures. Dev Sci 2005, 8:F1-F12.

554. Schultz RT, Gauthier I, Klin A, Fulbright RK, Anderson AW, Volkmar F, Skudlarski P, Lacadie C, Cohen DJ, Gore JC: Abnormal ventral temporal cortical activity during face discrimination among individuals with autism and Asperger syndrome. Arch Gen Psychiatr 2000, 57(4):331-340.

555. Klin A, Lin DJ, Gorrindo P, Ramsay G, Jones W: Two-year-olds with autism orient to non-social contingencies rather than biological motion. Nature 2009, 459(7244):257-261.

556. Klin A, Jones W, Schultz R, Volkmar F, Cohen D: Visual fixation patterns during viewing of naturalistic social situations as predictors of social competence in individuals with autism. Arch Gen Psychiatr 2002, 59(9): 809-816.

557. Chevallier C, Grèzes J, Molesworth C, Berthoz S, Happé F: Brief report: Selective social anhedonia in high functioning autism. J Autism Dev Disord 2012. http://www.springerlink.com/content/q83152232p71m363/.

558. Sasson N, Tsuchiya N, Hurley R, Couture SM, Penn DL, Adolphs R, Piven J: Orienting to social stimuli differentiates social cognitive impairment in autism and schizophrenia. Neuropsychologia 2007, 45(11):2580-2588.

559. Sasson N, Turner-Brown L, Holtzclaw T, Lam KS, Bodfish J: Children with autism demonstrate circumscribed attention during passive viewing of complex social and nonsocial picture arrays. Autism Res 2008, 1:31-42.

560. Sasson NJ, Elison JT, Turner-Brown LM, Dichter GS, Bodfish JW: Brief report: Circumscribed attention in young children with autism. J Autism Dev Disord 2011, 41(2):242-247.

561. Soderstrom H, Rastam M, Gillberg C: Temperament and character in adults with Asperger syndrome. Autism 2002, 6(3):287-290.

562. Johnson SA, Yechiam E, Murphy RR, Queller S, Stout JC: Motivational processes and autonomic responsivity in Asperger's disorder: Evidence from the lowa Gambling Task. J Int Neuropsychol Soc 2006, 12(05):668-676.

563. Schmitz N, Rubia K, van Amelsvoort T, Daly E, Smith A, Murphy DG: Neural correlates of reward in autism. Br J Psychiatr 2008, 192:19-24.

564. Scott-Van Zeeland AA, Dapretto M, Ghahremani DG, Poldrack RA, Bookheimer SY: Reward processing in autism. Autism Res 2010, 3(2):53-67.

565. Garretson HB, Fein D, Waterhouse L: Sustained attention in children with autism. J Autism Dev Disord 1990, 20(1):101-114.

566. Ingersoll B, Schreibman L, Tran QH: Effect of sensory feedback on immediate object imitation in children with autism. J Autism Dev Disord 2003, 33(6):673-683.

567. Ozonoff S: Reliability and Validity of the Wisconsin Card Sorting Test in Studies of Autism. Neuropsychology 1995, 9(4):491-500.

568. Pascualvaca DM, Fantie BD, Papageorgiou M, Mirsky AF: Attentional capacities in children with autism: Is there a general deficit in shifting focus? J Autism Dev Disord 1998, 28(6):467-478.
569. Dichter GS, Richey JA, Rittenberg AM, Sabatino A, Bodfish JW: Reward circuitry function in autism during face anticipation and outcomes. $J$ Autism Dev Disord 2012, 42(2):147-160.

570. Kohls G, Schulte-Rüther M, Nehrkorn B, Müller K, Fink GR, Kamp-Becker I, Herpertz-Dahlmann B, Schultz RT, Konrad K: Reward system dysfunction in spectrum disorders. Soc Cognit Affect Neurosci 2011, 41:1523-1533.

571. Kylliainen A, Wallace S, Coutanche MN, Leppanen JM, Cusack J, Bailey AJ, Hietanen JK: Affective-motivational brain responses to direct gaze in children with autism spectrum disorder. J Child Psychol Psychiatr 2012, 53:790797.

572. Sutton SK, Burnette CP, Mundy PC, Meyer J, Vaughan A, Sanders C, Yale M: Resting cortical brain activity and social behavior in higher functioning children with autism. J Child Psychol Psychiatr 2005, 46(2):211-222.

573. Larson MJ, South M, Krauskopf E, Clawson A, Crowley MJ: Feedback and reward processing in high-functioning autism. Psychiatr Res 2011, 187(1-2):198-203.

574. Lewis MH, Bodfish JW: Repetitive behavior disorders in autism. Ment Retard Dev Disabil Res Rev 1998, 4:80-89.

575. Dichter GS, Felder JN, Green SR, Rittenberg AM, Sasson NJ, Bodfish JW: Reward circuitry function in autism spectrum disorders. Soc Cognit Affect Neurosci 2012, 7:160-172.

576. Dawson G, Rogers S, Munson J, Smith M, Winter J, Greenson J, Donaldson A, Varley J: Randomized, controlled trial of an intervention for toddlers with autism: the Early Start Denver Model. Pediatrics 2010, 125(1):e17.

577. Lovaas Ol: Behavioral treatment and normal educational and intellectual functioning in young autistic children. J Consult Clin Psychol 1987, 55(1):3.

578. Mesibov GB, Shea V: The TEACCH program in the era of evidence-based practice. J Autism Dev Disord 2010, 40(5):570-579.

579. Kasari C: Assessing change in early intervention programs for children with autism. J Autism Dev Disord 2002, 32(5):447-461.

580. Sherer MR, Schreibman L: Individual behavioral profiles and predictors of treatment effectiveness for children with autism. J Consult Clin Psychol 2005, 73(3):525.

581. Smith T, Groen AD, Wynn JW: Randomized trial of intensive early intervention for children with pervasive developmental disorder. Am J Ment Retard 2000, 105(4):269-285.

582. Spreckley M, Boyd R: Efficacy of applied behavioral intervention in preschool children with autism for improving cognitive, language, and adaptive behavior: A systematic review and meta-analysis. J Pediatr 2009, 154(3):338-344.

583. McDougle CJ, Posey DJ, Potenza MN: Neurobiology of serotonin function in autism. In Autism Spectrum Disorders. Edited by Hollander E. New York: Marcel Dekker; 2003:199-220.

584. Makkonen I, Riikonen R, Kokki H, Airaksinen MM, Kuikka JT: Serotonin and dopamine transporter binding in children with autism determined by SPECT. Dev Med Child Neurol 2008, 50(8):593-597.

585. Sun X, Yue J, Zheng C: Study of dopamine transporter imaging on the brain of children with autism. Sheng Wu Yi Xue Gong Cheng Xue Za Zhi 2008, 25(2):327-330.

586. Nakamura K, Sekine $Y$, Ouchi $Y$, Tsujii M, Yoshikawa E, Futatsubashi M, Tsuchiya KJ, Sugihara G, Iwata Y, Suzuki K, Matsuzaki H, Suda S, Sugiyama T, Takei N, Mori N: Brain serotonin and dopamine transporter bindings in adults with high-functioning autism. Arch Gen Psychiatr 2010, 67(1):59-68

587. Ernst M, Zametkin AJ, Matochik JA, Pascualvaca D, Cohen RM: Low medial prefrontal dopaminergic activity in autistic children. Lancet 1997, 350 (9078):638.

588. Nieminen-von Wendt TS, Metsahonkala L, Kulomaki TA, Aalto S, Autti TH, Vanhala R, Eskola O, Bergman J, Hietala JA, von Wendt LO: Increased presynaptic dopamine function in Asperger syndrome. Neuroreport 2004, 15(5):757-760.

589. Makkonen I, Kokki H, Kuikka J, Turpeinen U, Riikonen R: Effects of fluoxetine treatment on striatal dopamine transporter binding and cerebrospinal fluid insulin-like growth factor-1 in children with autism. Neuropediatrics 2011, 42:207-209.

590. Buchsbaum MS, Hollander E, Haznedar MM, Tang C, Spiegel-Cohen J, Wei TC, Solimando A, Buchsbaum BR, Robins D, Bienstock C, Cartwright C, Mosovich S: Effect of fluoxetine on regional cerebral metabolism in autistic spectrum disorders: a pilot study. Int I Neuropsychopharmacol 2001, 4(2):119-125.

591. Hollander E, Phillips A, Chaplin W, Zagursky K, Novotny S, Wasserman S, lyengar R: A placebo controlled crossover trial of liquid fluoxetine on 
repetitive behaviors in childhood and adolescent autism. Neuropsychopharmacology 2005, 30(3):582-589.

592. McDougle CJ, Naylor ST, Cohen DJ, Volkmar FR, Heninger GR, Price LH: A double-blind, placebo-controlled study of fluvoxamine in adults with autistic disorder. Arch Gen Psychiatr 1996, 53(11):1001-1008.

593. Namerow LB, Thomas P, Bostic JQ, Prince J, Monuteaux MC: Use of citalopram in pervasive developmental disorders. J Dev Behav Pediatr 2003, 24(2):104-108.

594. Owley T, Walton L, Salt J, Guter SJ Jr, Winnega M, Leventhal BL, Cook EH Jr: An open-label trial of escitalopram in pervasive developmental disorders. J Am Acad Child Adolesc Psychiatr 2005, 44(4):343-348.

595. King BH, Hollander E, Sikich L, McCracken JT, Scahill L, Bregman JD, Donnelly CL, Anagnostou E, Dukes K, Sullivan L, Hirtz D, Wagner A, Ritz L: Lack of efficacy of citalopram in children with autism spectrum disorders and high levels of repetitive behavior: Citalopram ineffective in children with autism. Arch Gen Psychiatr 2009, 66(6):583-590.

596. Aman MG, Hollway JA, McDougle CJ, Scahill L, Tierney E, McCracken JT, Arnold LE, Vitiello B, Ritz L, Gavaletz A: Cognitive effects of risperidone in children with autism and irritable behavior. J Child Adolesc Psychopharmacol 2008, 18(3):227-236.

597. Aman MG, Lam KSL, Van Bourgondien ME: Medication patterns in patients with autism: Temporal, regional, and demographic influences. J Child Adolesc Psychopharmacol 2005, 15(1):116-126.

598. Arnold LE, Farmer C, Kraemer HC, Davies M, Witwer A, Chuang S, DiSilvestro R, McDougle CJ, McCracken J, Vitiello B: Moderators, mediators, and other predictors of risperidone response in children with autistic disorder and irritability. J Child Adolesc Psychopharmacol 2010, 20(2):83-93.

599. Pandina GJ, Bossie CA, Youssef E, Zhu Y, Dunbar F: Risperidone improves behavioral symptoms in children with autism in a randomized, doubleblind, placebo-controlled trial. J Autism Dev Disord 2007, 37(2):367-373.

600. Williams H, Clarke R, Bouras N, Martin J, Holt G: Use of the atypical antipsychotics Olanzapine and Risperidone in adults with intellectual disability. J Intellect Disabil Res 2000, 44(2):164-169.

601. McCracken JT, McGough J, Shah B, Cronin P, Hong D, Aman MG, Arnold LE, Lindsay R, Nash P, Hollway J: Risperidone in children with autism and serious behavioral problems. New Engl J Med 2002, 347(5):314-321.

602. McDougle CJ, Stigler KA, Erickson CA, Posey DJ: Atypical antipsychotics in children and adolescents with autistic and other pervasive developmental disorders. J Clin Psychiatr 2008, 69:15.

603. Nagaraj $R$, Singhi $P$, Malhi $P$ : Risperidone in children with autism: Randomized, placebo-controlled, double-blind study. J Child Neurol 2006, 21(6):450.

604. Owen R, Sikich L, Marcus RN, Corey-Lisle P, Manos G, McQuade RD, Carson $\mathrm{WH}$, Findling RL: Aripiprazole in the treatment of irritability in children and adolescents with autistic disorder. Pediatrics 2009, 124(6):1533.

605. Marcus RN, Owen R, Manos G, Mankoski R, Kamen L, McQuade RD, Carson WH, Corey-Lisle PK, Aman MG: Aripiprazole in the treatment of irritability in pediatric patients (aged 6-17 years) with Autistic Disorder: Results from a 52-week, open-label study. J Child Adolesc Psychopharmacol 2011, 21(3):229-236

606. Akhondzadeh S, Erfani S, Mohammadi M, Tehrani Doost M, Amini H, Gudarzi S, Yasamy M: Cyproheptadine in the treatment of autistic disorder: a double blind placebo controlled trial. J Clin Pharm Ther 2004, 29(2):145-150

607. Parikh MS, Kolevzon A, Hollander E: Psychopharmacology of aggression in children and adolescents with autism: A critical review of efficacy and tolerability. J Child Adolesc Psychopharmacol 2008, 18(2):157-178.

608. Stigler KA, Erickson CA, Mullett JE, Posey DJ, McDougle CJ: Paliperidone for irritability in autistic disorder. J Child Adolesc Psychopharmacol 2010, 20 (1):75-78.

609. Handen $B L$, Johnson CR, Lubetsky M: Efficacy of methylphenidate among children with autism and symptoms of attention-deficit hyperactivity disorder. J Autism Dev Disord 2000, 30(3):245-255.

610. Posey DJ, Stigler KA, Erickson CA, McDougle CJ: Antipsychotics in the treatment of autism. J Clin Investig 2008, 118(1):6.

611. McCracken JT: Safety issues with drug therapies for autism spectrum disorders. J Clin Psychiatr 2005, 66(Suppl 10):32-37.

612. McNaught KS, Mink JW: Advances in understanding and treatment of Tourette syndrome. Nat Rev Neurol 2011, 7(12):667-676.

613. Karagiannidis I, Rizzo R, Tarnok Z, Wolanczyk T, Hebebrand J, Nothen MM, Lehmkuhl G, Farkas L, Nagy P, Barta C, Szymanska U, Panteloglou G,
Miranda DM, Feng Y, Sandor P, Barr C, Paschou P: Replication of association between a SLITRK1 haplotype and Tourette Syndrome in a large sample of families. Mol Psychiatr 2011. http://www.nature.com/mp/ journal/vaop/ncurrent/full/mp2011151a.html.

614. O'Rourke JA, Scharf JM, Yu D, Pauls DL: The genetics of Tourette syndrome: A review. J Psychosom Res 2009, 67(6):533-545.

615. Katayama K, Yamada K, Ornthanalai VG, Inoue T, Ota M, Murphy NP, Aruga J: Slitrk1-deficient mice display elevated anxiety-like behavior and noradrenergic abnormalities. Mol Psychiatr 2008, 15(2):177-184.

616. Stillman AA, Krsnik Z, Sun J, Rasin MR, State MW, Sestan N, Louvi A: Developmentally regulated and evolutionarily conserved expression of SLITRK1 in brain circuits implicated in Tourette syndrome. J Comp Neurol 2009, 513(1):21-37.

617. Singer HS, Butler IJ, Tune LE, Seifert WF Jr, Coyle JT: Dopaminergic dysfunction in Tourette syndrome. Ann Neurol 1982, 12:361-366.

618. Singer HS, Hahn $\mathrm{H}$, Moran TH: Abnormal dopamine uptake sites in postmortem striatum from patients with Tourette's syndrome. Ann Neurol 1991, 30(4):558-562.

619. Wong DF, Brasic JR, Singer HS, Schretlen DJ, Kuwabara H, Zhou Y, Nandi A, Maris MA, Alexander M, Ye W, Rousset O, Kumar A, Szabo Z, Gjedde A, Grace AA: Mechanisms of dopaminergic and serotonergic neurotransmission in Tourette syndrome: Clues from an in vivo neurochemistry study with PET. Neuropsychopharmacology 2008, 33 (6):1239-1251

620. Grace AA: Phasic versus tonic dopamine release and the modulation of dopamine system responsivity: A hypothesis for the etiology of schizophrenia. Neuroscience 1991, 41(1):1-24.

621. Palminteri $S$, Lebreton $M$, Worbe $Y$, Hartmann A, Lehéricy S, Vidailhet $M$, Grabli D, Pessiglione M: Dopamine-dependent reinforcement of motor skill learning: Evidence from Gilles de la Tourette syndrome. Brain 2011, 134(8):2287-2301.

622. Mazzone L, Yu S, Blair C, Gunter BC, Wang Z, Marsh R, Peterson BS: An fMRI study of frontostriatal circuits during the inhibition of eye blinking in persons with Tourette Syndrome. Am J Psychiatr 2010, 167(3):341-349.

623. Peterson BS, Skudlarski P, Anderson AW, Zhang H, Gatenby JC, Lacadie CM, Leckman JF, Gore JC: A functional magnetic resonance imaging study of tic suppression in Tourette syndrome. Arch Gen Psychiatr 1998, 55(4): 326-333.

624. Leckman JF, Zhang H, Vitale A, Lahnin F, Lynch K, Bondi C, Kim YS, Peterson BS: Course of tic severity in Tourette syndrome: The first two decades. Pediatrics 1998, 102(1):14-19.

625. Spessot AL, Plessen KJ, Peterson BS: Neuroimaging of developmental psychopathologies: The importance of self-regulatory and neuroplastic processes in adolescence. Ann N Y Acad Sci 2004, 1021:86-104.

626. Comings DE, Comings BG, Muhleman D, Dietz G, Shahbahrami B, Tast D, Knell E, Kocsis $P$, Baumgarten $R$, Kovacs BW: The dopamine D2 receptor locus as a modifying gene in neuropsychiatric disorders. JAMA 1991, 266 (13): 1793.

627. Herzberg I, Valencia-Duarte AV, Kay VA, White DJ, Müller H, Rivas IC, Mesa SC, Cuartas M, García J, Bedoya G, Cornejo W, Ruiz-Linares A, Kremeyer B: Association of DRD2 variants and Gilles de la Tourette syndrome in a family-based sample from a South American population isolate. Psychiatr Genet 2010, 20(4):179-183.

628. Lee CC, Chou I: Dopamine receptor D2 gene polymorphisms are associated in Taiwanese children with Tourette syndrome. Pediatr Neurol 2005, 33(4):272-276.

629. Diaz-Anzaldua A, Joober R, Riviere J, Dion Y, Lesperance P, Richer F, Chouinard S, Rouleau G: Tourette syndrome and dopaminergic genes: a family-based association study in the French Canadian founder population. Mol Psychiatr 2004, 9(3):272-277.

630. Díaz Anzaldúa A, Rivière JB, Dubé MP, Joober $R$, Saint Onge J, Dion Y, Lespérance $P$, Richer F, Chouinard S, Rouleau GA: Chromosome 11 q24 region in Tourette syndrome: Association and linkage disequilibrium study in the French Canadian population. Am J Med Genet A 2005, 138 (3):225-228.

631. Gelernter J, Pakstis AJ, Pauls DL, Kurlan R, Gancher ST, Civelli O, Grandy D, Kidd KK: Gilles de la Tourette syndrome is not linked to D2-dopamine receptor. Arch Gen Psychiatr 1990, 47(11):1073.

632. Gelernter J, Pauls DL, Leckman J, Kidd KK, Kurlan R: D2 dopamine receptor alleles do not influence severity of Tourette's Syndrome: Results from four large kindreds. Arch Neurol 1994, 51(4):397. 
633. Nöthen MM, Hebebrand J, Knapp M, Hebebrand K, Camps A, von Gontard A, Wettke Schäfer R, Lisch S, Cichon S, Poustka F: Association analysis of the dopamine D2 receptor gene in Tourette's syndrome using the haplotype relative risk method. Am J Med Genet 1994, 54(3):249-252.

634. Wolf SS, Jones DW, Knable MB, Gorey JG, Lee KS, Hyde TM, Coppola R, Weinberger DR: Tourette syndrome: Prediction of phenotypic variation in monozygotic twins by caudate nucleus D2 receptor binding. Science 1996, 273(5279):1225-1227.

635. Yeh CB, Lee CS, Ma KH, Lee MS, Chang CJ, Huang WS: Phasic dysfunction of dopamine transmission in Tourette's syndrome evaluated with $99 \mathrm{mTc}$ TRODAT-1 imaging. Psychiatr Res 2007, 156(1):75-82.

636. Albin RL, Koeppe RA, Bohnen NI, Nichols TE, Meyer P, Wernette K, Minoshima S, Kilbourn MR, Frey KA: Increased ventral striatal monoaminergic innervation in Tourette syndrome. Neurology 2003, 61 (3):310-315

637. Liu Y, Aragona BJ, Young KA, Dietz DM, Kabbaj M, Mazei-Robison M, Nestler EJ, Wang Z: Nucleus accumbens dopamine mediates amphetamineinduced impairment of social bonding in a monogamous rodent species. Proc Natl Acad Sci 2010, 107(3):1217-1222

638. Muller-Vahl KR, Berding G, Brucke T, Kolbe H, Meyer GJ, Hundeshagen H, Dengler R, Knapp WH, Emrich HM: Dopamine transporter binding in Gilles de la Tourette syndrome. J Neurol 2000, 247(7):514-520.

639. Serra-Mestres J, Ring HA, Costa DC, Gacinovic S, Walker Z, Lees AJ, Robertson MM, Trimble MR: Dopamine transporter binding in Gilles de la Tourette syndrome: A [123I]FP-CIT/SPECT study. Acta Psychiatr Scand 2004, 109(2):140-146.

640. Singer HS, Szymanski S, Giuliano J, Yokoi F, Dogan AS, Brasic JR, Zhou Y, Grace AA, Wong DF: Elevated intrasynaptic dopamine release in Tourette's syndrome measured by PET. Am J Psychiatr 2002, 159(8): 1329-1336.

641. Cheon KA, Ryu YH, Namkoong K, Kim CH, Kim JJ, Lee JD: Dopamine transporter density of the basal ganglia assessed with [123I]IPT SPECT in drug-naive children with Tourette's disorder. Psychiatr Res 2004, 130 (1):85-95.

642. Hwang WJ, Yao WJ, Fu YK, Yang AS: [99mTc]TRODAT-1/[123I]IBZM SPECT studies of the dopaminergic system in Tourette syndrome. Psychiatr Res 2008, 162(2):159-166.

643. Stamenkovic M, Schindler SD, Asenbaum S, Neumeister A, Willeit M, Willinger $U$, de Zwaan M, Riederer F, Aschauer HN, Kasper S: No change in striatal dopamine re-uptake site density in psychotropic drug naive and in currently treated Tourette's disorder patients: A [(123)I]-beta-CIT SPECt-study. Eur Neuropsychopharmacol 2001, 11(1):69-74.

644. Yeh CB, Lee CH, Chou YH, Chang CJ, Ma KH, Huang WS: Evaluating dopamine transporter activity with $99 \mathrm{mTC}$-TRODAT-1 SPECT in drugnaive Tourette's adults. Nucl Med Comm 2006, 27(10):779-784.

645. Fasano A, Bentivoglio AR: Tetrabenazine. Expet Opin Pharmacother 2009, 10 (17):2883-2896.

646. Zheng G, Dwoskin LP, Crooks PA: Vesicular monoamine transporter 2: role as a novel target for drug development. AAPS J 2006, 8(4):E682.

647. Scahill L, Erenberg G, Berlin CM Jr, Budman C, Coffey BJ, Jankovic J, Kiessling L, King RA, Kurlan R, Lang A, Mink J, Murphy T, Zinner S, Walkup J: Contemporary assessment and pharmacotherapy of Tourette syndrome. NeuroRx 2006, 3(2):192-206.

648. Rubia K: "Cool" inferior frontostriatal dysfunction in attention-deficit/ hyperactivity disorder versus "hot" ventromedial orbitofrontal-limbic dysfunction in conduct disorder: a review. Biol Psychiatr 2011, 69(12):e69.

649. Canino G, Polanczyk G, Bauermeister JJ, Rohde LA, Frick PJ: Does the prevalence of CD and ODD vary across cultures? Soc Psychiatr Psychiatr Epidemiol 2010, 45(7):695-704.

650. Banaschewski T, Hollis C, Oosterlaan J, Roeyers H, Rubia K, Willcutt E, Taylor $\mathrm{E}$ : Towards an understanding of unique and shared pathways in the psychopathophysiology of ADHD. Dev Sci 2005, 8(2):132-140.

651. Rubia K, Smith AB, Halari R, Matsukura F, Mohammad M, Taylor E, Brammer MJ: Disorder-specific dissociation of orbitofrontal dysfunction in boys with pure conduct disorder during reward and ventrolateral prefrontal dysfunction in boys with pure ADHD during sustained attention. Am J Psychiatr 2009, 166(1):83-94.

652. Bjork JM, Chen G, Smith AR, Hommer DW: Incentive-elicited mesolimbic activation and externalizing symptomatology in adolescents. J Child Psychol Psychiatr 2010, 51(7):827-837.
653. Crowley TJ, Dalwani MS, Mikulich-Gilbertson SK, Du YP, Lejuez CW, Raymond KM, Banich MT: Risky decisions and their consequences: Neural processing by boys with antisocial substance disorder. PLOS One 2010, 5(9):e12835.

654. de Almeida RM, Ferrari PF, Parmigiani S, Miczek KA: Escalated aggressive behavior: Dopamine, serotonin and GABA. Eur J Pharmacol 2005, 526 (1-3):51-64.

655. Laakso A, Wallius E, Kajander J, Bergman J, Eskola O, Solin O, Ilonen T, Salokangas RK, Syvalahti E, Hietala J: Personality traits and striatal dopamine synthesis capacity in healthy subjects. Am J Psychiatr 2003, 160 (5):904-910.

656. Beaver KM, Wright JP, DeLisi M, Walsh A, Vaughn MG, Boisvert D, Vaske J: A gene $x$ gene interaction between DRD2 and DRD4 is associated with conduct disorder and antisocial behavior in males. Behav Brain Functions 2007, 3:30.

657. Burt SA, Mikolajewski AJ: Preliminary evidence that specific candidate genes are associated with adolescent-onset antisocial behavior. Aggress Behav 2008, 34(4):437-445.

658. Lahey BB, Rathouz PJ, Lee SS, Chronis-Tuscano A, Pelham WE, Waldman ID Cook EH: Interactions between early parenting and a polymorphism of the child's dopamine transporter gene in predicting future child conduct disorder symptoms. J Abnorm Psychol 2011, 120(1):33-45.

659. Sonuga-Barke EJ, Oades RD, Psychogiou L, Chen W, Franke B, Buitelaar J, Banaschewski T, Ebstein RP, Gil M, Anney R, Miranda A, Roeyers H, Rothenberger A, Sergeant J, Steinhausen HC, Thompson M, Asherson P, Faraone SV: Dopamine and serotonin transporter genotypes moderate sensitivity to maternal expressed emotion: The case of conduct and emotional problems in attention deficit/hyperactivity disorder. $J$ Child Psychol Psychiatr 2009, 50(9):1052-1063.

660. Farmer CA, Arnold LE, Bukstein OG, Findling RL, Gadow KD, Li X, Butter EM, Aman MG: The Treatment of Severe Child Aggression (TOSCA) Study: Design Challenges. Child Adolesc Psychiatr Ment Health 2011, 5(1):36.

661. Donovan SJ, Stewart JW, Nunes EV, Quitkin FM, Parides M, Daniel W, Susser E, Klein DF: Divalproex treatment for youth with explosive temper and mood lability: A double-blind, placebo-controlled crossover design. Am J Psychiatr 2000, 157(5):818-820.

662. Steiner H, Petersen ML, Saxena K, Ford S, Matthews Z: Divalproex sodium for the treatment of conduct disorder: A randomized controlled clinical trial. J Clin Psychiatr 2003, 64(10):1183-1191.

663. Cheng-Shannon J, McGough JJ, Pataki C, McCracken JT: Second-generation antipsychotic medications in children and adolescents. J Child Adolesc Psychopharmacol 2004, 14(3):372-394.

664. Findling RL, Aman MG, Eerdekens M, Derivan A, Lyons B: Long-term, open-label study of risperidone in children with severe disruptive behaviors and below-average IQ. Am J Psychiatr 2004, 161(4):677-684.

665. Findling RL, McNamara NK, Branicky LA, Schluchter MD, Lemon E, Blumer JL: A double-blind pilot study of risperidone in the treatment of conduct disorder. J Am Acad Child Adolesc Psychiatr 2000, 39(4):509-516.

666. Turgay A, Binder C, Snyder R, Fisman S: Long-term safety and efficacy of risperidone for the treatment of disruptive behavior disorders in children with subaverage IQs. Pediatrics 2002, 110(3):e34

667. Aman MG, De Smedt G, Derivan A, Lyons B, Findling RL: Double-blind, placebo-controlled study of risperidone for the treatment of disruptive behaviors in children with subaverage intelligence. Am J Psychiatry 2002, 159(8):1337-1346.

668. Snyder R, Turgay A, Aman M, Binder C, Fisman S, Carroll A: Effects of risperidone on conduct and disruptive behavior disorders in children with subaverage IQs. J Am Acad Child Adolesc Psychiatr 2002, 41(9): 1026-1036.

669. Holm VA, Cassidy SB, Butler MG, Hanchett JM, Greenswag LR, Whitman BY, Greenberg F: Prader-Willi syndrome: Consensus diagnostic criteria. Pediatrics 1993, 91(2):398-402.

670. Whittington JE, Holland AJ, Webb T, Butler J, Clarke D, Boer H: Population prevalence and estimated birth incidence and mortality rate for people with Prader-Willi syndrome in one UK Health Region. J Med Genet 2001, 38(11):792-798.

671. Glenn CC, Driscoll DJ, Yang TP, Nicholls RD: Genomic imprinting: Potential function and mechanisms revealed by the Prader-Willi and Angelman syndromes. Mol Hum Reprod 1997, 3(4):321-332.

672. Nicholls RD, Knepper JL: Genome organization, function, and imprinting in Prader-Willi and Angelman syndromes. Annu Rev Genom Hum Genet 2001, 2:153-175. 
673. Fieldstone A, Zipf WB, Sarter MF, Berntson GG: Food intake in Prader-Willi syndrome and controls with obesity after administration of a benzodiazepine receptor agonist. Obes Res 1998, 6(1):29-33.

674. Holland AJ, Treasure J, Coskeran P, Dallow J, Milton N, Hillhouse E: Measurement of excessive appetite and metabolic changes in PraderWilli syndrome. Int J Obes Relat Metab Disord 1993, 17(9):527-532.

675. von Deneen KM, Gold MS, Liu Y: Food addiction and cues in Prader-Willi syndrome. J Addiction Med 2009, 3(1):19-25.

676. Hinton EC, Isles AR, Williams NM, Parkinson JA: Excessive appetitive arousal in Prader-Willi syndrome. Appetite 2010, 54(1):225-228.

677. Swaab DF: Prader-Willi syndrome and the hypothalamus. Acta Paediatr Suppl 1997, 423:50-54.

678. Miller JL, James GA, Goldstone AP, Couch JA, He G, Driscoll DJ, Liu Y: Enhanced activation of reward mediating prefrontal regions in response to food stimuli in Prader-Willi syndrome. J Neurol Neurosurg Psychiatr 2007, 78(6):615-619.

679. Holsen LM, Zarcone JR, Brooks WM, Butler MG, Thompson TI, Ahluwalia JS, Nollen NL, Savage CR: Neural mechanisms underlying hyperphagia in Prader-Willi Syndrome. Obesity 2006, 14(6):1028-1037.

680. Dimitropoulos A, Schultz R: Food-related neural circuitry in Prader-Willi Syndrome: Response to high-versus low-calorie foods. J Autism Dev Disord 2008, 38(9):1642-1653.

681. Hinton EC, Holland AJ, Gellatly MS, Soni S, Owen AM: An investigation into food preferences and the neural basis of food-related incentive motivation in Prader-Willi syndrome. J Intellect Disabil Res 2006, 50:633-642.

682. Shapira NA, Lessig MC, He AG, James GA, Driscoll DJ, Liu Y: Satiety dysfunction in Prader-Willi syndrome demonstrated by fMRI. J Neurol Neurosurg Psychiatr 2005, 76(2):260-262.

683. Stromme P, Bjornstad PG, Ramstad K: Prevalence estimation of Williams syndrome. J Child Neurol 2002, 17(4):269-271.

684. Bellugi U, Adolphs R, Cassady C, Chiles M: Towards the neural basis for hypersociability in a genetic syndrome. Neuroreport 1999, 10(8):1653-1657.

685. Klein-Tasman BP, Mervis CB: Distinctive personality characteristics of 8-, 9-, and 10-year-olds with Williams syndrome. Dev Neuropsychol 2003, 23 (1-2):269-290.

686. Doyle TF, Bellugi U, Korenberg JR, Graham J: "Everybody in the world is my friend" hypersociability in young children with Williams syndrome. Am J Med Genet 2004, 124A(3):263-273.

687. Einfeld SL, Tonge BJ, Florio T: Behavioral and emotional disturbance in individuals with Williams syndrome. Am J Ment Retard 1997, 102(1):45-53.

688. Meyer-Lindenberg A, Mervis CB, Berman KF: Neural mechanisms in Williams syndrome: $A$ unique window to genetic influences on cognition and behaviour. Nat Rev Neurosci 2006, 7(5):380-393.

689. Haas BW, Hoeft F, Searcy YM, Mills D, Bellugi U, Reiss A: Individual differences in social behavior predict amygdala response to fearful facial expressions in Williams syndrome. Neuropsychologia 2009, 48(5): 1283-1288.

690. Mimura M, Hoeft F, Kato M, Kobayashi N, Sheau K, Piggot J, Mills D, Galaburda A, Korenberg JR, Bellugi U: A preliminary study of orbitofrontal activation and hypersociability in Williams Syndrome. J Neurodev Disord 2010, 2(2):93-98

691. Pober BR: Williams-Beuren syndrome. New Engl J Med 2010, 362(3):239-252.

692. Philpot BD, Thompson CE, Franco L, Williams CA: Angelman syndrome: Advancing the research frontier of neurodevelopmental disorders. $J$ Neurodev Disord 2011, 3(1):50-56.

693. Harting I, Seitz A, Rating D, Sartor K, Zschocke J, Janssen B, Ebinger F, Wolf $\mathrm{Nl}$ : Abnormal myelination in Angelman syndrome. Eur J Paediatr Neurol 2009, 13(3):271-276

694. Didden R, Korzilius H, Sturmey P, Lancioni GE, Curfs LM: Preference for water-related items in Angelman syndrome, Down syndrome and nonspecific intellectual disability. J Intellect Dev Disabil 2008, 33(1):59-64.

695. Pelc K, Cheron G, Dan B: Behavior and neuropsychiatric manifestations in Angelman syndrome. Neuropsychiatr Dis Treat 2008, 4(3):577-584.

696. Ferdousy F, Bodeen W, Summers K, Doherty O, Wright O, Elsisi N, Hilliard G, O'Donnell JM, Reiter LT: Drosophila Ube3a regulates monoamine synthesis by increasing GTP cyclohydrolase I activity via a non-ubiquitin ligase mechanism. Neurobiol Dis 2011, 41(3):669-677.

697. Mulherkar SA, Jana NR: Loss of dopaminergic neurons and resulting behavioural deficits in mouse model of Angelman syndrome. Neurobiol Dis 2010, 40(3):586-592.
698. Chahrour M, Zoghbi HY: The story of Rett syndrome: From clinic to neurobiology. Neuron 2007, 56(3):422-437.

699. Percy AK: Rett syndrome: exploring the autism link. Arch Neurol 2011, 68 (8):985-989.

700. Hutchinson AN, Deng JV, Aryal DK, Wetsel WC, West AE: Differential regulation of $\mathrm{MeCP} 2$ phosphorylation in the CNS by dopamine and serotonin. Neuropsychopharmacology 2012, 37:321-337.

701. Panayotis N, Ghata A, Villard L, Roux JC: Biogenic amines and their metabolites are differentially affected in the Mecp2-deficient mouse brain. BMC Neurosci 2011, 12:47.

702. Panayotis N, Pratte M, Borges-Correia A, Ghata A, Villard L, Roux JC: Morphological and functional alterations in the substantia nigra pars compacta of the Mecp2-null mouse. Neurobiol Dis 2011, 41(2):385-397.

703. Gantz SC, Ford CP, Neve KA, Williams JT: Loss of Mecp2 in substantia nigra dopamine neurons compromises the nigrostriatal pathway. J Neurosci 2011, 31(35):12629-12637.

704. Dunn HG, Stoessl AJ, Ho HH, MacLeod PM, Poskitt KJ, Doudet DJ, Schulzer M, Blackstock D, Dobko T, Koop B, de Amorim GV: Rett syndrome: Investigation of nine patients, including PET scan. Can J Neurol Sci 2002, 29(4):345-357

705. Chiron C, Bulteau C, Loc'h C, Raynaud C, Garreau B, Syrota A, Maziere B: Dopaminergic D2 receptor SPECT imaging in Rett syndrome: Increase of specific binding in striatum. J Nucl Med 1993, 34(10):1717-1721.

706. Crawford DC, Acuna JM, Sherman SL: FMR1 and the fragile $X$ syndrome: Human genome epidemiology review. Genet Med 2001, 3(5):359-371.

707. Verkerk AJ, Pieretti M, Sutcliffe JS, Fu YH, Kuhl DP, Pizzuti A, Reiner O, Richards S, Victoria MF, Zhang FP, et al: Identification of a gene (FMR-1) containing a CGG repeat coincident with a breakpoint cluster region exhibiting length variation in fragile X syndrome. Cell 1991, 65(5):905-914.

708. Lightbody AA, Reiss AL: Gene, brain, and behavior relationships in fragile X syndrome: Evidence from neuroimaging studies. Dev Disabil Res Rev 2009, 15(4):343-352.

709. Bennetto L, Pennington BF, Porter D, Taylor AK, Hagerman RJ: Profile of cognitive functioning in women with the fragile $\mathrm{X}$ mutation. Neuropsychology 2001, 15(2):290-299.

710. Lightbody AA, Hall SS, Reiss AL: Chronological age, but not FMRP levels, predicts neuropsychological performance in girls with Fragile $X$ syndrome. Am J Med Genet 2006, 141(5):468-472.

711. Roberts JE, Schaaf JM, Skinner M, Wheeler A, Hooper S, Hatton DD, Bailey DB Jr: Academic skills of boys with Fragile $X$ syndrome: Profiles and predictors. Am J Ment Retard 2005, 110(2):107-120.

712. Bakker CE, Verheij C, Willemsen R, van der Helm R, Oerlemans F, Vermey M, Bygrave A, Hoogeveen AT, Oostra BA: Fmr1 knockout mice: a model to study fragile $X$ mental retardation. The Dutch-Belgian Fragile $X$ Consortium. Cell 1994, 78(1):23-33.

713. Fulks JL, O'Bryhim BE, Wenzel SK, Fowler SC, Vorontsova E, Pinkston JW, Ortiz AN, Johnson MA: Dopamine release and uptake impairments and behavioral alterations observed in mice that model Fragile $X$ mental retardation syndrome. ACS Chem Neurosci 2010, 1(10):679-690.

714. Weinshenker D, Warren ST: Neuroscience: fragile dopamine. Nature 2008 455(7213):607-608

715. Wang H, Wu LJ, Kim SS, Lee FJ, Gong B, Toyoda H, Ren M, Shang YZ, Xu H, Liu F, Zhao MG, Zhuo M: FMRP acts as a key messenger for dopamine modulation in the forebrain. Neuron 2008, 59(4):634-647.

716. Wang H, Kim SS, Zhuo M: Roles of Fragile X mental retardation protein in dopaminergic stimulation-induced synapse-associated protein synthesis and subsequent alpha-amino-3-hydroxyl-5-methyl-4-isoxazole-4propionate (AMPA) receptor internalization. J Biol Chem 2010, 285 (28):21888-21901.

717. Farzin F, Perry H, Hessl D, Loesch D, Cohen J, Bacalman S, Gane L, Tassone F, Hagerman P, Hagerman R: Autism spectrum disorders and attentiondeficit/hyperactivity disorder in boys with the Fragile X premutation. J Dev Behaiv Pediatr 2006, 27(2 Suppl):S137-S144.

718. Mazzocco MM, Pennington BF, Hagerman RJ: Social cognition skills among females with Fragile X. J Autism Dev Disord 1994, 24(4):473-485.

719. Smith DV, Hayden BY, Truong TK, Song AW, Platt ML, Huettel SA: Distinct value signals in anterior and posterior ventromedial prefrontal cortex. $J$ Neurosci 2010, 30(7):2490.

720. Garrett AS, Menon V, MacKenzie K, Reiss AL: Here's looking at you, kid: Neural systems underlying face and gaze processing in Fragile $X$ syndrome. Arch Gen Psychiatr 2004, 61(3):281-288. 
721. Watson C, Hoeft F, Garrett AS, Hall SS, Reiss AL: Aberrant brain activation during gaze processing in boys with Fragile X syndrome. Arch Gen Psychiatr 2008, 65(11):1315-1323.

722. Holsen LM, Dalton KM, Johnstone T, Davidson RJ: Prefrontal social cognition network dysfunction underlying face encoding and social anxiety in fragile X syndrome. Neuroimage 2008, 43(3):592-604.

723. Dalton KM, Holsen L, Abbeduto L, Davidson RJ: Brain function and gaze fixation during facial-emotion processing in fragile $\mathrm{X}$ and autism. Autism Res 2008, 1(4):231-239.

724. Ceravolo R, Antonini A, Volterrani D, Rossi C, Goldwurm S, Di Maria E, Kiferle $L$, Bonuccelli $U$, Murri $L$ : Dopamine transporter imaging study in parkinsonism occurring in fragile X premutation carriers. Neurology 2005 65(12):1971-1973.

725. Berry-Kravis E, Lewin F, Wuu J, Leehey M, Hagerman R, Hagerman P, Goetz CG: Tremor and ataxia in fragile $\mathrm{X}$ premutation carriers: Blinded videotape study. Ann Neurol 2003, 53(5):616-623.

726. Roberts J, Symons F, Johnson AM, Hatton D, Boccia M: Blink rate in boys with fragile $\mathrm{X}$ syndrome: Preliminary evidence for altered dopamine function. J Intellect Disabil Res 2005, 49(9):647-656.

727. Berry-Kravis E, Potanos K: Psychopharmacology in fragile $X$ syndrome-present and future. Ment Retard Dev Disabil Res Rev 2004 10(1):42-48

728. Hagerman RJ: Medical follow-up and pharmacotherapy. In Fragile $X$ Syndrome: Diagnosis, Treatment, and Research. 3rd edition. Edited by Hagerman RJ, Hagerman PJ. Baltimore: The Johns Hopkins University Press: 2002:287-338

729. Valdovinos MG, Parsa RA, Alexander ML: Results of a nation-wide survey evaluating psychotropic medication use in Fragile X syndrome. J Dev Phys Disabil 2009, 21:23-37.

730. Hall SS: Treatments for fragile X syndrome: a closer look at the data. Dev Disabil Res Rev 2009, 15(4):353-360.

731. Hagerman RJ, Murphy MA, Wittenberger MD: A controlled trial of stimulant medication in children with the fragile $X$ syndrome. Am J Med Genet 1988, 30(1-2):377-392.

732. Erickson CA, Stigler KA, Posey DJ, McDougle CJ: Aripiprazole in Autism Spectrum Disorders and Fragile X syndrome. Neurotherapeutics 2010, 7 (3):258-263.

733. Erickson CA, Stigler KA, Wink LK, Mullett JE, Kohn A, Posey DJ, McDougle CJ: A prospective open-label study of aripiprazole in Fragile $\mathrm{X}$ syndrome. Psychopharmacology 2011, 216:85-90.

734. World Health Organization: International statistical classification of diseases and related health problems. 10th edition.; 2007. Retrieved from http://apps. who.int/classifications/apps/icd/icd10online.

735. Robinson TE, Berridge KC: Addiction. Annu Rev Psychol 2003, 54:25-53.

736. McGinty VB, Hayden BY, Heilbronner SR, Dumont EC, Graves SM, Mirrione MM, du Hoffmann J, Sartor GC, Espana RA, Millan EZ, Difeliceantonio AG, Marchant NJ, Napier TC, Root DH, Borgland SL, Treadway MT, Floresco SB, McGinty JF, Haber S: Emerging, reemerging, and forgotten brain areas of the reward circuit: Notes from the 2010 Motivational Neural Networks conference. Behav Brain Res 2011, 225(1):348-357.

737. Pecina S, Smith KS, Berridge KC: Hedonic hot spots in the brain. Neuroscientist 2006, 12(6):500-511

738. Baxter MG, Murray EA: The amygdala and reward. Nat Rev Neurosci 2002, 3 (7):563-573.

739. Cardinal RN, Parkinson JA, Hall J, Everitt BJ: Emotion and motivation: The role of the amygdala, ventral striatum, and prefrontal cortex. Neurosci Biobehav Rev 2002, 26(3):321-352

740. Volkow ND, Fowler JS, Wang GJ: The addicted human brain: Insights from imaging studies. J Clin Investig 2003, 111(10):1444-1451.

741. Carlezon WA Jr, Thomas MJ: Biological substrates of reward and aversion: A nucleus accumbens activity hypothesis. Neuropharmacology 2009, 56 (Suppl 1):122-132.

742. Matsumoto M, Hikosaka O: Two types of dopamine neuron distinctly convey positive and negative motivational signals. Nature 2009, 459 (7248):837-841.

743. Carver CS, White TL: Behavioral inhibition, behavioral activation, and affective responses to impending reward and punishment: The BIS/BAS scales. J Pers Soc Psychol 1994, 67(2):319-333.

744. Chapman LJ, Chapman JP, Raulin ML: Scales for physical and social anhedonia. J Abnorm Psychol 1976, 85(4):374-382.
745. Gard DE, Gard MG, Kring AM, John OP: Anticipatory and consummatory components of the experience of pleasure: a scale development study. J Res Pers 2006, 40:1086-1102.

746. Heerey EA, Robinson BM, McMahon RP, Gold JM: Delay discounting in schizophrenia. Cognit Neuropsychiatry 2007, 12(3):213-221.

747. Kessler RC: The epidemiology of dual diagnosis. Biol Psychiatr 2004, 56 (10):730-737.

748. Lasser K, Boyd JW, Woolhandler S, Himmelstein DU, McCormick D, Bor DH: Smoking and mental illness: A population-based prevalence study. JAMA 2000, 284(20):2606-2610.

749. Ziedonis D, Hitsman B, Beckham JC: Tobacco use cessation in psychiatric disorders. Nicotine Tobac Res Nat Inst Ment Health (NIMH) Rep 2008, 10:1691-1715

750. Regier DA, Farmer ME, Rae DS, Locke BZ, Keith SJ, Judd LL, Goodwin FK: Comorbidity of mental disorders with alcohol and other drug abuse. Results from the Epidemiologic Catchment Area (ECA) Study. JAMA 1990, 264(19):2511-2518

751. Towbin KE, Pradella A, Gorrindo T, Pine DS, Leibenluft E: Autism spectrum traits in children with mood and anxiety disorders. J Child Adoles Psychopharmacol 2005, 15(3):452-464.

752. Cederlund M, Hagberg B, Gillberg C: Asperger syndrome in adolescent and young adult males. Interview, self- and parent assessment of social, emotional, and cognitive problems. Res Dev Disabil 2010, 31(2):287-298.

753. Leyfer OT, Folstein SE, Bacalman S, Davis NO, Dinh E, Morgan J, Tager-Flusberg H, Lainhart JE: Comorbid psychiatric disorders in children with autism: Interview development and rates of disorders. J Autism Dev Disord 2006, 36(7):849-861.

754. Glassman AH: Cigarette smoking: Implications for psychiatric illness. Am J Psychiatr 1993, 150(4):546-553.

755. Hughes JR, Hatsukami DK, Mitchell JE, Dahlgren LA: Prevalence of smoking among psychiatric outpatients. Am J Psychiatr 1986, 143(8):993-997.

756. Mueser KT, Drake RE, Wallach MA: Dual diagnosis: a review of etiological theories. Addict Behav 1998, 23(6):717-734.

doi:10.1186/1866-1955-4-19

Cite this article as: Dichter et al:: Reward circuitry dysfunction in psychiatric and neurodevelopmental disorders and genetic syndromes: animal models and clinical findings. Journal of Neurodevelopmental Disorders 2012 4:19.

\section{Submit your next manuscript to BioMed Central and take full advantage of:}

- Convenient online submission

- Thorough peer review

- No space constraints or color figure charges

- Immediate publication on acceptance

- Inclusion in PubMed, CAS, Scopus and Google Scholar

- Research which is freely available for redistribution 